A $11703 \quad 087530$

NATL INST OF STANDARDS \& TECH R.I.C.

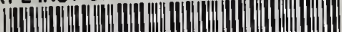

........

A11103087530

Devaney John R/Notes on SEM examination

QC100.U57 NO.400-, 35, 1977 C.2 NBS-PUB

?

NBS SPECIAL PUBLICATION 400-35

U.S. DEPARTMENT OF COMMERCE / National Bureau of Standards

Semiconductor Measurement Technology:

\title{
Notes on SEM Examination of Microclectronic Devices
}




\section{NATIONAL BUREAU OF STANDARDS}

The National Bureau of Standards ${ }^{1}$ was established by an act of Congress March 3, 1901. The Bureau's overall goal is strengthen and advance the Nation's science and technology and facilitate their effective application for public benefit. To t end, the Bureau conducts research and provides: (1) a basis for the Nation's physical measurement system, (2) scientific a technological services for industry and government, (3) a technical basis for equity in trade, and (4) technical services to p mote public safety. The Bureau consists of the Institute for Basic Standards, the Institute for Materials Research, the Instit for Applied Technology, the Institute for Computer Sciences and Technology, the Office for Information Programs, and Office of Experimental Technology Incentives Program.

THE INSTITUTE FOR BASIC STANDARDS provides the central basis within the United States of a complete and cons ent system of physical measurement; coordinates that system with measurement systems of other nations; and furnishes ess tial services leading to accurate and uniform physical measurements throughout the Nation's scientific community, indust and commerce. The Institute consists of the Office of Measurement Services, and the following center and divisions:

Applied Mathematics - Electricity - Mechanics - Heat - Optical Physics - Center for Radiation Research - L oratory Astrophysics ${ }^{2}-$ Cryogenics $^{2}-$ Electromagnetics $^{2}-$ Time and Frequency ${ }^{2}$.

THE INSTITUTE FOR MATERIALS RESEARCH conducts materials research leading to improved methods of measu ment, standards, and data on the properties of well-characterized materials needed by industry, commerce, educational in tutions, and Government; provides advisory and research services to other Government agencies; and develops, produces, a distributes standard reference materials. The Institute consists of the Office of Standard Reference Materials, the Office of . and Water Measurement, and the following divisions:

Analytical Chemistry - Polymers - Metallurgy - Inorganic Materials - Reactor Radiation - Physical Chemistry

THE INSTITUTE FOR APPLIED TECHNOLOGY provides technical services developing and promoting the use of av able technology; cooperates with public and private organizations in developing technological standards, codes, and test mi ods; and provides technical advice services, and information to Government agencies and the public. The Institute consists the following divisions and centers:

Standards Application and Analysis - Electronic Technology - Center for Consumer Product Technology: Prod Systems Analysis; Product Engineering - Center for Building Technology: Structures, Materials, and Safety; Build

Environment; Technical Evaluation and Application - Center for Fire Research: Fire Science; Fire Safety Engineeri

THE INSTITUTE FOR COMPUTER SCIENCES AND TECHNOLOGY conducts research and provides technical servi designed to aid Government agencies in improving cost effectiveness in the conduct of their programs through the selecti acquisition, and effective utilization of automatic data processing equipment; and serves as the principal focus wthin the es utive branch for the development of Federal standards for automatic data processing equipment, techniques, and compl languages. The Institute consist of the following divisions:

Computer Services - Systems and Software - Computer Systems Engineering - Information Technology.

THE OFFICE OF EXPERIMENTAL TECHNOLOGY INCENTIVES PROGRAM seeks to affect public policy and pro to facilitate technological change in the private sector by examining and experimenting with Government policies and pl tices in order to identify and remove Government-related barriers and to correct inherent market imperfections that imp the innovation process.

THE OFFICE FOR INFORMATION PROGRAMS promotes optimum dissemination and accessibility of scientific infor. tion generated within NBS; promotes the development of the National Standard Reference Data System and a system of formation analysis centers dealing with the broader aspects of the National Measurement System; provides appropriate serv to ensure that the NBS staff has optimum accessibility to the scientific information of the world. The Office consists of following organizational units:

Office of Standard Reference Data - Office of Information Activities - Office of Technical Publications - Library Office of International Standards - Office of International Relations.

\footnotetext{
${ }^{1}$ Headquarters and Laboratories at Gaithersburg, Maryland, unless otherwise noted; mailing address Washington, D.C. 20234.

2 Located at Boulder, Colorado 80302.
} 
- Semiconductor Measurement Technology:

\section{Notes on SEM Examination of \\ Microelectronic Devices}

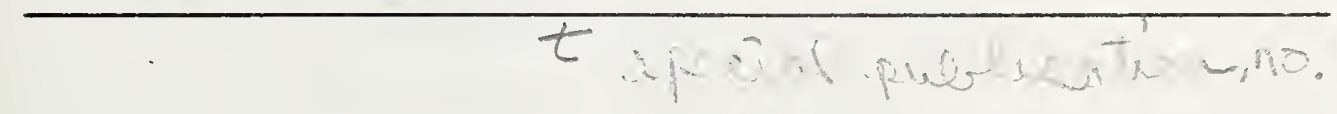

John R. Devaney

Hi-Rel Laboratories

Monrovia, Ca. 91016

K. O. Leedy and W. J. Keery

Electronic Technology Division

Institute for Applied Technology

National Bureau of Standards

Washington, D.C. 20234

Jointly supported by:

The Defense Advanced Research Projects Agency

and

The National Bureau of Standards

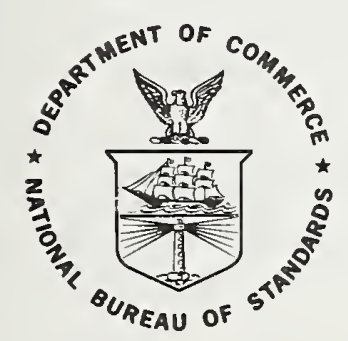

U.S. DEPARTMENT OF COMMERCE, Juanita M. Kreps, Secretary

Dr. Betsy Ancker-Johnson, Assistant Secretary for Science and Technology

U.S.NATIONAL BUREAU OF STANDARDS, Ernest Ambler, Acting Director 


\section{Library of Congress Cataloging in Publication Data}

Devaney, John R.

Notes on SEM examination of microelectronic devices.

(Semiconductor measurement technology) (NBS special publication ; 400-35)

Supt. of Docs. no.: C13.10:400-35.

1. Miniature electronic equipment-Testing. 2. SemiconductorsTesting. 3. Scanning electron microscope-Technique. I. Leedy, K. O., joint author. II. Keery, W. J., joint author. III. Title. IV. Series. V. Series: United States. National Bureau of Standards. Special publication ; 400-35.

QC100.U57 no. 400-35 [TK7874] 602'.1s [621.381'7I'028] 77-608011

\section{National Bureau of Standards Special Publication 400-35}

Nat. Bur. Stand. (U.S.), Spec. Publ. 400-35, 54 pages (Apr. 1977) CODEN: XNBSAV

\section{U.S. GOVERNMENT PRINTING OFFICE}

WASHINGTON: 1977 
Semiconductor Measurement Technology:

Notes on SEM Examination of Microelectronic Devices

TABLE OF CONTENTS

PAGE

1. Introduction . . . . . . . . . . . . . 1

2. Secondary and Backscattered Electron Images ......... 3

3. Accelerating Voltage . . . . . . . . . 8

4. Beam Current . . . . . . . . . . . . 14

5. Specimen Tilt . . . . . . . . . . . . 14

6. Scan Line and Frame Time . . . . . . . . . . . 18

7. Artifacts Introduced by the Beam . . . . . . . . . . 26

8. Conclusion . . . . . . . . . . . . . 36

Appendix I - Voltage Contrast . . . . . . . . . . . 38

Electron-Beam-Induced Current . . . . . . . 38

Appendix II - Semiconductor Specimen Preparation . . . . . . 43

References ................ . . 47

TABLE OF FIGURES

PAGE

1. Primary electron penetration showing the volumes of secondary and backscattered electron generation . . . . . 4

2. Emission trajectories of secondary and backscattered electron signals . . . . . . . . . . . . 4

3. Difference in the apparent illumination of a device with respect to the imaging electrons... . . . . . . . 5

4. Backscattered and secondary electron images of a relatively smooth surface ............... 6

5. Micrograph of a wire bond and probe mark in which the shadow effect produced by the backscattered electron image reveals some upturned metal not seen in the secondary image . 9

6. Series of micrographs which illustrates the change in contrast as the accelerating voltage is varied ....... 10

7. A portion of a microcircuit imaged with a beam voltage at $3 \mathrm{kV}$ and $30 \mathrm{kV} \ldots \ldots . . . \ldots 13$ 
8. A portion of a microcircuit imaged at high and low beam voltage illustrating an application of the greater beam penetration at $20 \mathrm{kV}$. . . . . . . . . . . 15

9. Compression ball bond intermetallic formation imaged at $3 \mathrm{kV}$ and $20 \mathrm{kV}$ illustrating an application of high accelerating voltages ............. . 16

10. Diagram illustrating specimen tilt angle . . . . . . . 17

11. Series of micrographs which illustrate the changes in contrast and SNR as specimen tilt angle is increased from 0 to $60 \mathrm{deg}$. . . . . . . . . . . . 19

12. The effect of specimen tilting when viewing a passivated microcircuit . . . . . . . . . . . . . . 22

13. Series of micrographs illustrating the effects of variations in scan line time, frame time, and the number of lines in the micrograph . . . . . . . . . . . . 24

14. Two examples of charging . . . . . . . . . . 27

15. Micrographs which show the effects of charging of areas outside the field of view . . . . . . . . . . . . 29

16. Additional examples of the effects of charging . . . . . 31

17. The use of backscattered electrons rather than secondaries to form the image to eliminate charging effects . . . . . . 34

18. Contamination due to the polymerization of pump oil . . . . 35

19. A secondary electron image of a biased microcircuit showing voltage contrast . . . . . . . . . . . 39

20. Micrographs of an interdigitated npn transistor made with a beam current of $350 \mathrm{pA}$ and a beam voltage of $30 \mathrm{kV}$. . . . 41

21. EBIC images of portions of two similar shift registers with the arrows indicating the region of difference . . . . . 4 42

22. A microcircuit window covered by globs of metal introduced by poor evaporation techniques 
Semiconductor Measurement Technology:

Notes on SEM Examination of Microelectronic Devices*

\author{
John R. Devaney \\ Hi-ReI Laboratories
}

and

K. O. Leedy and W. J. Keery

National Bureau of Standards

Abstract: This report reviews selected scanning electron microscope (SEM) techniques which are appropriate for the examination of microelectronic devices. Illustrated are the results of individual variations in SEM operating parameters such as accelerating voltage, specimen tilt, scan line time, and frame time. Techniques which utilize secondary and backscattered electron emissions are compared and electron-beam-induced current and voltage contrast modes are discussed. Specimen preparation and beam-induced charging artifacts are also discussed. This report demonstrates the need for flexibility in selecting and using SEM parameters and analytic procedures to obtain the maximum information when examining semiconductor devices.

Key Words: Backscattered emission; EBIC; microelectronic devices; scanning electron microscope; secondary emission; voltage contrast.

\title{
1. Introduction
}

The scanning electron microscope (SEM) is an instrument widely used in the electronic components industry. Its advantages over other types of microscopes for topographical examination are its greater depth of focus, spatial resolution, and the ease of specimen preparation. In addition to secondary and backscattered electron emission techniques, voltage contrast and electron-beam-induced-current modes can be used to gain additional information on semiconductor devices.

This report is intended to describe selected techniques for obtaining optimum scanning electron micrographs of semiconductor device specimens. It is assumed that the reader is familiar with basic SEM principles. ${ }^{1-9}$ The various techniques described here are manipulations of

*This work was conducted as a part of the Semiconductor Technology Program of the National Bureau of Standards and was supported by the Defense Advanced Research Projects Agency (Order No. 2397) and the NBS. The work at Hi-Rel Laboratories was funded under Contract 4-35897. 
instrument variables. Unless otherwise indicated, the variable of interest was changed while all others were held constant.

The devices examined were made by standard silicon technology. All passivating layers were first removed and the devices were then mounted on specimen stubs. (The preparation of specimens is described in Appendix II.) Secondary electron imaging is emphasized but the backscattered electron image is also discussed. The voltage contrast and the electron-beam-induced-current (EBIC) modes are briefly addressed in Appendix I.

There are several factors to consider when judging a good micrograph: signal-to-noise ratio (SNR), point-to-point resolution (PPR), and contrast. The SNR is the ratio between rms amplitude of the desired signal and the rms fluctuation due to noise. The SNR is a measure of the efficiency of the signal generation. The PPR is the quantitative measure of the SEM resolving power which defines the ability of the SEM to resolve two adjacent points. Resolution is dependent on the interaction volume of the electron beam in the specimen which is dependent on the primary electron beam diameter and the atomic number of the specimen surface. It also depends on the nature of the signal detection system. The contrast is the degree of difference in tone between the lightest and darkest areas of an SEM image. There are a number of types of contrast: topographical, chemical (atomic number), voltage, current, crystallographic, and magnetic. These are generated by the primary electron beam interaction with the differences in topography, chemistry, electrical potential, crystallography, and magnetic fields of the device.

Artifacts introduced by vacuum evaporated thin films, diffusion pump oil polymerization in the SEM, and careless sample preparation are of concern in the interpretation of SEM images. Specimen charging due to stray electrostatic activity in the SEM specimen chamber can be another source of misleading information. Contaminants introduced during manufacture or failure of semiconductor devices cannot be considered anomalous, since such contaminants are often the subject of SEM investigation.

The SEM operating parameters that affect micrograph quality for semiconductor device specimens are the type of image (secondary or backscattered electron), the accelerating voltage of the primary beam, the current of the primary beam, the specimen tilt, the beam scan rate, and the frame time. These are each considered in detail in subsequent sections of this paper. The effect of the electron beam on the specimen and anomalous artifacts introduced by the beam are also considered. Procedures for specimen coating are addressed in Appendix II. 


\section{Secondary and Backscattered Electron Images}

The detection of secondary electron emission is the most of ten used mode for operation of an SEM. The secondary electrons are the low energy electrons emitted from the specimen when it is bombarded by a high energy electron beam. Secondary electrons are arbitrarily defined as those having kinetic energies less than $50 \mathrm{eV}$. Secondary electrons are generated throughout the volume of primary electron penetration, but only those emitted within several interatomic distances ( $10 \mathrm{~nm}$ ) from the surface escape, as shown in figure 1 . As illustrated in figure $2 \mathrm{a}$, the secondary electrons emitted from the specimen are detected by an electron detector. The secondary electrons are deflected along curved trajectories toward the positively biased detector regardless of the initial direction of their emission.

Backscattered electrons are primary beam electrons with energies greater than $50 \mathrm{eV}$ scattered from the specimen. They can come from depths of up to several micrometers beneath the surface. These backscattered electrons have kinetic energies ranging from $50 \mathrm{eV}$ to near that of the incident primary electron energy and, unlike secondary electrons, these higher energy electrons tend to travel in straight lines. As shown in figure $2 \mathrm{~b}$, the backscattered electrons are detected only when intercepted by the solid angle of the detector. The backscattered electron mode is often referred to as the reflection mode.

The secondary electron image appears to be illuminated from all directions and has no definite shadows, while the backscattered electron image appears as if there were oblique illumination of the specimen from the direction of the detector. This type of illumination forms images with very distinct shadows. Figure 3 demonstrates the omnidirectional illumination of a device in a secondary electron image in (a) and the shadowy unidirectional illumination of the same device in a backscattered electron image in (b).

The secondary electron image (SEI) usually has better point-topoint resolution and depth of focus than the backscattered electron image (BEI). The detector normally employed in commercially available SEM's is the Everhart-Thornley (E-T) detector ${ }^{10}$ which is optimized for detection of secondary electrons. Therefore, in the backscattered mode, large beam currents are required to generate sufficient signal electrons, and the electrons forming the image are from a larger volume than in the secondary electron image. The advantage of the BEI is the information obtained relating to the atomic number of the material and surface topography of the device. The topographical information is characterized by high contrast due to the highly directional nature of the backscattered electrons and the highly directional E-T detector normally employed. Figure 4 shows three attempts to record a micrograph of a device which failed to produce suitable topographical contrast in the secondary electron mode. Three different accelerating voltages were used: (a) 3, (b) 


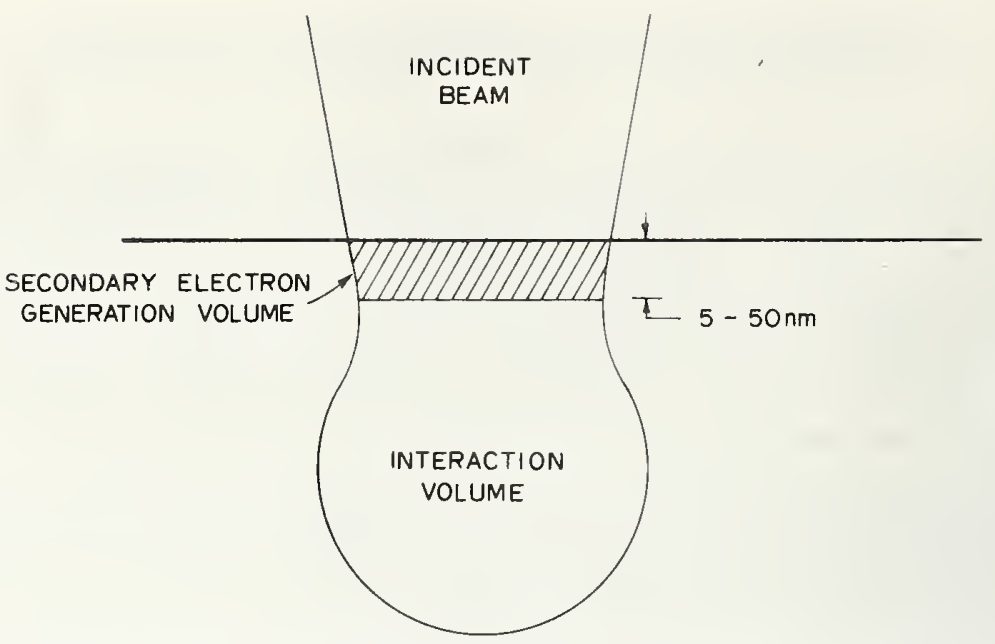

Figure 1. Primary electron penetration showing the volumes of secondary and backscattered electron generation.

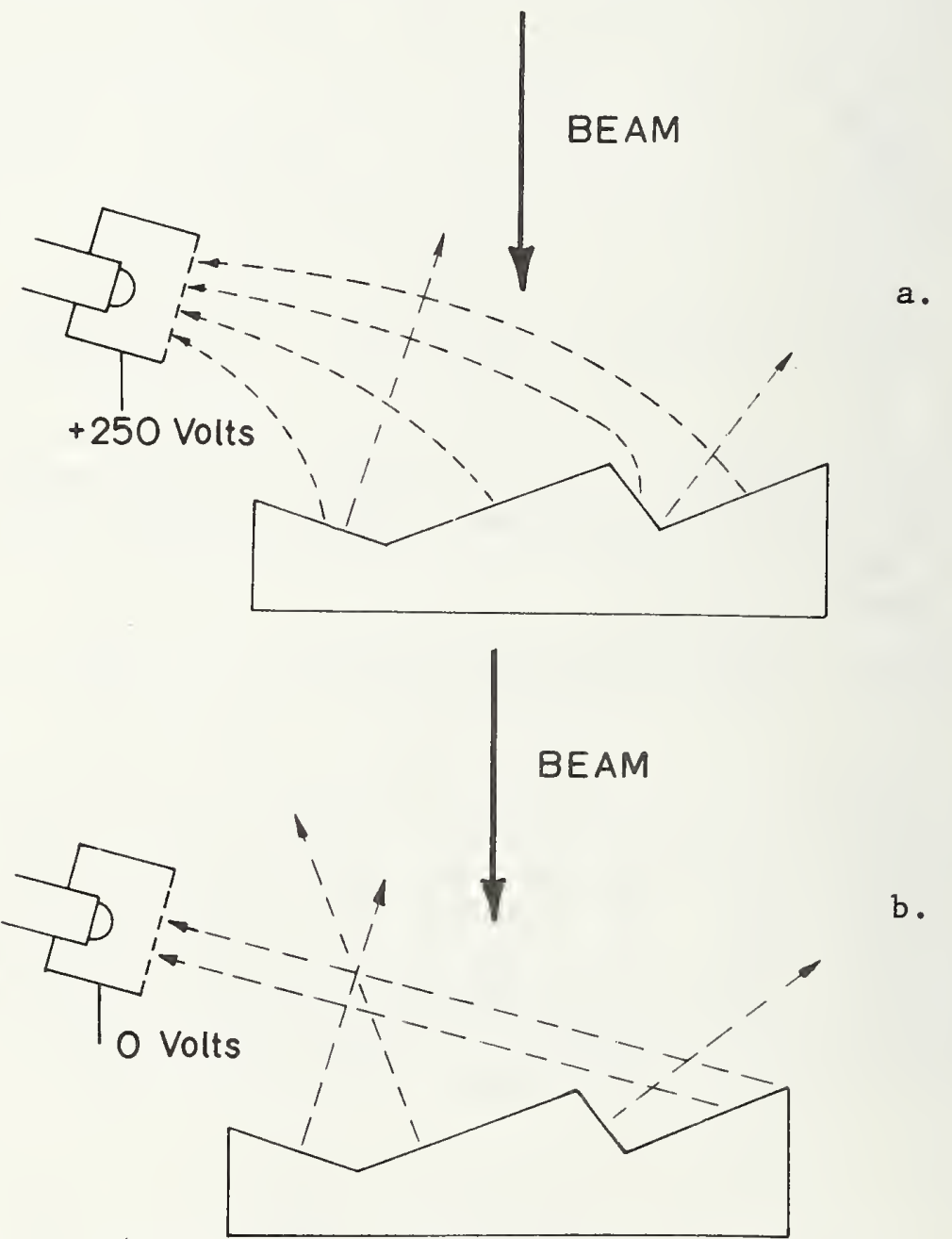

Figure 2. Emission trajectories of secondary and backscattered electron signals. 


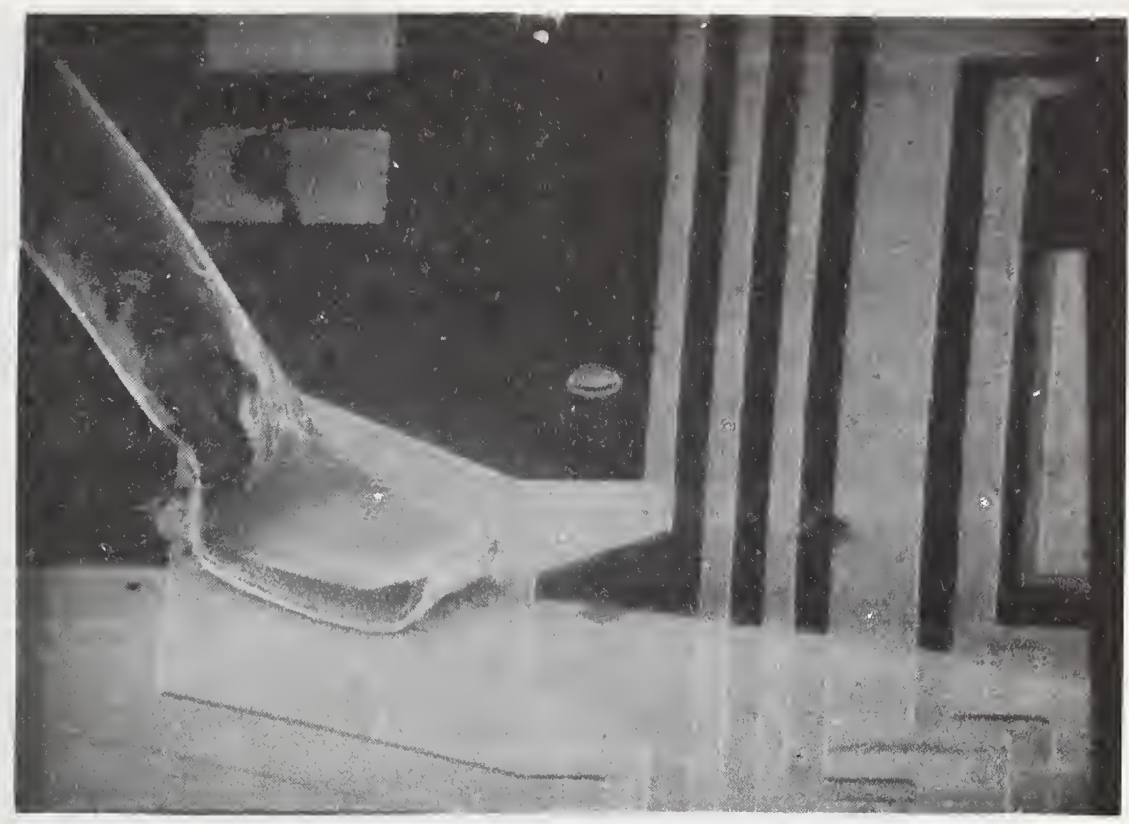

a. Omnidirectional illumination in a secondary electron image.

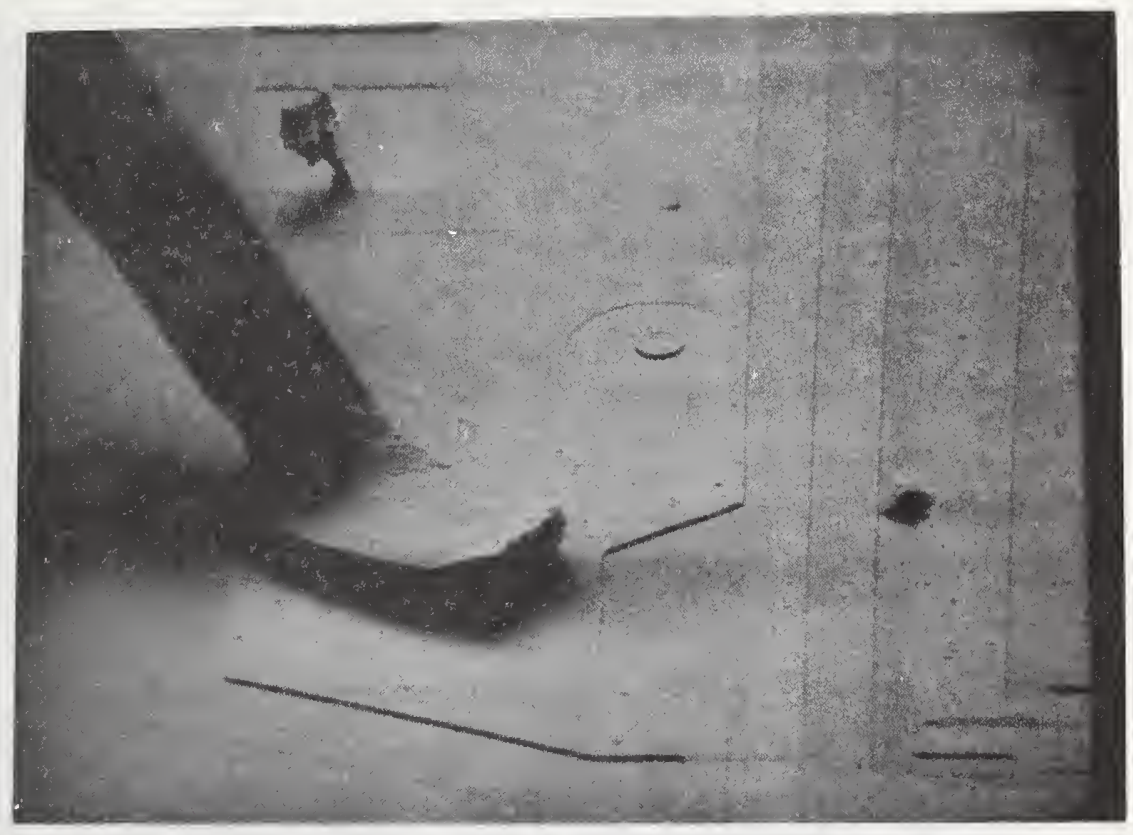

b. Shadowy unidirectional illumination in a backscattered electron image.

Figure 3. Difference in the apparent illumination of a device with respect to the imaging electrons. 


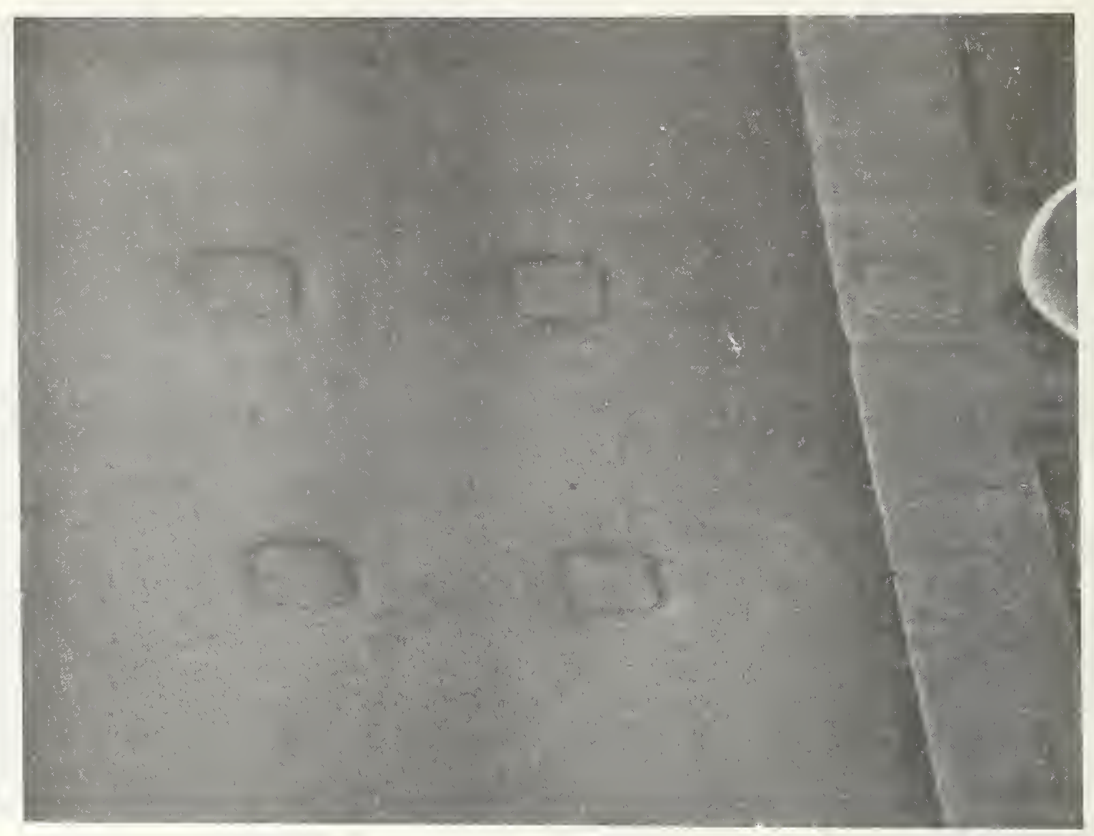

a. Secondary electron image recorded at $3 \mathrm{kV}$.

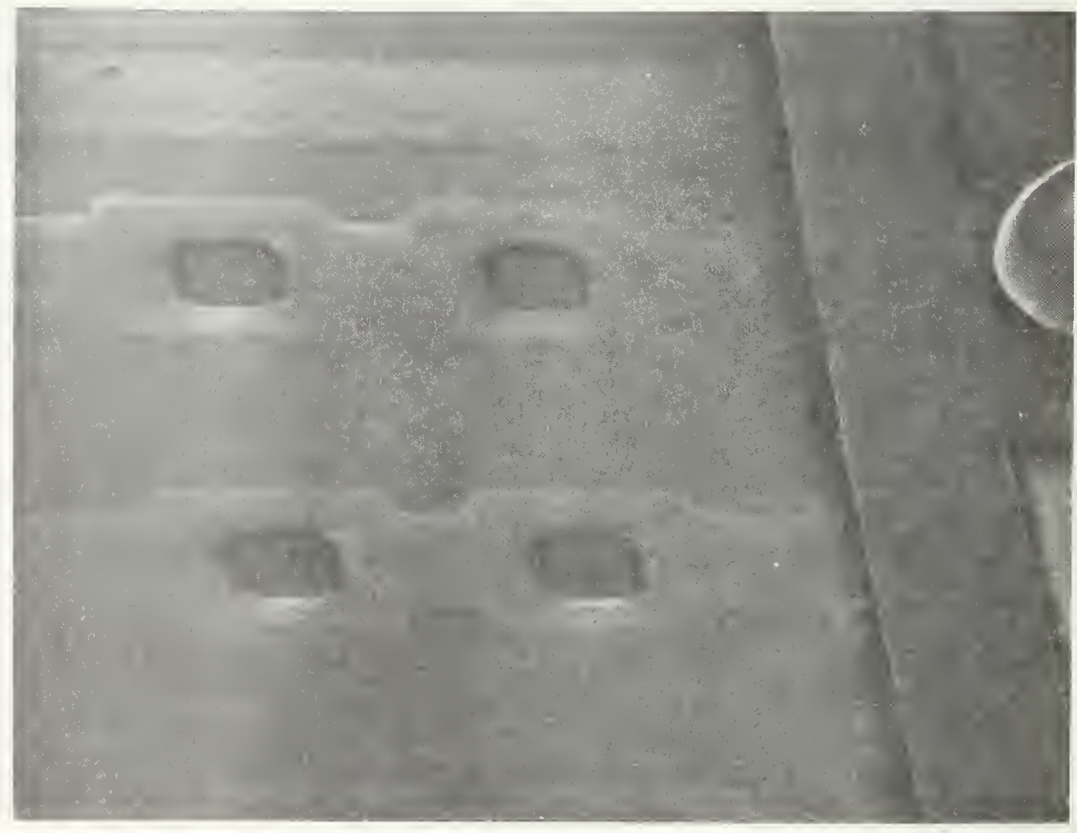

b. Secondary electron image recorded at $5 \mathrm{kV}$.

Figure 4. Backscattered and secondary electron images of a relatively smooth surface. 


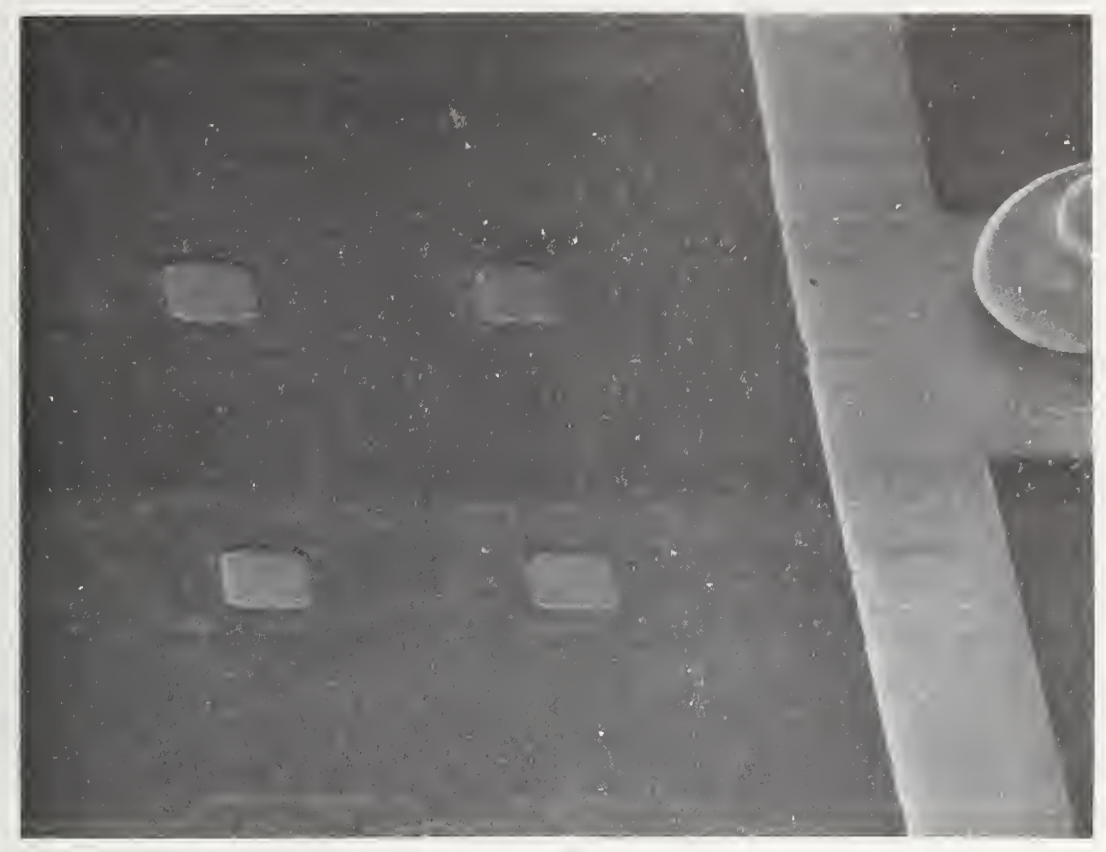

c. Secondary electron image recorded at $10 \mathrm{kV}$.

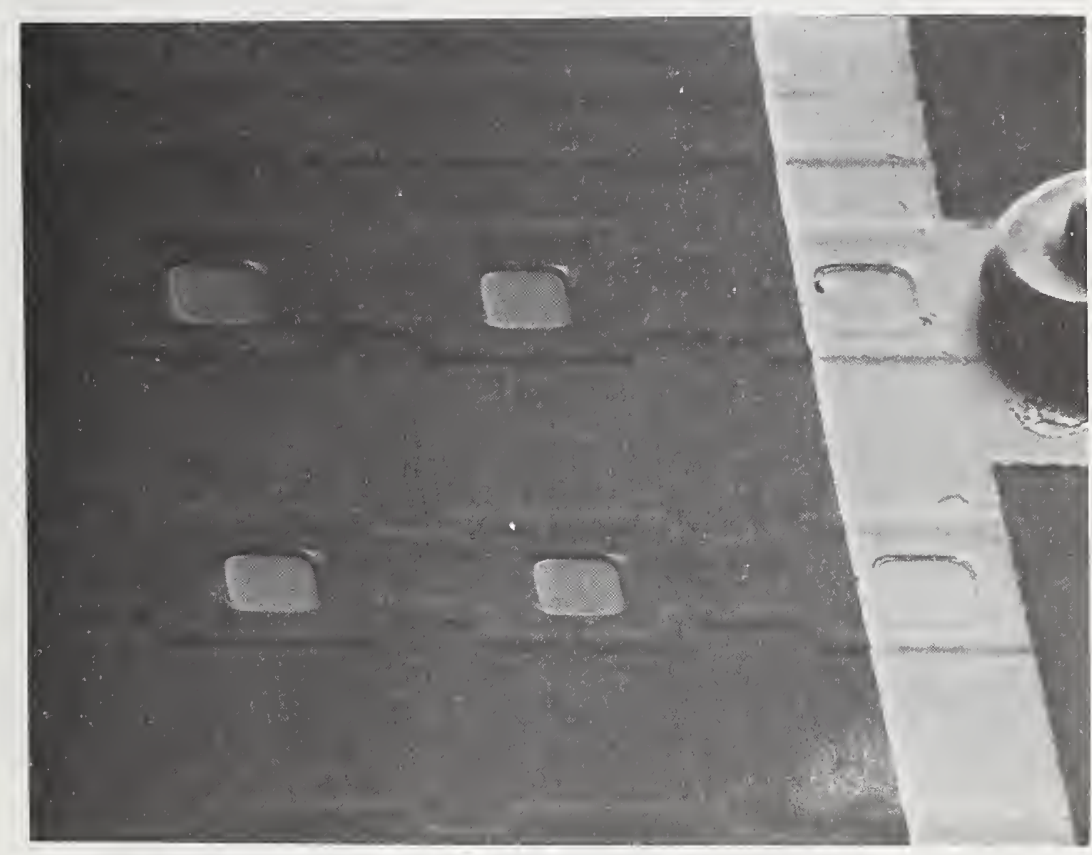

d. Backscattered electron image. 
5, and (c) $10 \mathrm{kV}$. Figure 4d shows a BEI of the exceptional topographical and chemical contrast of this same region. This particular device had very low secondary emission characteristics. In figure $5 a$ a BEI of a probe mark was used to reveal information not seen in (b), an SEI.

\section{Accelerating Voltage}

The accelerating voltage of the electron beam is a high potential difference applied between the filament (cathode) and anode of the SEM electron gun. This voltage accelerates the electrons emitted from the cathode towards the specimen surface. Commercial scanning electron microscopes are capable of a wide range of accelerating voltages from 1 to $50 \mathrm{kV}$. The use of either a high or low accelerating voltage is advantageous for different types of specimens. In general, the higher the accelerating voltage, the smaller the diameter of the primary beam, resulting in better point-to-point resolution. However, for semiconductors, the minimum spot size obtained by using a higher accelerating voltage does not always yield the optimum micrograph.

If the accelerating voltage is reduced, the electron beam penetration into the specimen is reduced. This may result in improved contrast due to both an increase in secondary electron emission at the surface of a device and a decrease in the background secondary emission generated by backscattered electrons at considerable distances from the beam impact point. The increased emission improves the SNR, thus the contrast.

To illustrate the effects of accelerating voltage on secondary electron emission, six different accelerating voltages were used to obtain SEM images of the same semiconductor device; the resulting micrographs are displayed in figure 6. The accelerating voltages chosen represent a typical range available on most commercial scanning electron microscopes: $2,3,5,10,20$, and $30 \mathrm{kV}$. The same beam current was used in each case. The chemical and topographical contrast deteriorates as accelerating voltage is increased. There is also a progressive increase in the noise, as indicated by the grainy appearance of the micrographs made with higher voltages. The image with the most noise is at $30 \mathrm{kV}$ where the beam penetration is at a maximum so that fewer secondary electrons are generated within an escape depth of the surface. It can be concluded that lower accelerating voltages are superior to higher accelerating voltages for obtaining better contrast and less noise in the imaging of this semiconductor device.

Figure 7 demonstrates the superiority of lower accelerating voltages for resolving surface detail at low magnification. Figure $7 a$ shows an area of a microcircuit examined using a primary electron beam of 3 $\mathrm{kV}$. Note the resolution of surface structure on the metallization. Figure $7 \mathrm{~b}$ shows this same area examined using a $30-\mathrm{kV}$ primary electron beam, and it is obvious that most of the surface structure is obscured. The loss of visible surface structure is the result of excessive penetration and diminished surface electron emission. 


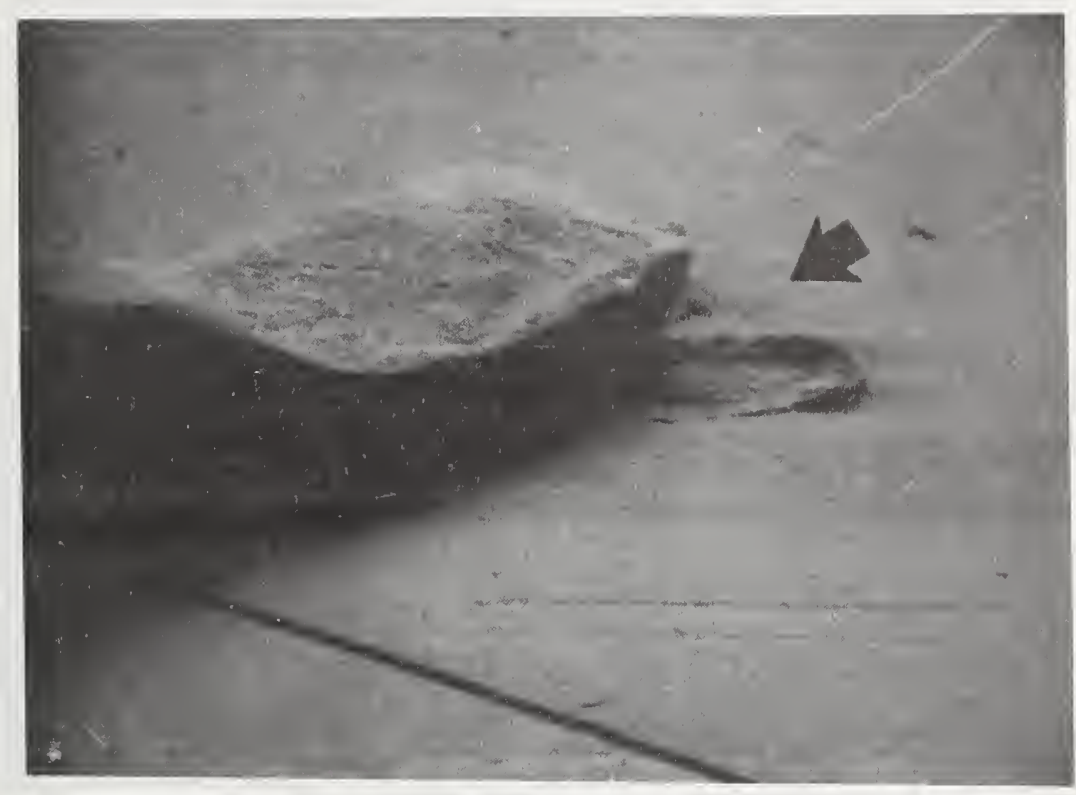

a. Backscattered electron image with the arrow showing the upturned metal.

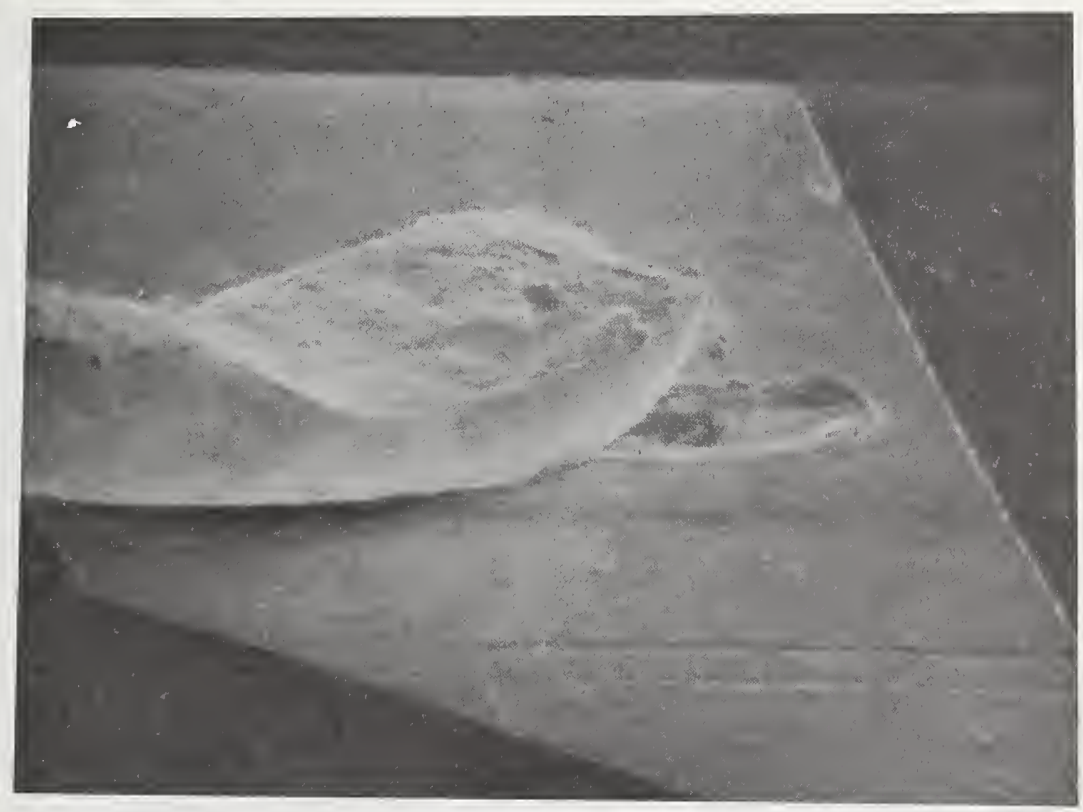

b. Secondary electron image in which flat illumination fails to reveal metal detail.

Figure 5. Micrograph of a wire bond and probe mark in which the shadow effect produced by the backscattered electron image reveals some upturned metal not seen in the secondary image. 


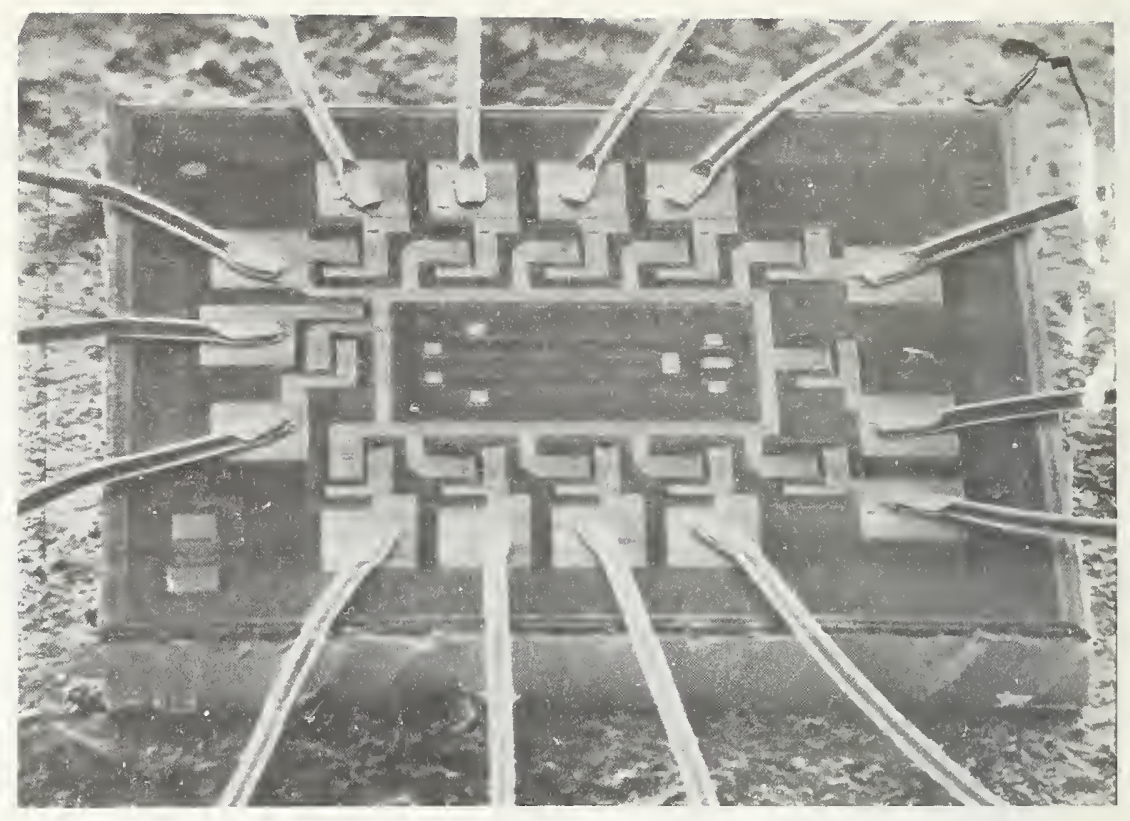

a. Micrograph recorded at $2 \mathrm{kV}$ in which the chemical and topographical contrast is outstanding.

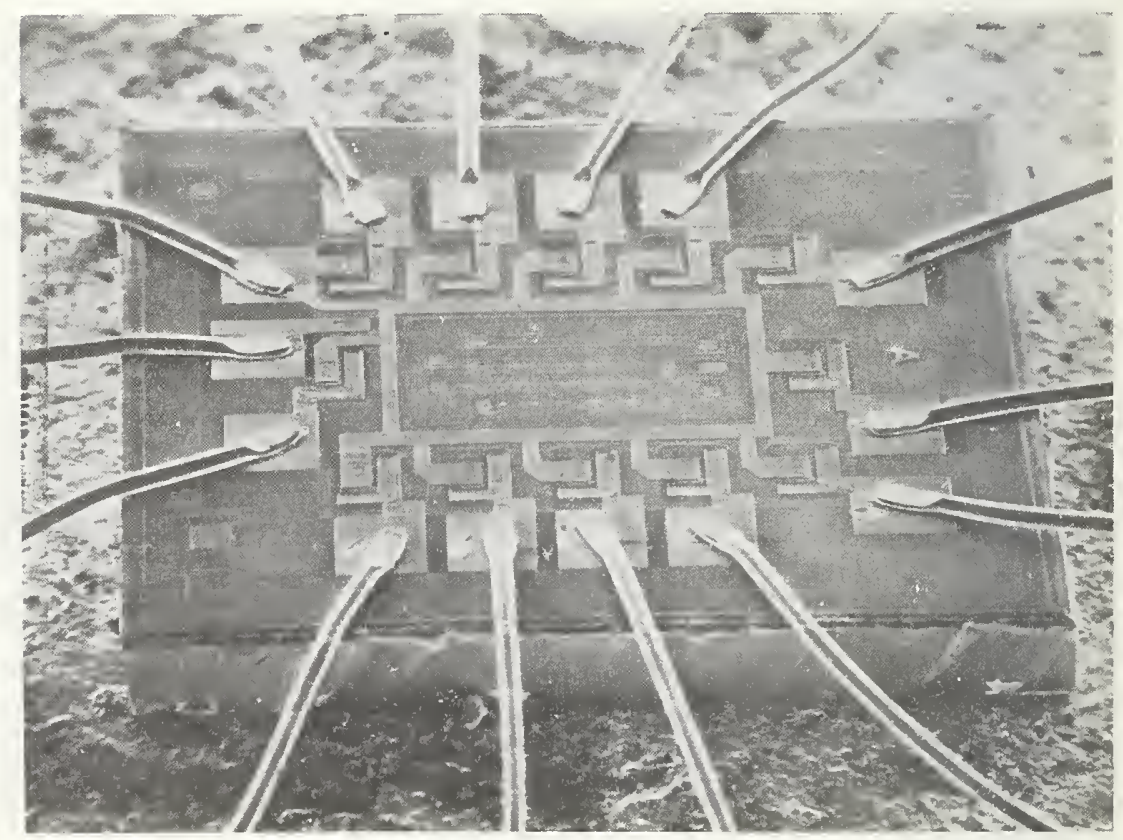

b. Micrograph recorded at $3 \mathrm{kV}$ in which the chemical and topographical contrast is still very good.

Figure 6. Series of micrographs which illustrates the change in contrast as the accelerating voltage is varied. 


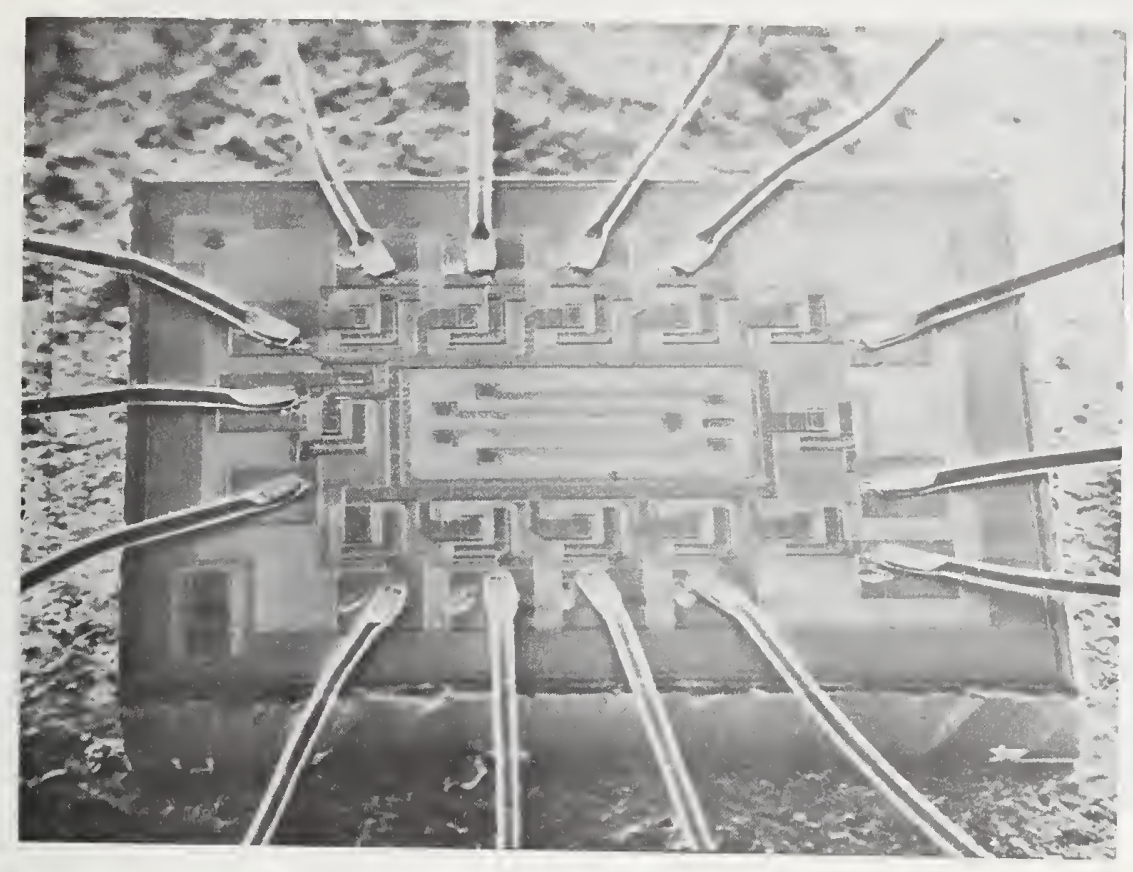

c. Micrograph recorded at $5 \mathrm{kV}$.

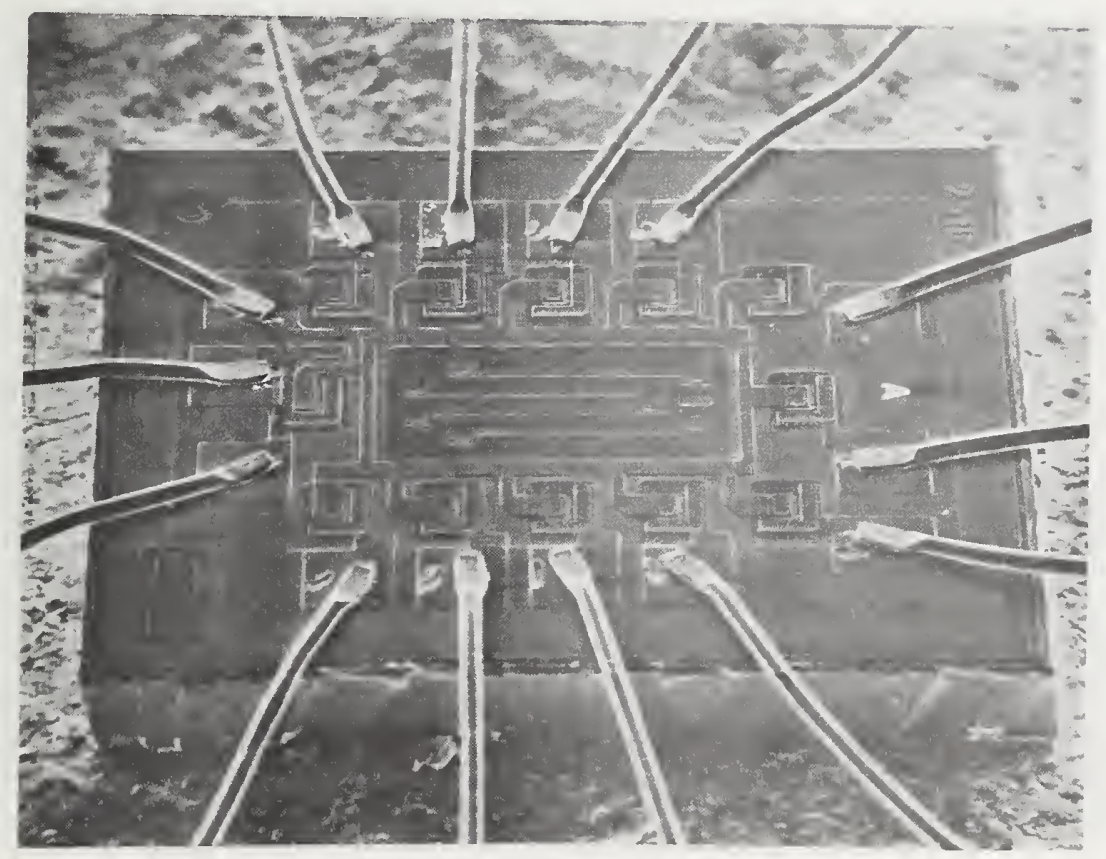

d. Micrograph recorded at $10 \mathrm{kV}$ showing decreased contrast. 


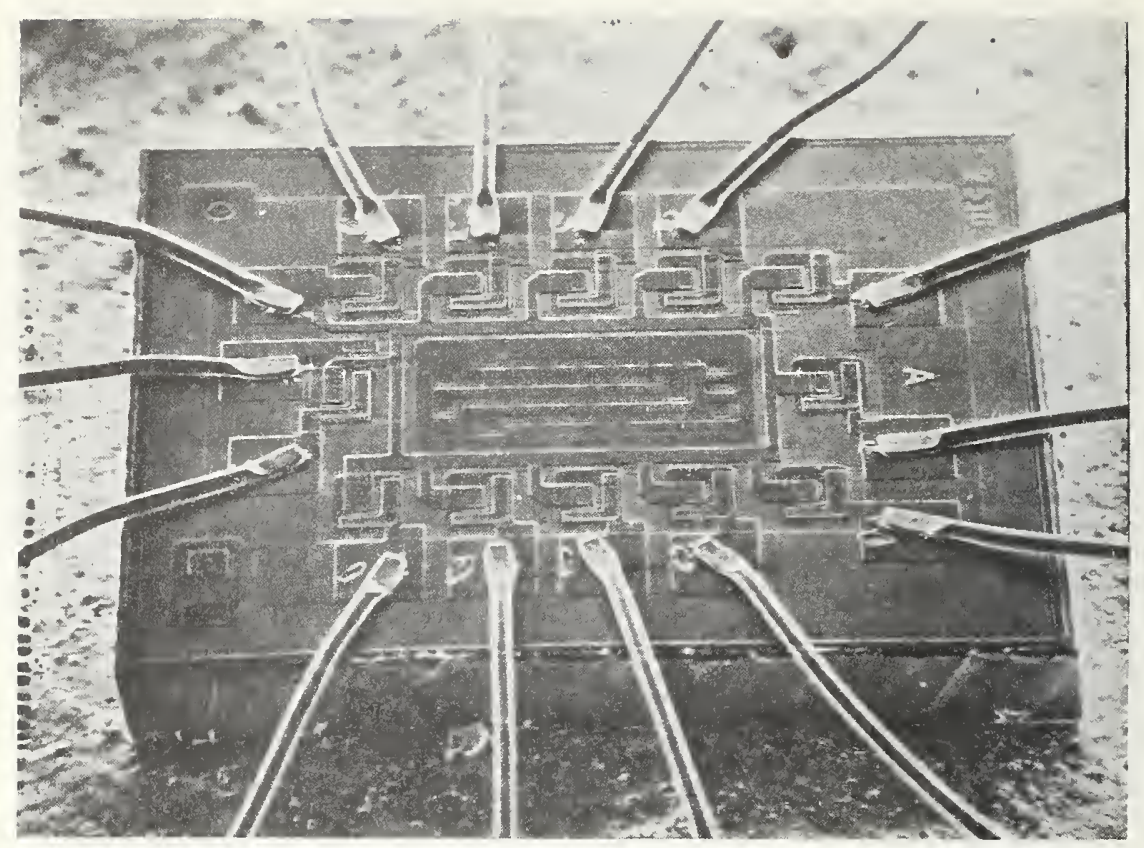

e. Micrograph recorded at $20 \mathrm{kV}$ showing further decreased contrast.

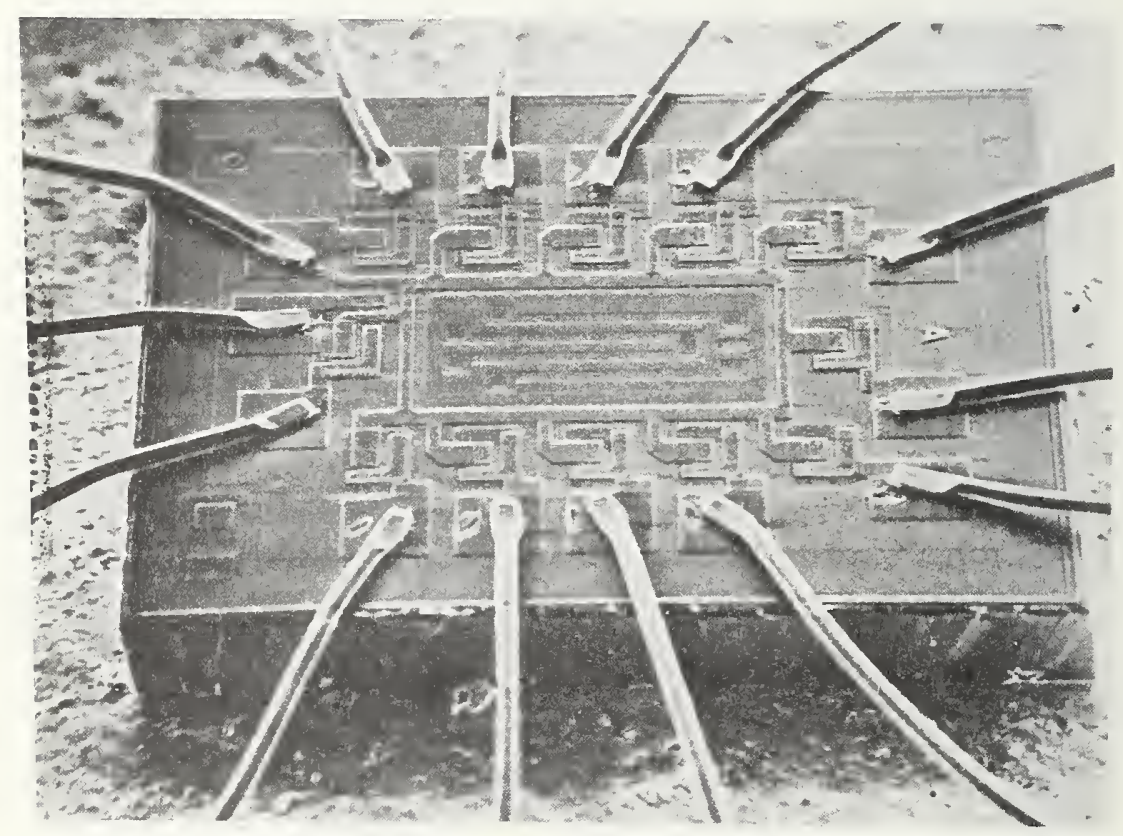

f. Micrograph recorded at $30 \mathrm{kV}$ which shows the most noisy image and almost no contrast. 


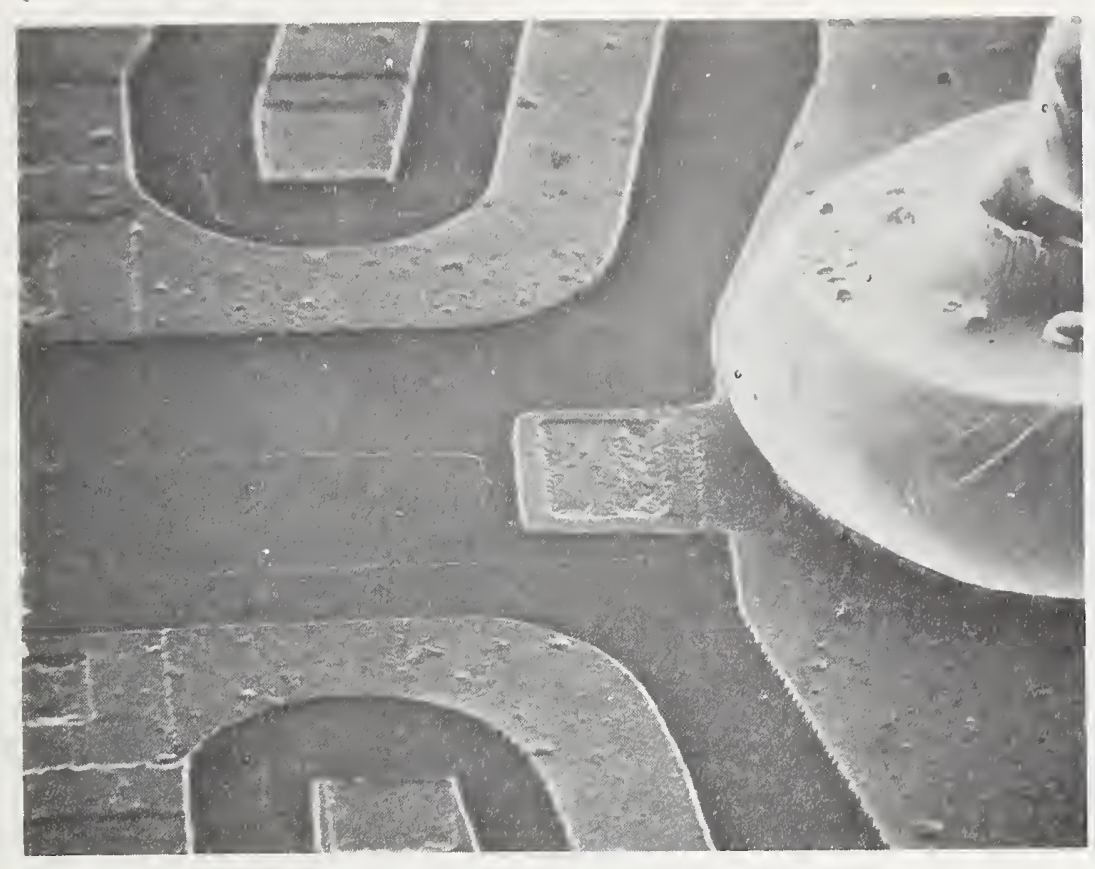

a.

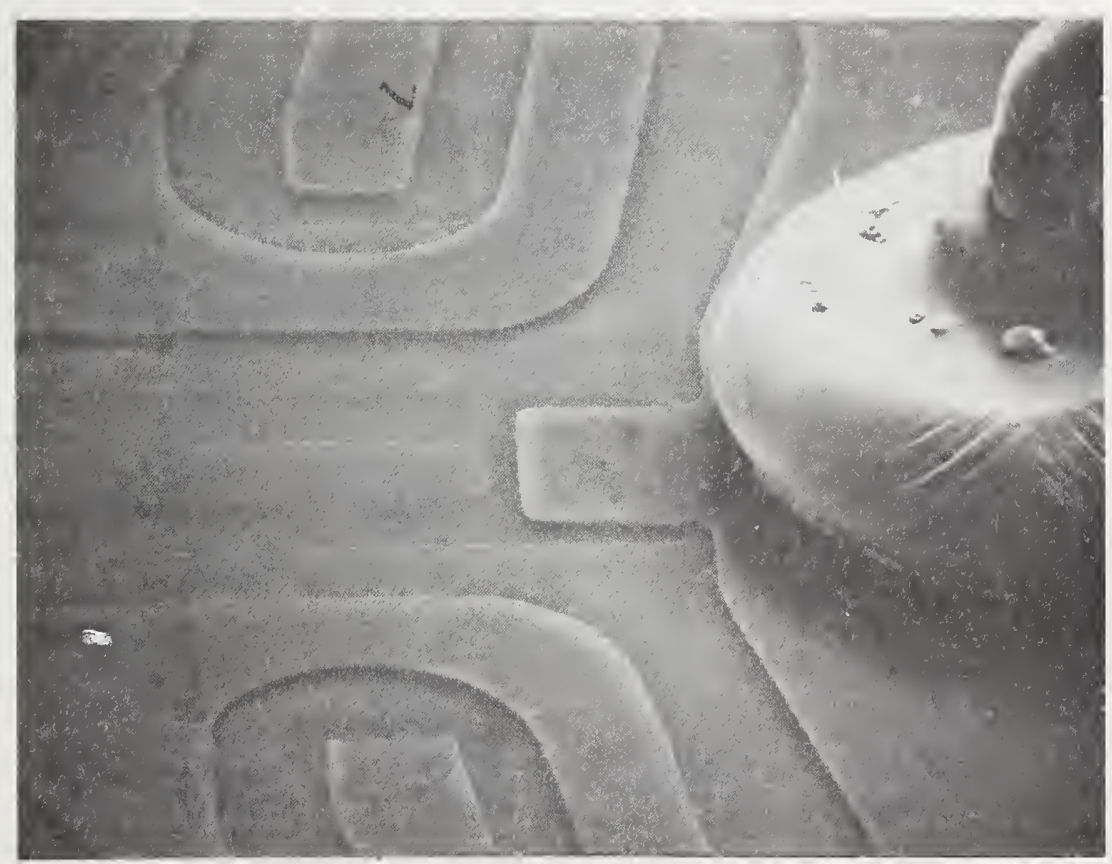

b.

Figure 7. A portion of a microcircuit imaged with a beam voltage at $3 \mathrm{kV}$ (a) and $30 \mathrm{kV}$ (b). 
The greater beam penetration depth at a high accelerating voltage can be advantageously used even at low magnification to provide subsurface information. Figure $8 \mathrm{a}$ shows the surface of a device covered with contamination viewed at $3 \mathrm{kV}$ while figure $8 \mathrm{~b}$ shows the same area viewed at $20 \mathrm{kV}$. The original contaminated surface is not seen at the higher beam energy and the device surface itself can be studied.

The advantage of using high accelerating voltage for high magnification applications is illustrated in figure 9 which shows micrographs of the intermetallic region between a compression ball bond and a pad at a magnification of $10,000 x$. The upper micrograph was recorded with an accelerating voltage of $3 \mathrm{kV}$ and the lower with an accelerating voltage of $10 \mathrm{kV}$. The lower accelerating voltage produces electrons of lower velocity, resulting in an increased width of the primary electron beam and poorer point-to-point resolution in the image, thus the fuzziness in figure $9 \mathrm{a}$. The higher accelerating voltage used for figure $9 \mathrm{~b}$ produces a much sharper primary beam, and the PPR and general resolution are improved.

\section{Beam Current}

The micrographs illustrating this report were taken using a tung sten hairpin filament which is the most common electron source used in commercial instruments. The use of a brighter source would permit higher beam current density, thus better SNR for the same beam diameter, or, conversely, would yield the same beam current and SNR using a finer probe. Two brighter electron sources are becoming available for use on an SEM. The $\mathrm{LaB}_{6}$ gun ${ }^{1}$ is approximately ten times brighter than the tungsten filament. This source usually adds somewhat to instrument complexity. A field emission source is the brightest source presently available. It is about 1000 times brighter than the tungsten filament but requires a correspondingly better vacuum for operation. At the present level of development, it has stability and lifetime problems.

\section{Specimen Tilt}

Semiconductor devices to be examined in an SEM specimen chamber must first be mechanically and electrically secured to a holder designed to be mechanically attached to the SEM stage. The ability of a stage to incline the specimen surface toward the electron detector by means of an external control is termed specimen tilt. The angle of inclination $(\theta)$ formed by specimen tilting is defined as the angle between the plane normal to the path of the primary electron beam and the specimen surface, as shown in figure 10. The primary function of tilt is to obtain a favorable position for viewing the specimen. Advantages obtained by proper adjustment of specimen tilt include increased electron emission, improved contrast, and reduced electrostatic charging. 


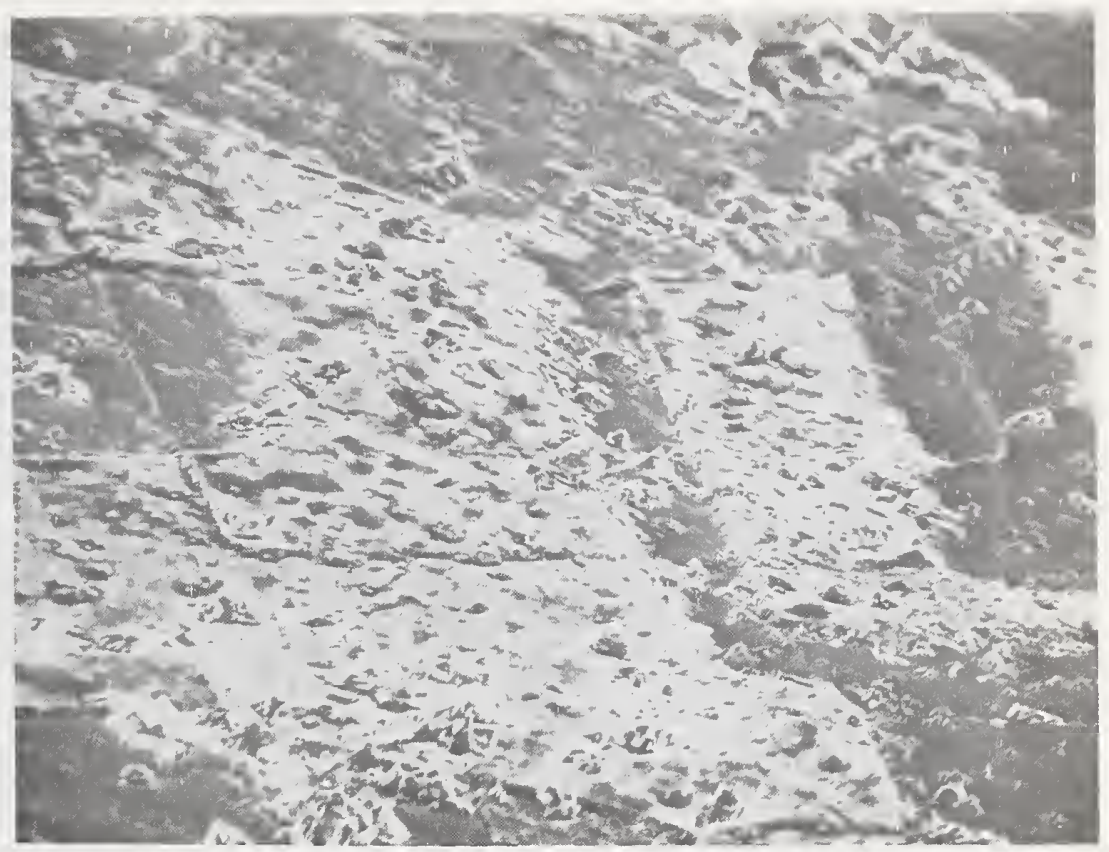

a. With a beam voltage of $3 \mathrm{kV}$, there is clearly visible a layer of contamination on the device surface.

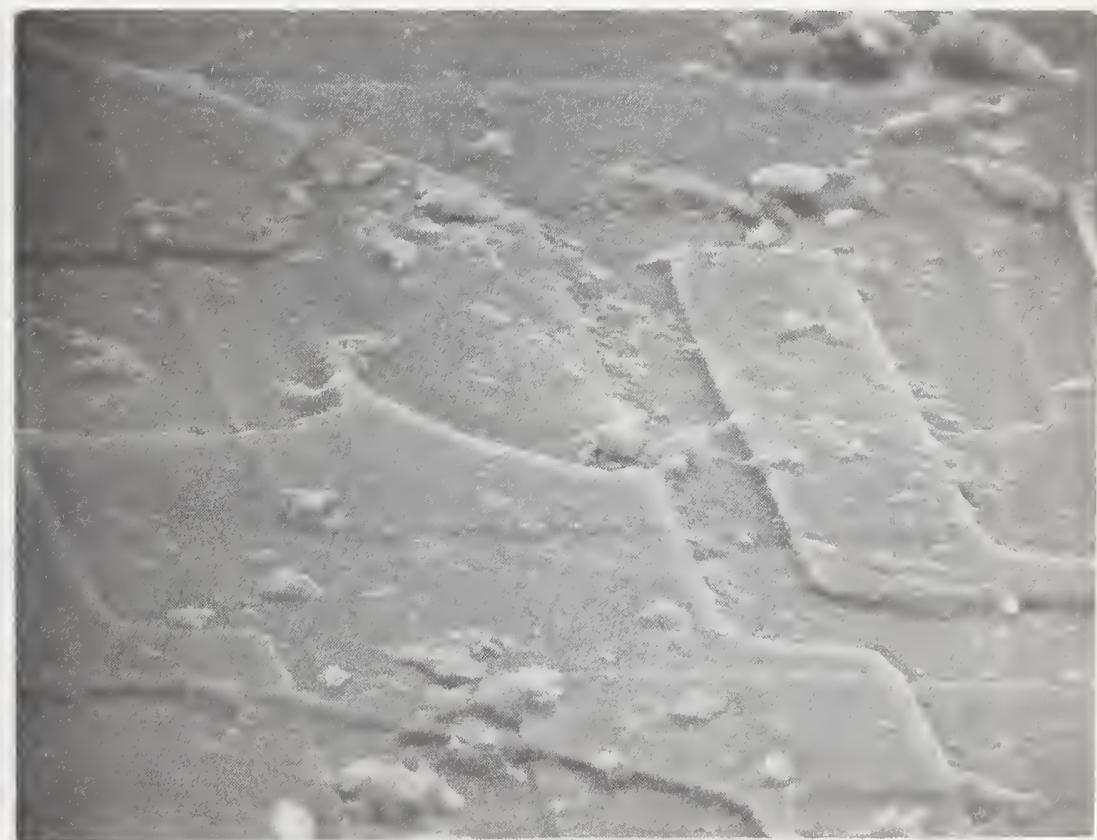

b. With a beam voltage of $20 \mathrm{kV}$, details of the device surface under the contamination become visible.

Figure 8. A portion of a microcircuit imaged at high and low beam voltage illustrating an application of the greater beam penetration at $20 \mathrm{kV}$. 


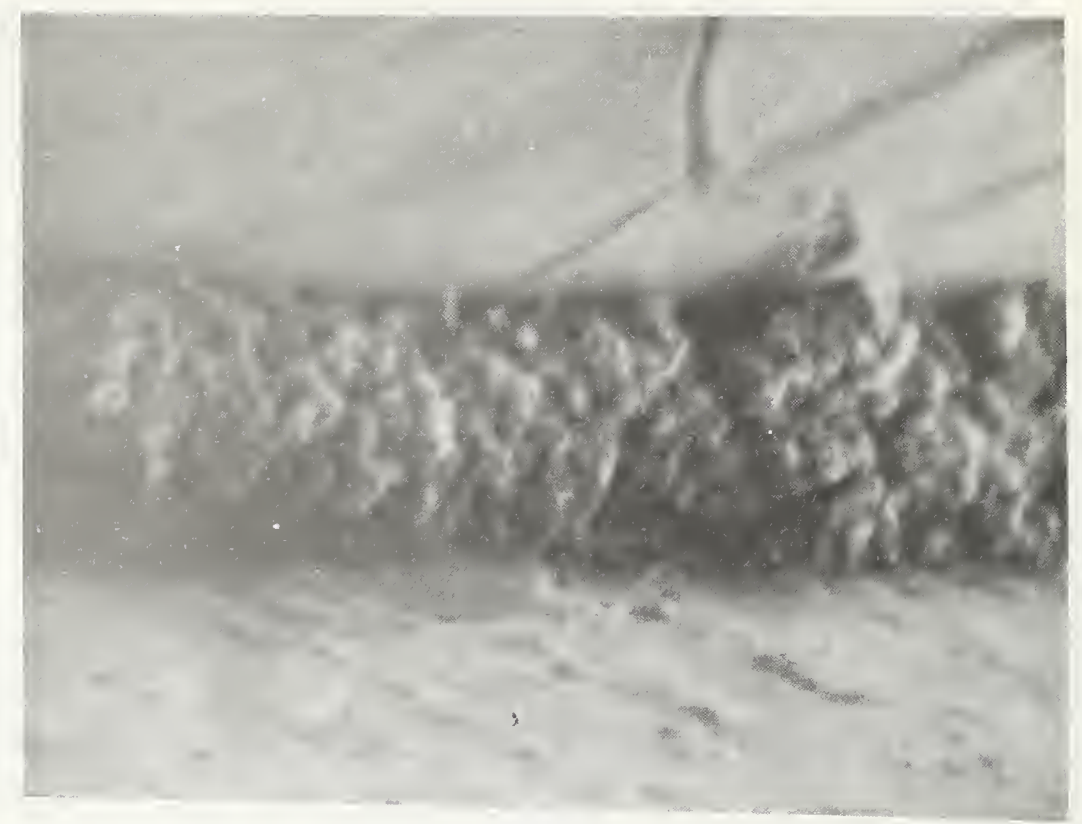

a.

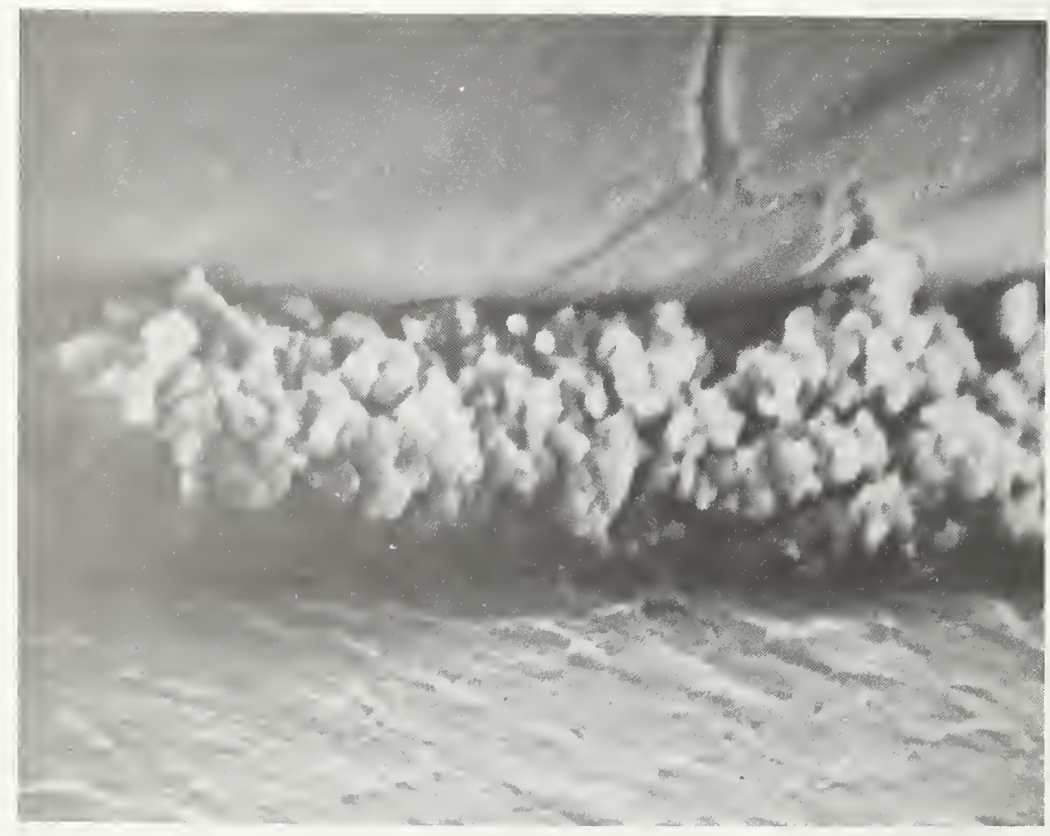

b.

Figure 9. Compression ball bond intermetallic formation imaged at $3 \mathrm{kV}$ (a) and $20 \mathrm{kV}$ (b) illustrating an application of high accelerating voltages. 


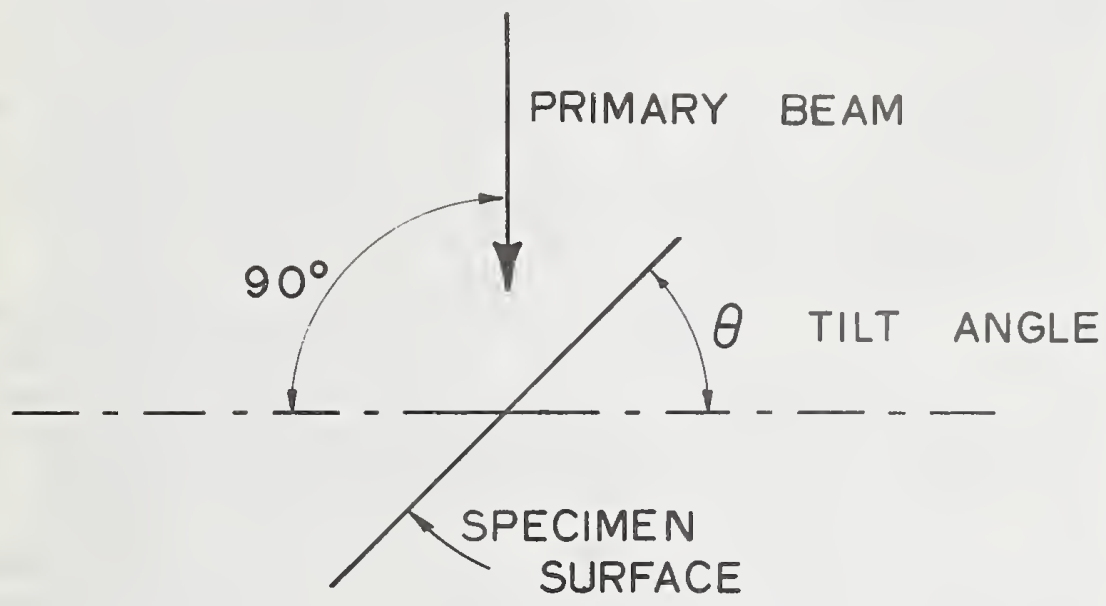

Figure 10. Diagram illustrating specimen tilt angle. 
Improvement in both secondary and backscattered electron emission occurs because the primary electron beam penetration is reduced as the tilt angle is increased from 0 to $90 \mathrm{deg}$. For specimens at a high tilt, more of the primary electron penetration volume is within an escape depth of the surface, thus more electrons are emitted. Increasing the number of emitted electrons improves the SNR, which in turn improves contrast. Both a high tilt angle and a low accelerating voltage limit primary beam penetration.

Another reason that a tilt angle of $45 \mathrm{deg}$ or greater improves the SNR and contrast is that the SEM goniometer stage is designed to tilt the specimen surface toward the E-T detector which is usually optimized for a tilt angle of $45^{\circ}$. Therefore, tilting causes an increase in the number of signal electrons that can reach the electron detector.

These effects are demonstrated in figure 11. These micrographs were made with an accelerating voltage of $5 \mathrm{kV}$ and a constant beam current. In figure $1 \mathrm{la}$ where $\theta$ is $0 \mathrm{deg}$, there is little topographical or chemical contrast. Figures $11 \mathrm{~b}$ and $11 \mathrm{c}$ demonstrate the advantage of tilt in revealing the character of the topography more clearly. In the latter micrograph, a distinct improvement in SNR and topographical contrast can be noted when compared to figure 1la. An interesting development in chemical contrast is seen in figure 11d. Such intense contrast of this quality can only be attained using an accelerating voltage less than approximately $7 \mathrm{kV}$ with a tilt angle of about $45 \mathrm{deg}$ or greater. As $\theta$ increases to $60 \mathrm{deg}$, enhancement of chemical contrast and SNR continues as shown in figure 1le. Examination at high angles provides an increased capability of interpreting the quality of the metallization, bonding, and oxide steps which is valuable to SEM semiconductor analysis. This is especially true for regions of the device where tools have been used to trim, bond, and cut portions of the device. These are areas where heavy mechanical damage often occurs.

Another very useful consequence of tilting a semiconductor device can be seen in figure 12. Figure 12a shows a passivated microcircuit examined at a $\theta$ of 0 deg without any prior preparation to prevent charging. Charging is manifested by the very bright regions with the very dark adjacent areas which results in the obscuring of detail in both. In figure $12 \mathrm{~b}$ the same circuit is examined at a $\theta$ of $60 \mathrm{deg}$. The high tilt angle has increased the number of backscattered and secondary electrons which leave the surface, thus reducing the net charge in the insulating layer. The resolution is not good in this image, but it demonstrates that specimen tilt is a technique which can be used to reduce specimen charging, as well as improve contrast. Further discussion on specimen charging will be found in Section 7.

\section{Scan Line and Frame Time}

In an SEM the same sweep or scan generator is used to synchronously deflect both the primary electron beam in the column and the electron beam in the cathode ray tube (CRT) used for imaging. 


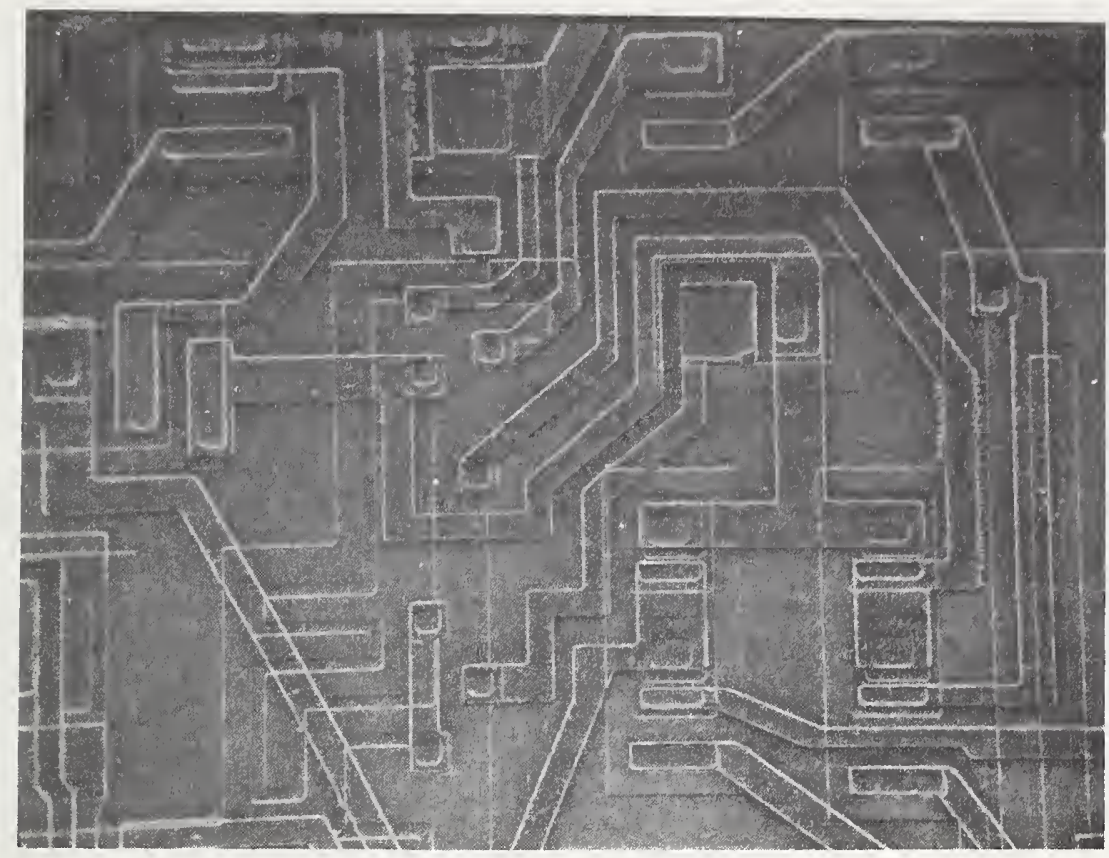

a. Tilt angle is $0 \mathrm{deg}$.

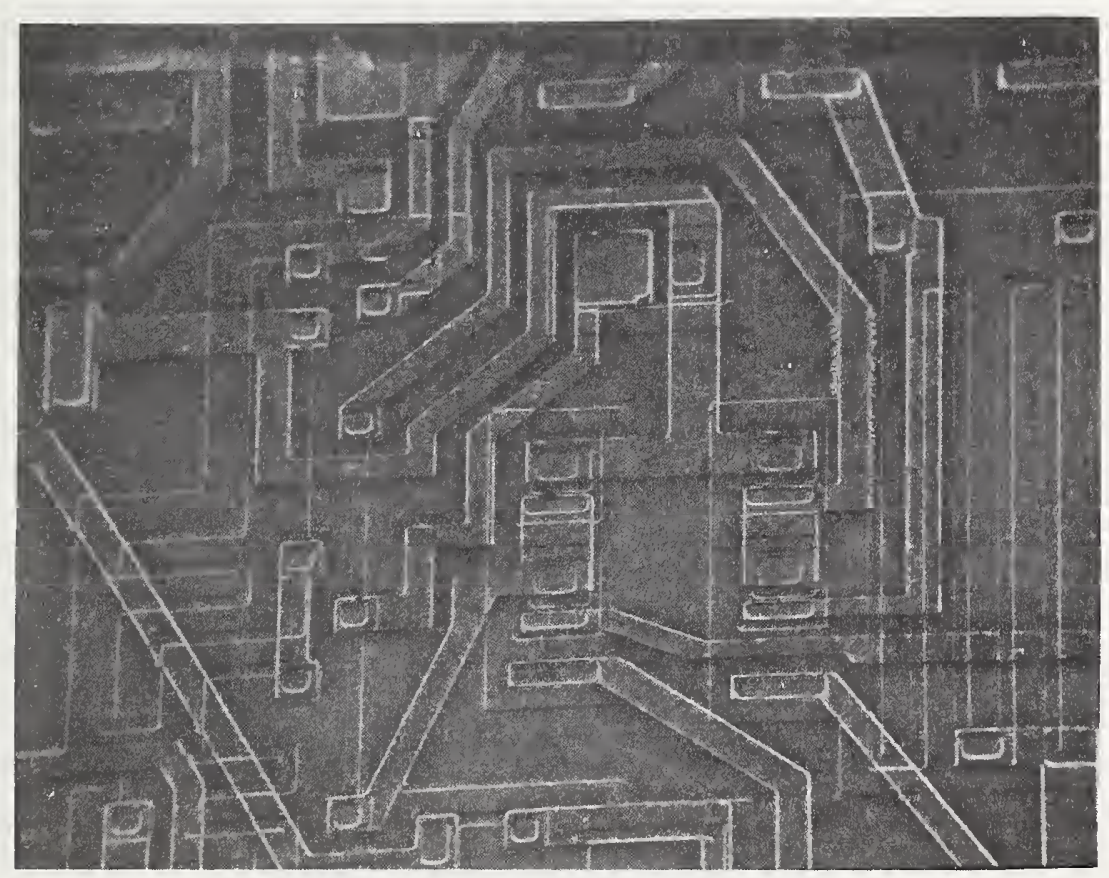

b. Tilt angle is $20 \mathrm{deg}$.

Figure 11. Series of micrographs which illustrate the changes in contrast and SNR as specimen tilt angle is increased from 0 to $60 \mathrm{deg}$. 


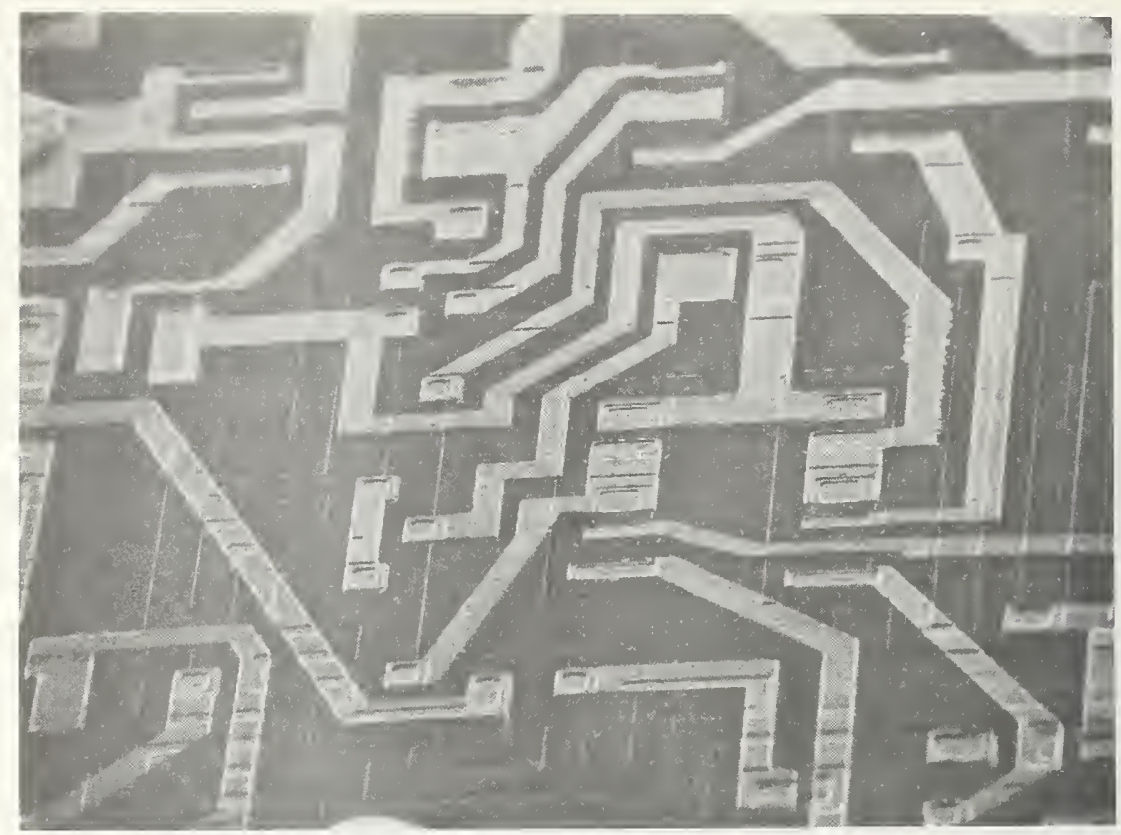

c. Tilt angle is $40 \mathrm{deg}$.

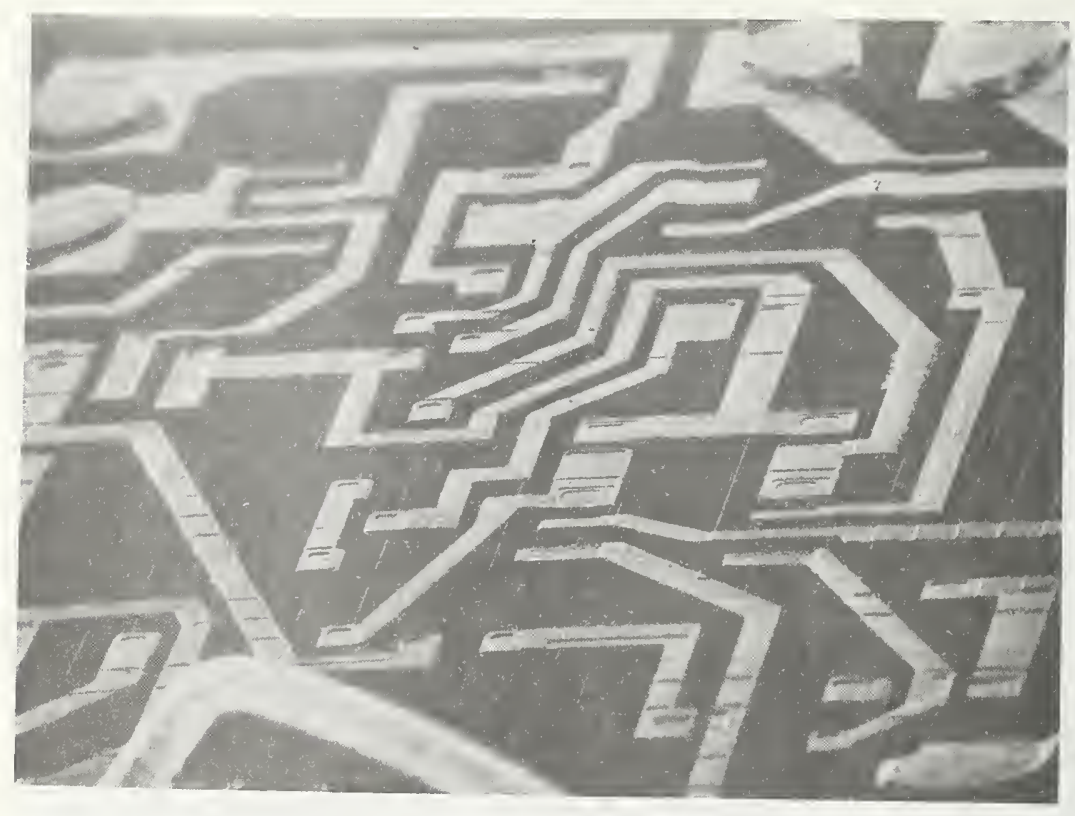

d. Tilt angle is $50 \mathrm{deg}$. 


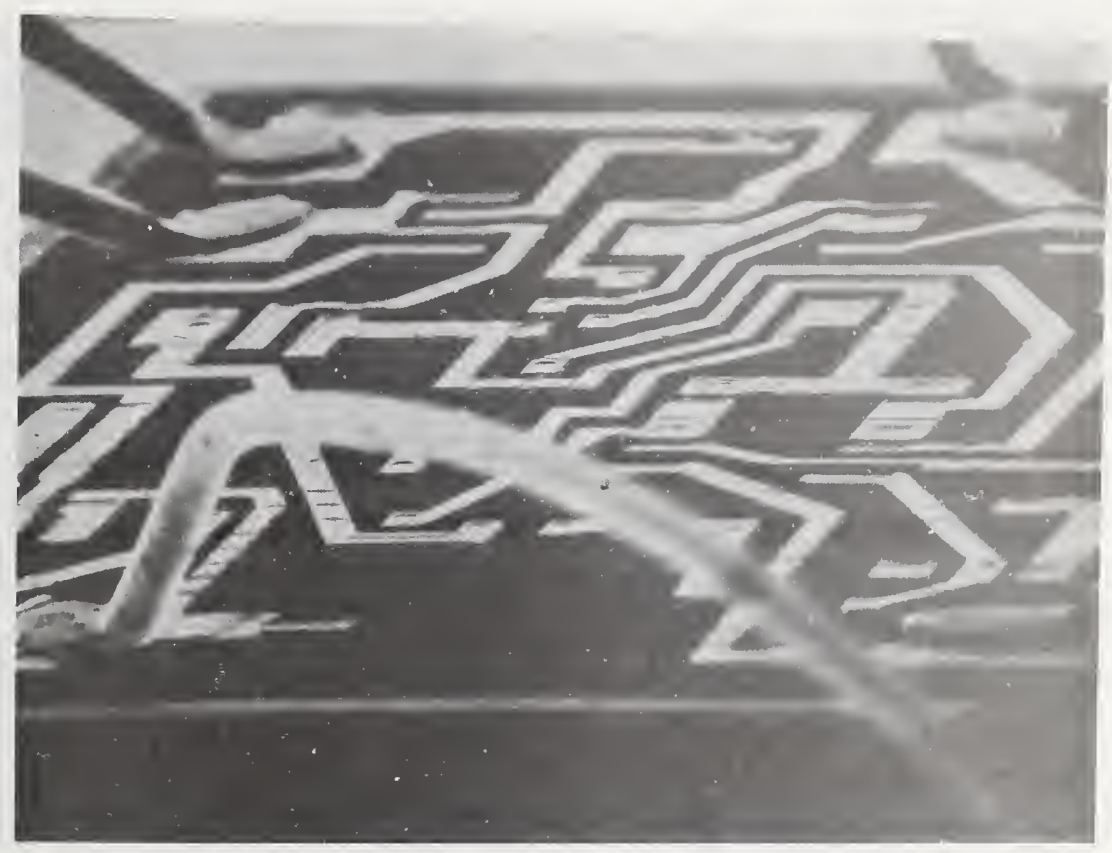

e. Tilt angle is $60 \mathrm{deg}$. 


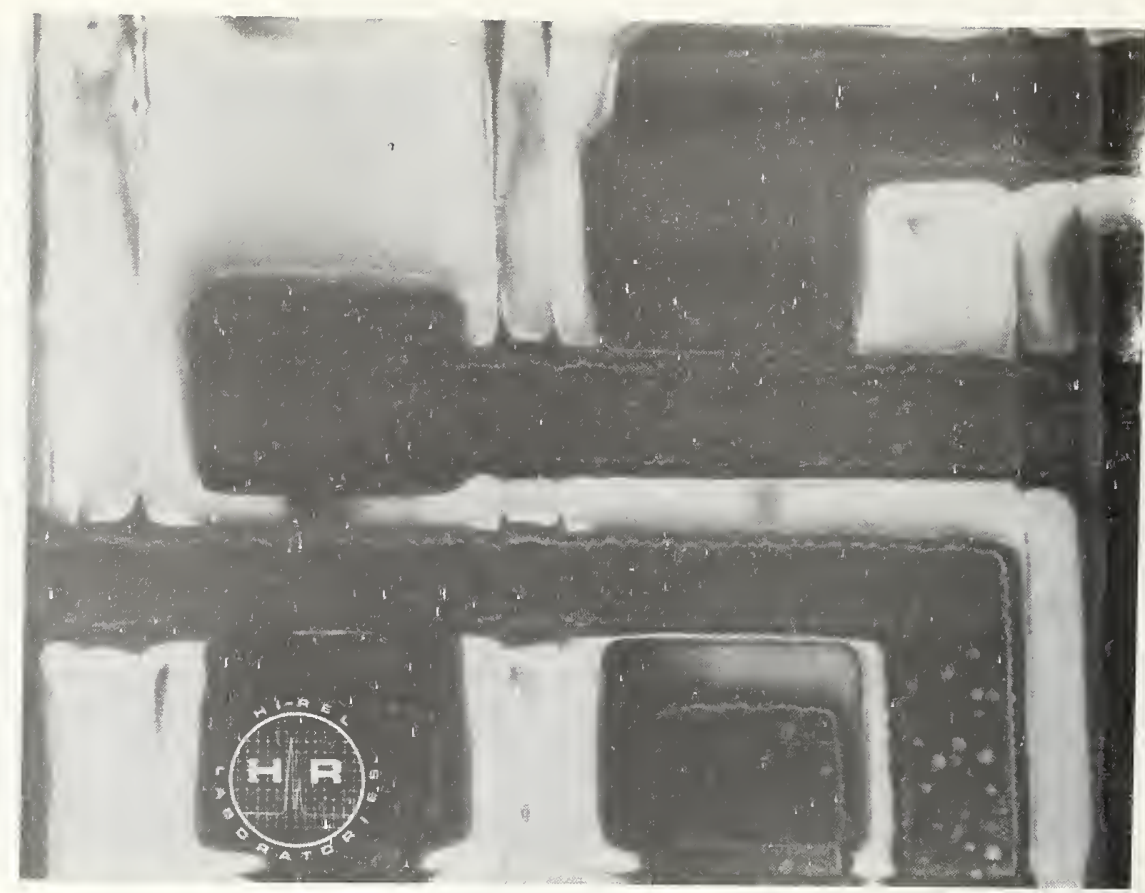

a. With a tilt angle of 0 deg, a large amount of charging is apparent due to trapping of primary electrons in the glass layer.

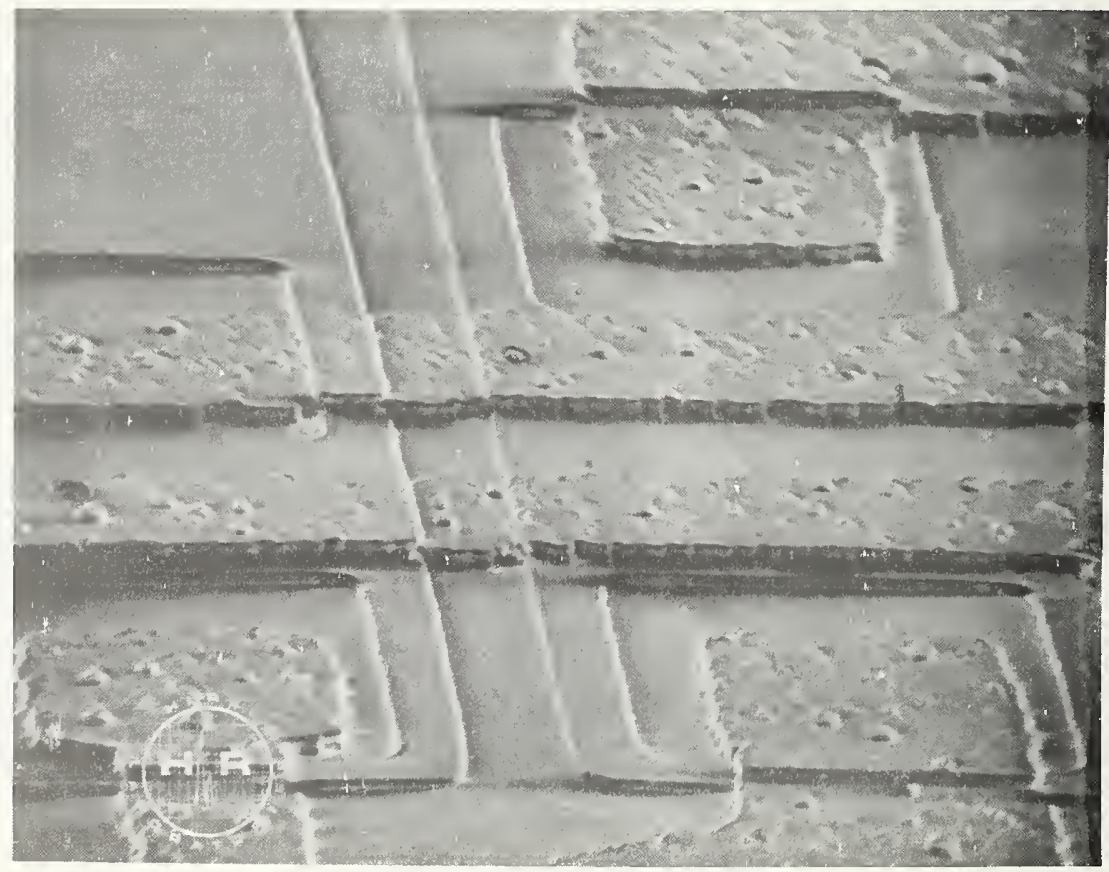

b. With a tilt angle of $60 \mathrm{deg}$, the charging has been greatly reduced because fewer electrons are captured in the glass.

Figure 12. The effect of specimen tilting when viewing a passivated microcircuit. 
The line scan time is the amount of time taken for a single line to be scanned from left to right across the CRT display screen. The frame time is the amount of time taken to complete a compilation of single lines sweeping the display screen from top to bottom. These two parameters determine the number of lines, the number of picture points, and the beam dwe11 time for each picture point in the SEM image. The amount of time the electron beam rests on a point of the specimen surface determines the number of electrons emitted from that point. Therefore for a given beam current and detector gain, it is the number of picture points and dwell time per point which ultimately determine the SNR. These principles apply whether the scan generator is a digital or analog type. The range of scan line and frame times on commercial SEM's is large. The factor to be considered when selecting the line scan and frame time for SEM photomicrography is the selection of a suitable number of scan lines per frame so that none are visible within the resolution limits of the eye. Another consideration is that the number of scan lines used should not be so high that the scan time per point is reduced causing the SNR to suffer significantly. In addition, the frame time should be short enough to allow the economical recording of micrographs.

In order to illustrate the proper selection of line scan and frame time for SEM photomicrography, micrographs of the same semiconductor device recorded under different raster time conditions are compared. The values of accelerating voltage, beam current, and tilt are held constant. If too few scan lines are used, the individual lines can be differentiated in the micrograph. The result is poor PPR caused by the picture voids between the lines. This effect can be seen with about 500 scan lines per frame or less. (Due to the loss of resolution in printing, this example is not shown.) In order to fill these picture voids and improve the $\mathrm{PPR}$, an image of the device was recorded using a frame time of $10 \mathrm{~s}$ and scan line time of $0.005 \mathrm{~s}$. The resulting micrograph, shown in figure 13a, has a total of 2000 lines; as a result, there are no picture line voids. However, there is an increase in noise due to the reduced scan time per point producing a lower SNR. It is apparent that for a frame time of $10 \mathrm{~s}$, neither 500 nor 2000 scan lines are suitable for photomicrography.

Figure $13 \mathrm{~b}$ was recorded using a $10 \mathrm{~s}$ frame and a $0.01 \mathrm{~s}$ line scan time, producing a total of 1000 lines. It shows an improvement in PPR and SNR. However, there is still considerable noise in the image. To decrease this noise, the line scan time was increased to $0.1 \mathrm{~s}$, and the frame time increased to $100 \mathrm{~s}$, keeping a total of 1000 scan 1ines. The result shown in figure $13 \mathrm{c}$ demonstrates excellent PPR, SNR, and contrast. However, the economics of the SEM operation might dictate that micrographs be made in less than $100 \mathrm{~s}$. Figure 13d shows a compromise between SEM resolution and efficiency. This micrograph was recorded with a $40 \mathrm{~s}$ frame time, and a scan line time of $0.04 \mathrm{~s}$, keeping the 1000 scan line total. These final values are generally very effective for good micrograph quality. Of course, should a better SNR be required, one method of improvement would be to increase the frame time. 


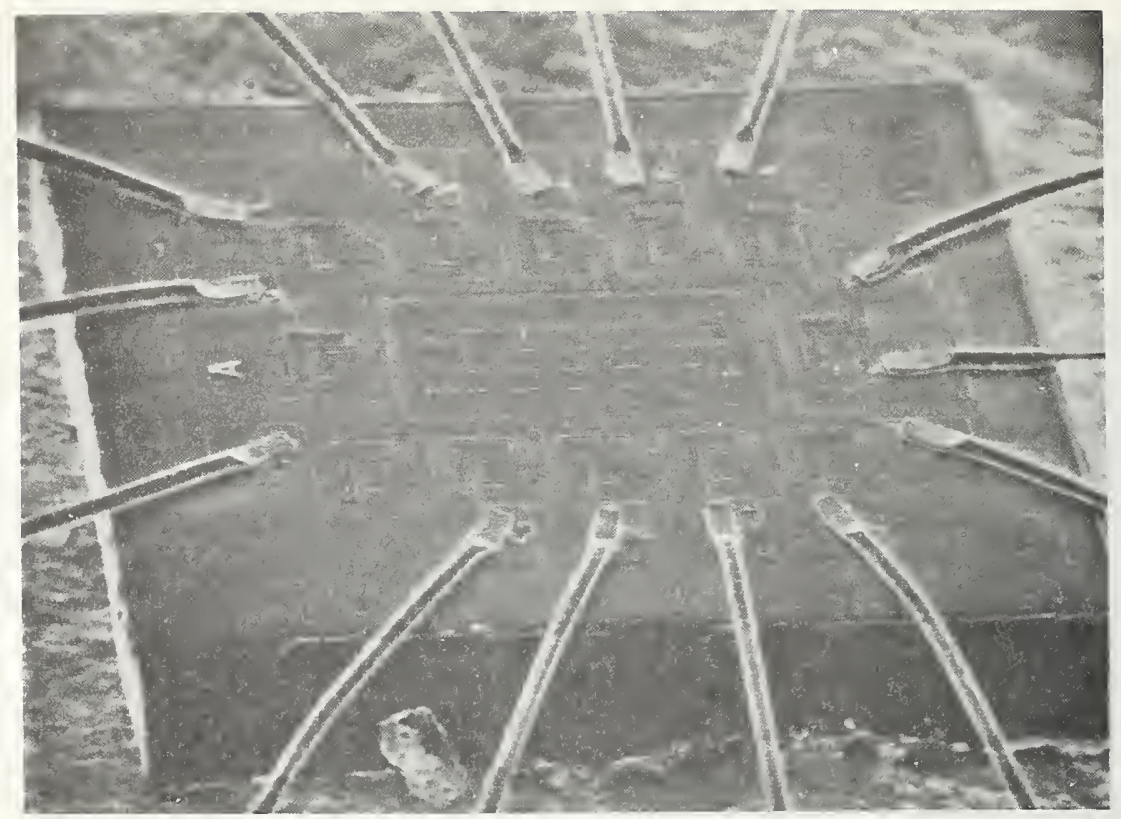

a. Scan time $0.005 \mathrm{sec} /$ line and 2000 lines per frame. There is increased noise due to the short dwell time per picture point.

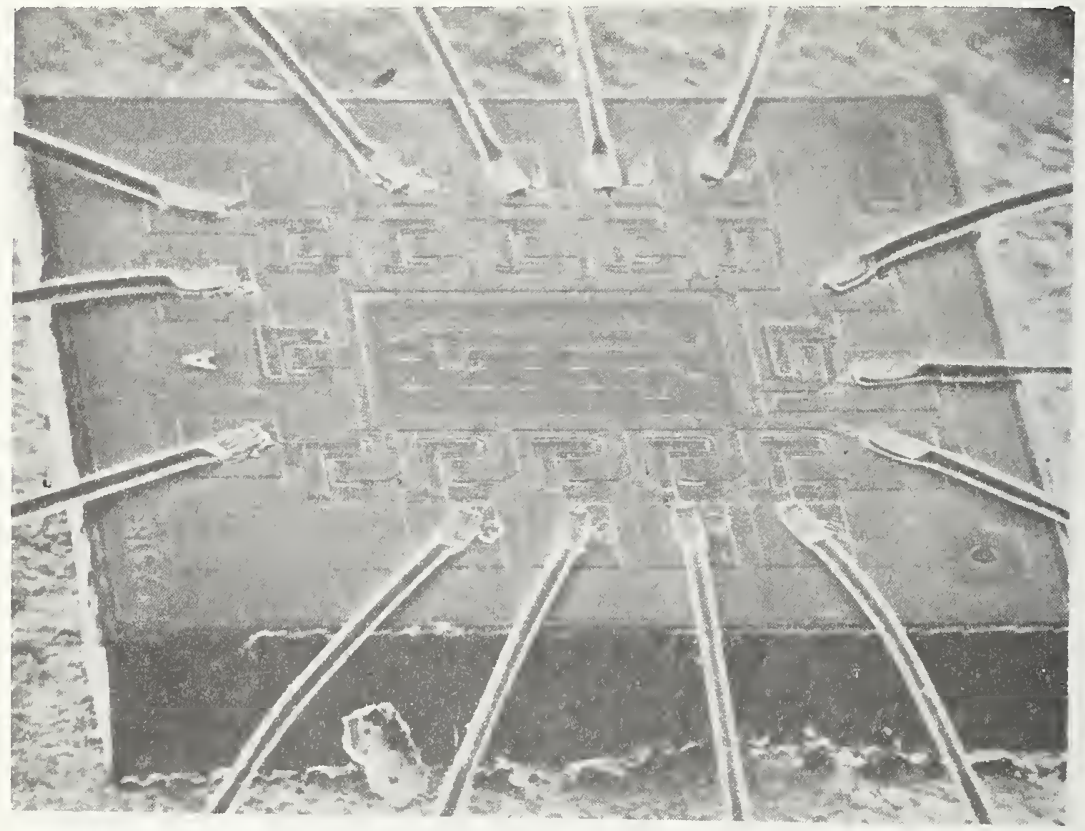

b. Scan time $0.01 \mathrm{sec} /$ Iine and 1000 lines per frame. The image shows better PPR and SNR as compared to (a).

Figure 13. Series of micrographs illustrating the effects of variations in scan line time, frame time, and the number of lines in the micrograph. 


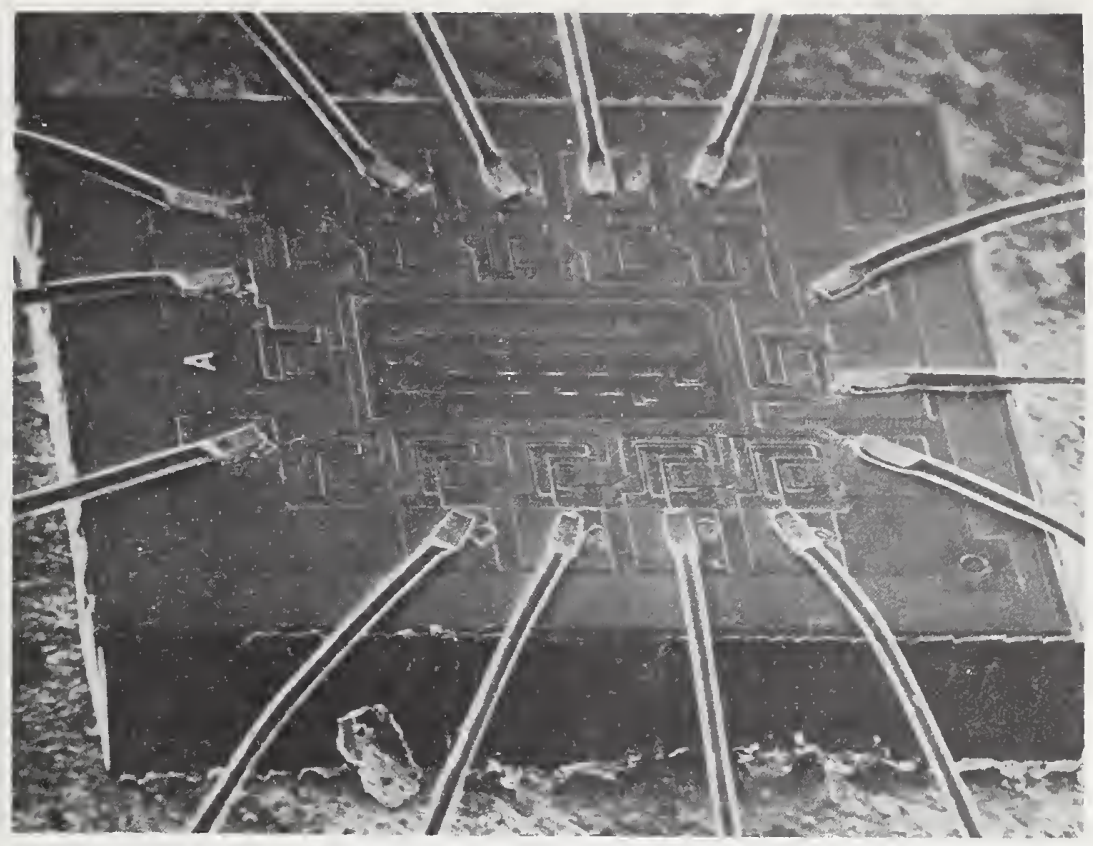

c. Scan time $0.1 \mathrm{sec} / 1$ ine and 1000 lines per frame. Contrast, PPR, and SNR are excellent.

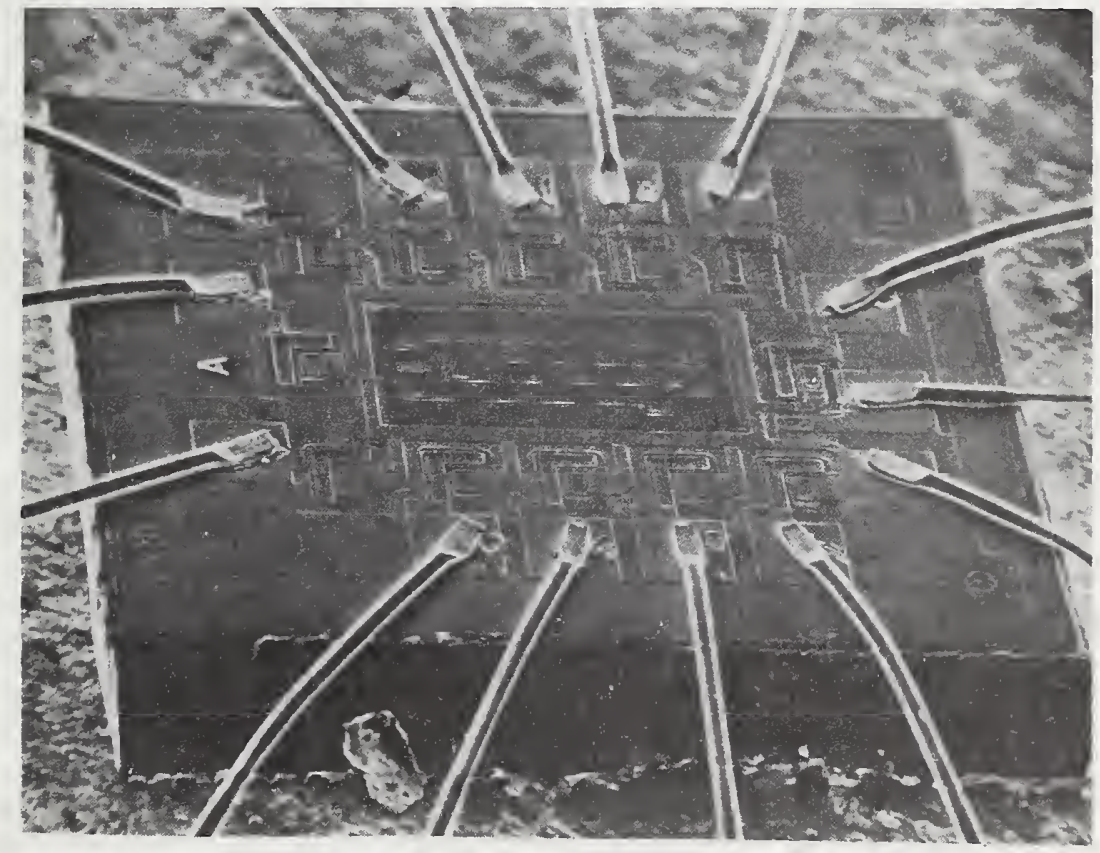

d. Scan time $0.04 \mathrm{sec} /$ line and 1000 lines per frame. This represents a compromise giving good contrast, PPR, and SNR while limiting total exposure to 40 seconds for efficient use of time. 
In setting up the SEM, focusing and stigmator adjustment are most conveniently performed using a frame time of 1 to $5 \mathrm{~s}$. An expedient technique is to reduce the display screen raster size to 3 by $3 \mathrm{~cm}$ or 4 by $4 \mathrm{~cm}$ instead of the standard 10 by $10 \mathrm{~cm}$ to eliminate slow scan flicker and aid focus and stigmator adjustment by providing a more continuous image.

A separate monitor which scans at a television rate is a versatile means for quick examination of semiconductor devices. However, the 500line picture is scanned in $1 / 30 \mathrm{~s}$ giving a very short scan time per picture point and reducing the SNR greatly. To increase the SNR for adequate viewing, it is necessary to increase the beam current and consequently beam size which in turn reduces the PPR. The resulting picture is useful as a visual display for rapid search and for the study of dynamic effects but seldom is suitable for good photomicrographs.

\section{Artifacts Introduced by the Beam}

In scanning electron microscopy, three of the most common artifacts introduced by the primary electron beam are electrostatic charging, vacuum pump oil polymerization, and electron beam damage. These artifacts present special problems for examining semiconductor devices because of the materials used in their construction and the fact that active electronic components are susceptible to radiation damage.

Electrostatic charging is due to the presence of a negative potential on an insulating portion or point of the specimen surface. Charging is caused by the collection of electrons on the surface of the insulator. The accumulation of electrons builds up a space charge which can deflect the incident beam, causing severe image distortion. The presence of the surface charge will also change secondary emission greatly. A charged area can cause the darkening of the image of a nearby uncharged region by deflecting the emitted secondaries away from the detector. The charging effect is time dependent since a charged region may discharge by a breakdown to ground and then the region can recharge.

Portions of semiconductor devices charge readily, because of the insulating materials used in their fabrication. Glass, alumina, and silicon dioxide are examples of insulating materials used as substrates, packages, or passivating layers in semiconductor fabrication. These materials, along with nonconductive contaminant particles, are possible sites for charging.

In order to recognize how charging manifests itself, some examples are given. One example has already been seen in figure $12 \mathrm{a}$ in the discussion of tilt angle. Figure $14 \mathrm{a}$ shows glass passivation which has become charged over a metallization pattern. A single nonconducting particle whose image has become extremely bright is shown in figure $14 \mathrm{~b}$. As a result of the high negative potential at its surface, the secondary electron emission has been reduced in the vicinity of the particle. 


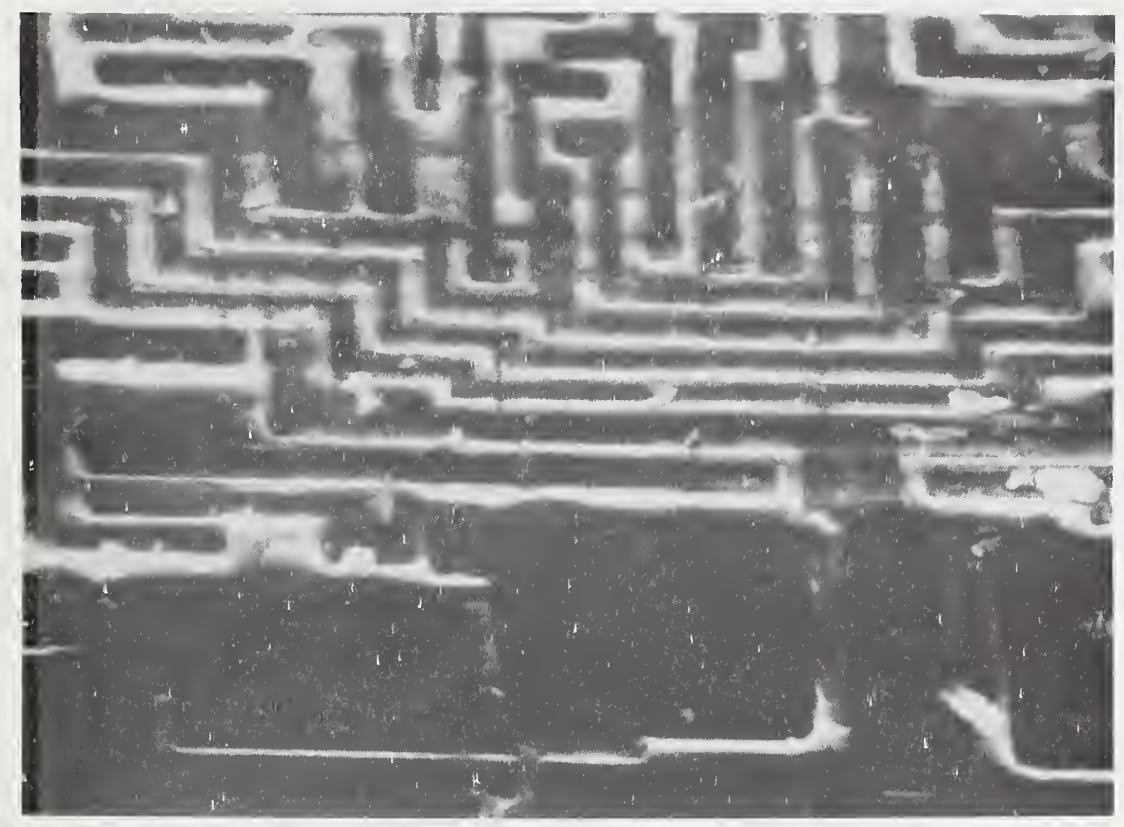

a. A glass passivation layer which has become charged by the electron beam.

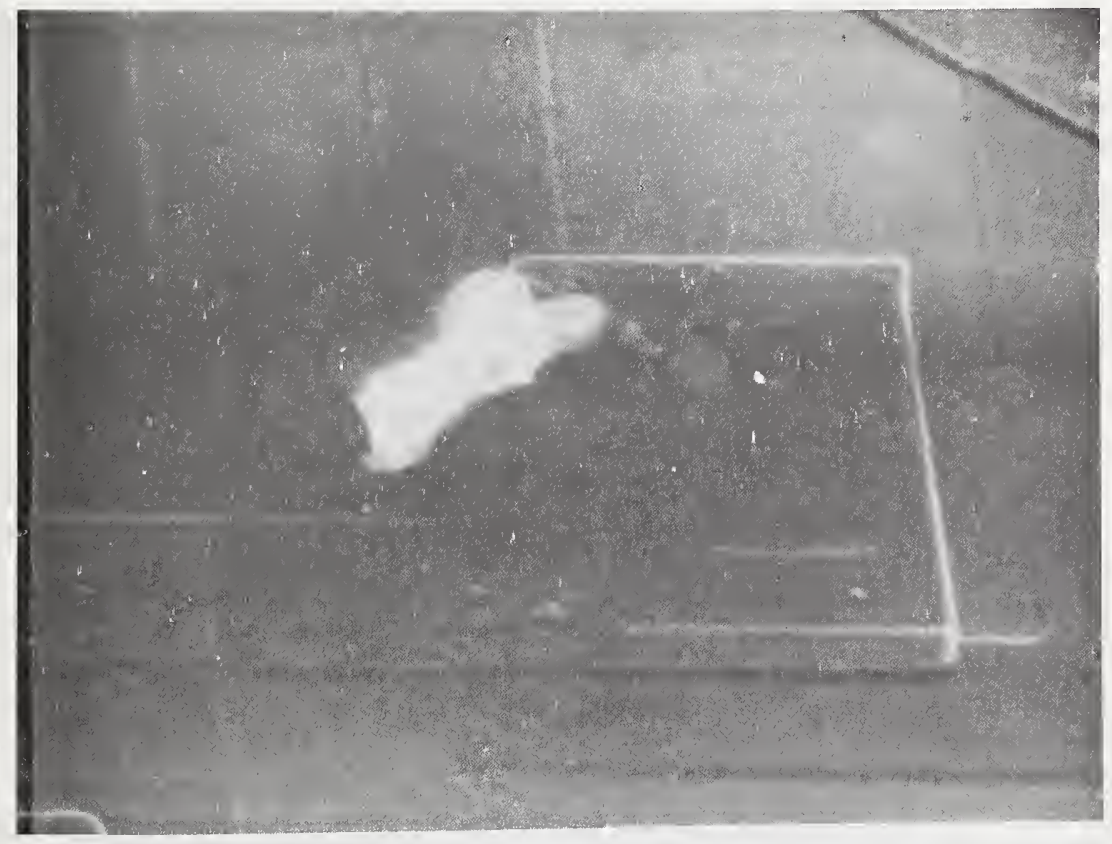

b. An insulating particle which has become charged. Figure 14. Two examples of charging. 
It is not necessary for an area of the specimen to be in the field of view for it to become charged. There can be a charge build-up where scattered electrons strike a surface. Figure 15a shows a device which had been previously viewed with an accelerating voltage of $10 \mathrm{kV}$ at a higher magnification. The raster area during that exposure is shown by the darkened region near the top of the device. The electrons scattered from this area formed a charge build-up on the ceramic package in the area that appears bright (indicated by the arrow). The darkened area around this bright spot indicates the suppression of secondary electron emission in the vicinity of the charged region. The effect of this suppression can be seen more clearly in the next two figures which show two versions of the high magnification view. Figure $15 \mathrm{~b}$ is a micrograph made before the charge build-up while figure $15 \mathrm{c}$ was made afterward. Charging of the package has suppressed a wide range of signal electrons and reduced the contrast even though the charged area is not located in the area of the micrograph.

Charging is often seen as a distortion of the image in the photomicrograph. Figure 16a shows the characteristic bright areas of charging, but in addition there are bright lines breaking the continuity of the image at the top and center. These are caused by unsynchronized discharges of the charged specimen surface during scanning. Figure 16b is an example of a particularly deceptive charging symptom. There is poor PPR which no amount of manipulation of the SEM controls could significantly improve. In this case, there is a charge build-up in the residual glass left behind by poor etching. As a result, the primary beam cross-section is distorted from its normal circular shape to that of an ellipse which results in a loss of PPR. This distortion is very similar to the uncorrectable instrumentation astigmatism caused by dirty apertures in the electron beam column. Figure 16c shows severe image distortion of a metallization window. The entire raster has been slowly deflected by the charged residual glass during the exposure of the micrograph. This effect is best seen in the long blurred streaks in the upper half of the image.

It is not difficult to see that charging can render SEM images useless. Reducing the electron beam current wil1 reduce but not eliminate charging. Two techniques for reducing the effects of charging are illustrated in figure 16d. The penetration of primary electrons into an insulating surface, and their storage on and beneath the surface is the cause of charging. In figure 16d, a microcircuit similar to the microcircuit in figure 15 is shown. However, the high magnification raster at the top of the die in figure $16 \mathrm{~d}$ was irradiated using a high tilt angle and a $3-\mathrm{kV}$ accelerating voltage instead of $10 \mathrm{kV}$ as in figure $15 \mathrm{c}$. The energy of the backscattered electrons is $3 \mathrm{keV}$ which is too low for these electrons to penetrate and charge the top of the die well, unlike the 10-keV backscattered electrons which caused the charging seen in figure 15a. In the section on specimen tilt, figure 12 demonstrates that specimen tilt could be used as a method to reduce electron penetration, and, therefore, charging. Using low accelerating voltage and specimen tilt is the most expedient means of preventing charging. It 


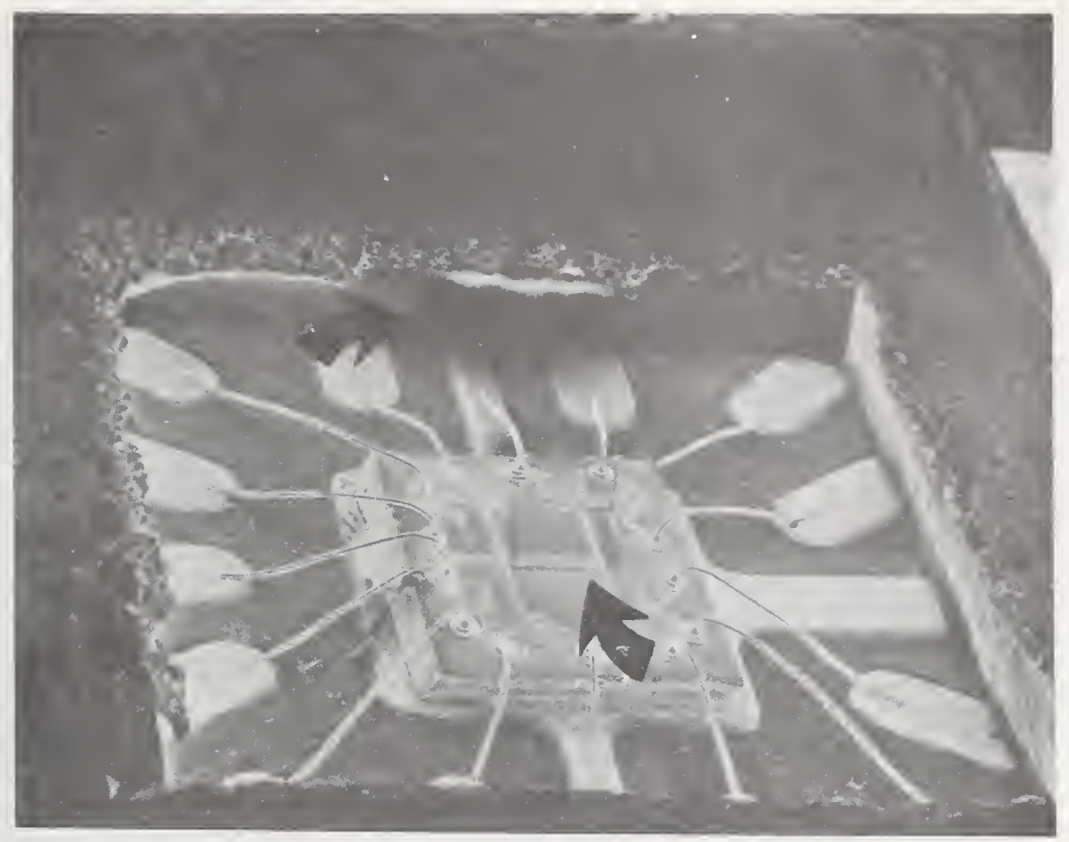

a. A low magnification photo of a microcircuit which has just been examined at a higher magnification. The dark area of the circuit shows the area scanned. Backscattered electrons have caused charging of the ceramic package which has caused a darkening. (See arrows.)

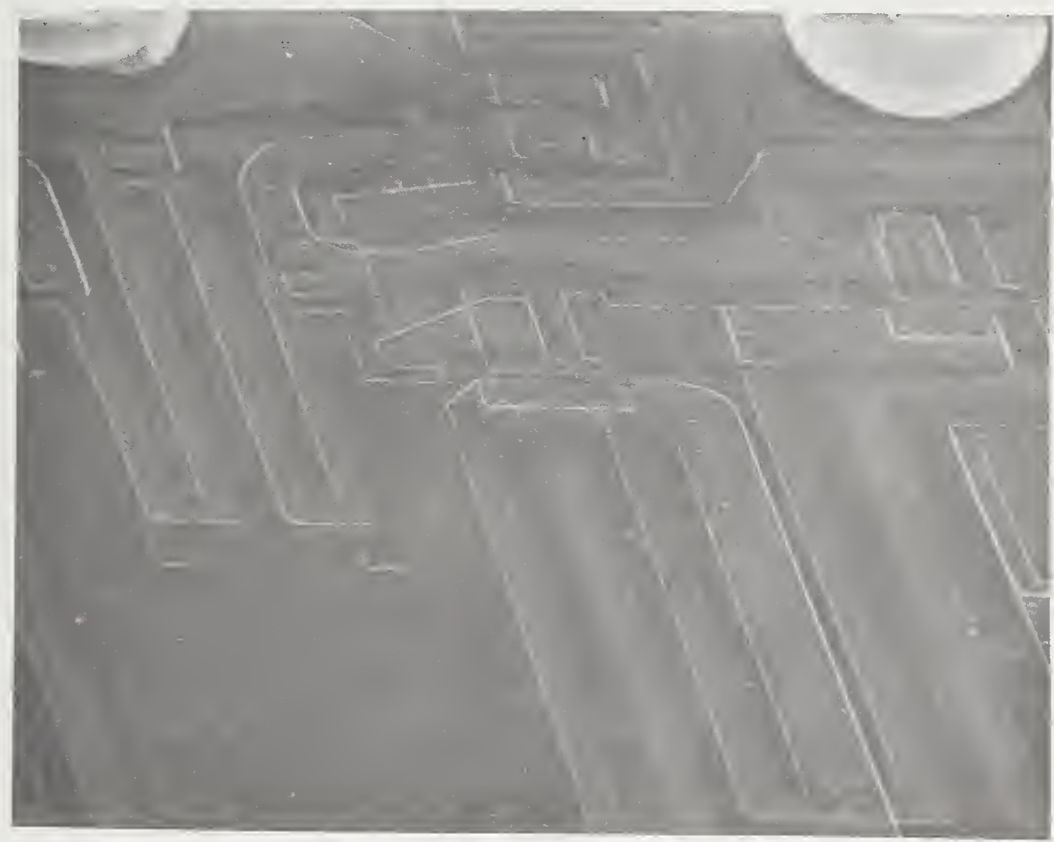

b. A circuit similar to that shown in (a). This micrograph was made shortly after the beam was turned on and shows adequate contrast and topographic detail.

Figure 15. Micrographs which show the effects of charging of areas outside the field of view. 


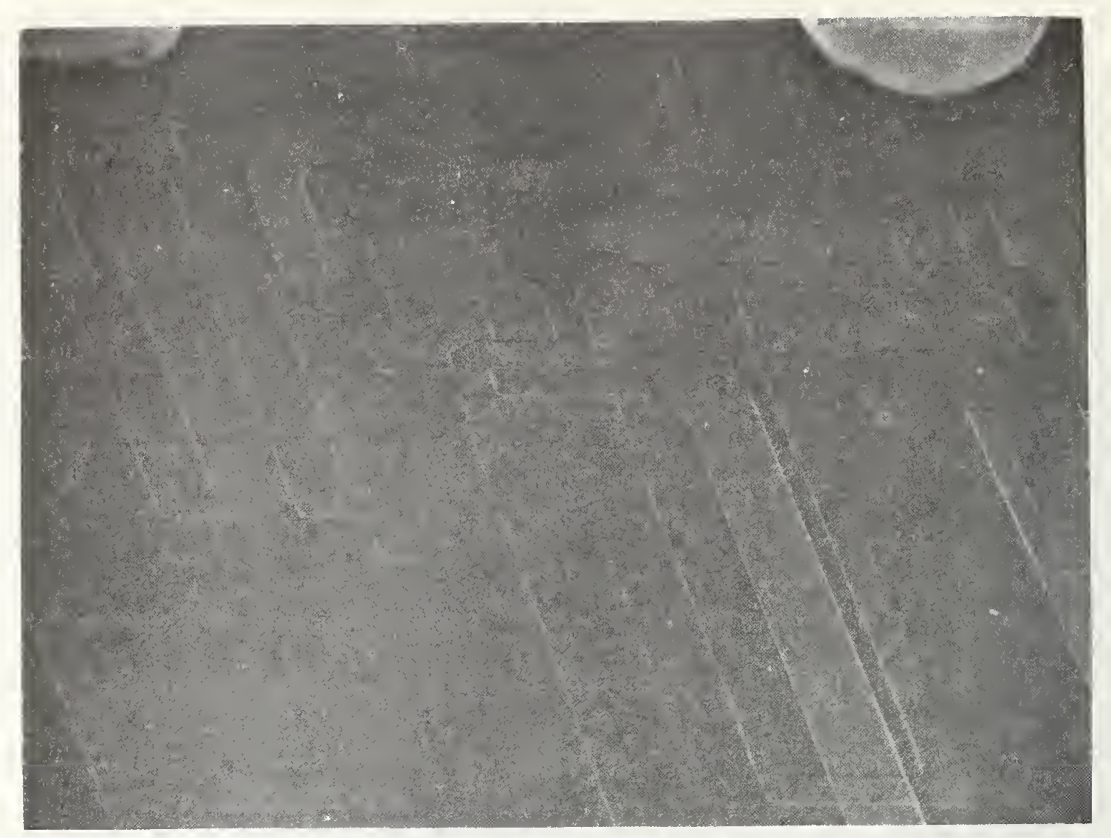

c. The same area as shown in (b) after a long exposure to the electron beam. There is a reduction in the number of secondary electrons detected which results in a reduction in contrast. This is due to charging which is occurring outside the field of view. 


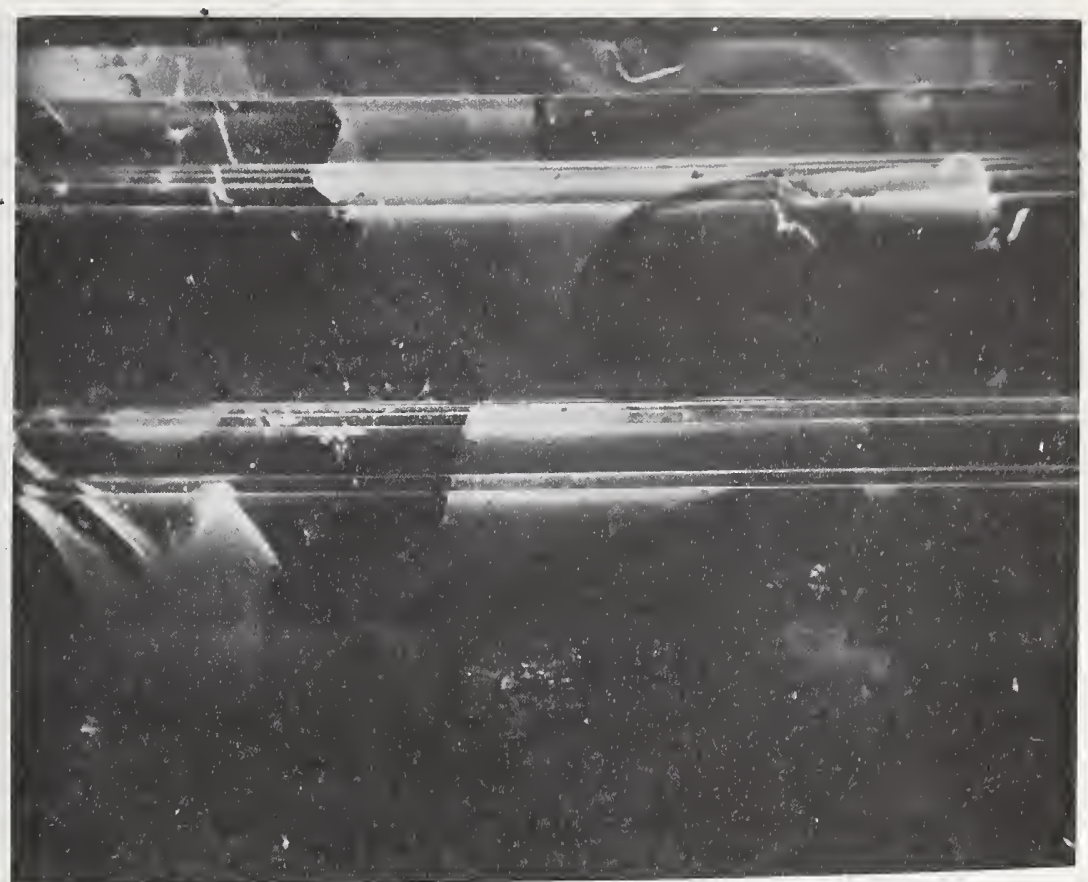

a. A sample showing typical bright areas of charging and horizontal streaks caused by unsynchronized discharges.

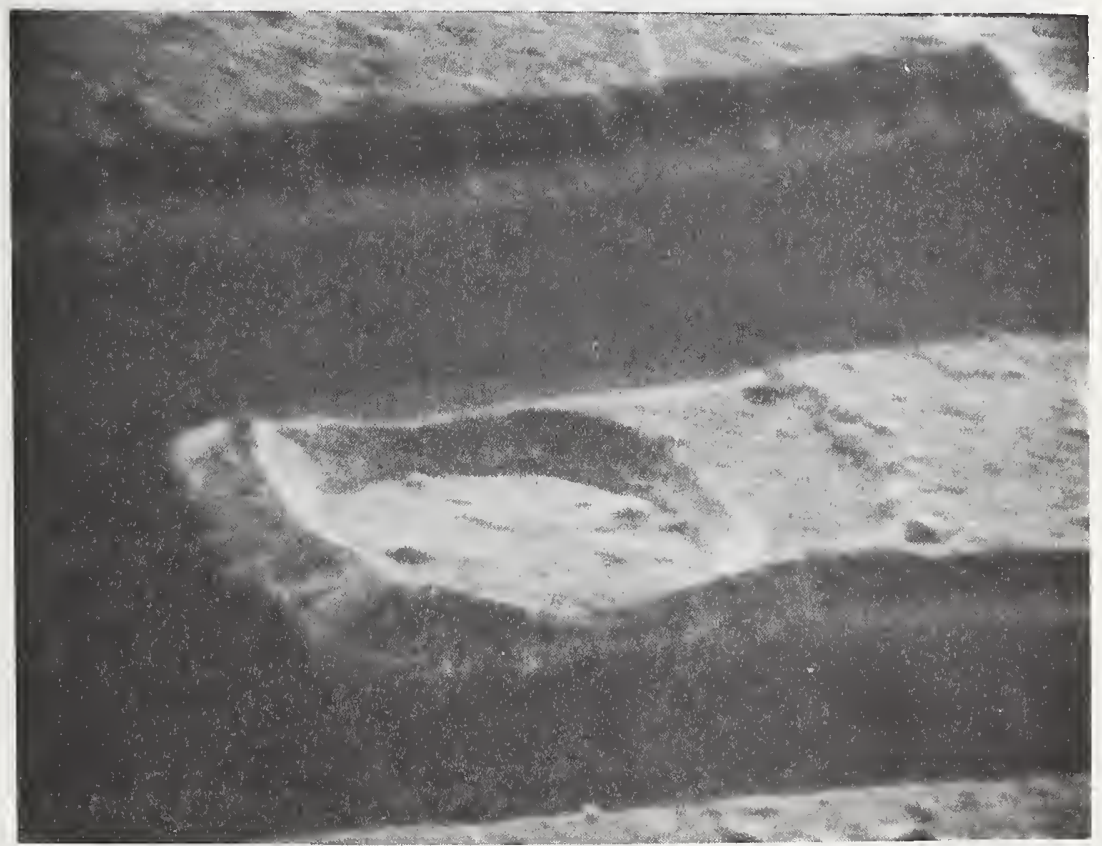

b. Poor PPR which cannot be corrected by any adjustment of time SEM controls.

Figure 16. Additional examples of the effects of charging. 


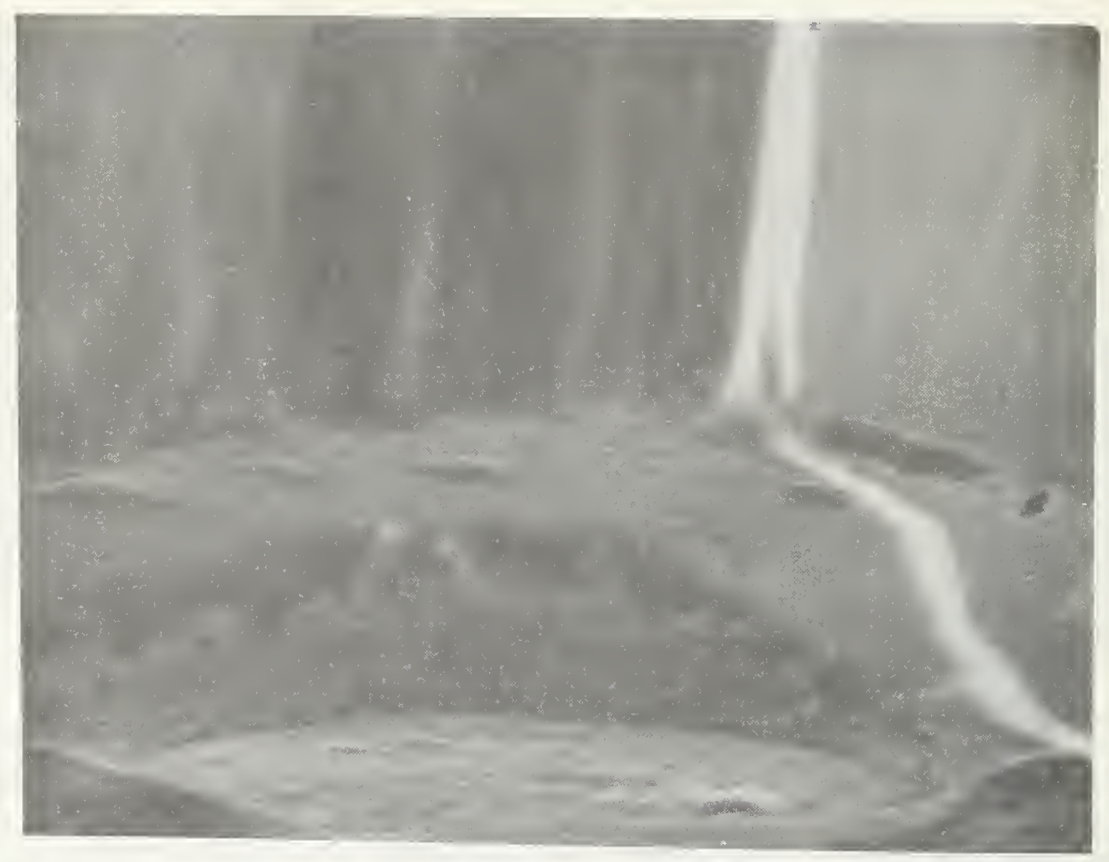

c. Severe image distortion caused by charging of residual glass not removed by the etching procedure.

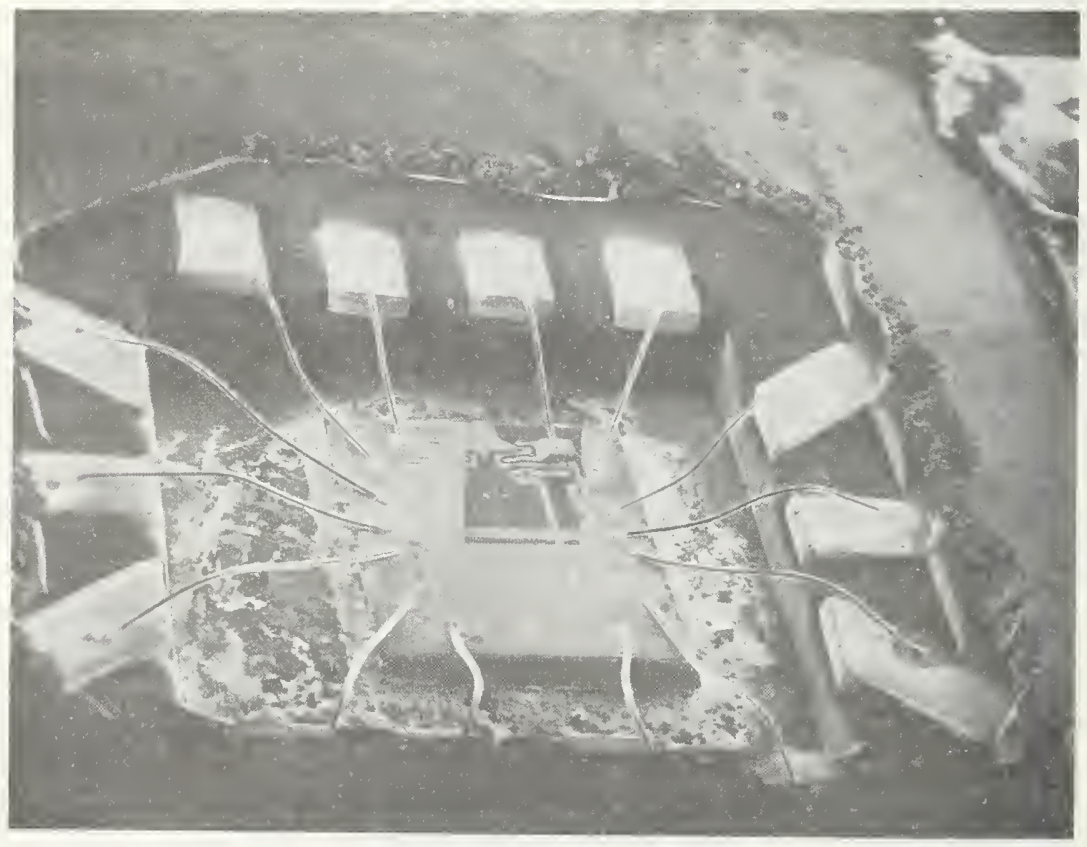

d. The use of a low accelerating voltage and high tilt angle to reduce charging and increase contrast. 
can be seen in figure 16d that another by-product of these techniques is better contrast. The contrast in the dark square area in figure 16d is rich in comparison to that in figure $15 \mathrm{a}$.

Figure 17a shows a secondary electron image of a device with a charged passivation layer. Figure 17b shows a backscattered electron image of the same area. The characteristic dark areas adjacent to regions of charging is a result of the distortion in the paths of secondary electrons while higher energy backscattered electrons are not affected. Therefore, using backscattered electrons will eliminate contrast distortion due to charging. A treatment of electron beam interactions with metals and insulators and effects of specimen tilt and accelerating voltage has been given by Oatley. 12

One technique commonly used to prevent specimen charging, applying a conductive coating over the sample, has not been covered. Because of the nature of semiconductor devices, such a coating should be a last resort and undertaken only after careful consideration of all phases of the examination to which the device will be subjected. Once coated, a device can no longer be operated nor will use of voltage contrast and EBIC modes of SEM examination be possible. X-ray analysis can become more difficult after application of any coating but carbon. See Appendix II for further discussion of specimen preparation.

Scanning a semiconductor surface at high magnification can crosspolymerize hydrocarbon monolayers deposited by an oil-pumped vacuum system. This effect appears as a very dark square area as in figure 18. Such contamination is an unwanted artifact, and can be avoided by not making prolonged high magnification scans on a localized area. All focusing should be done outside, but adjacent to, the surface area to be photomicrographed. Alternatively, the hydrocarbon diffusion pump oil can be replaced with an oil that will not be polymerized by the primary beam. A good alternative is found in perfluorinated polyether oil. This oil fractures into molecules of low molecular weight which are swept away by the vacuum system. Another method is to employ a cold finger or trap to help reduce specimen contamination by capturing the oil contaminates on a cold surface. Pump oil contamination is not a problem with an SEM equipped with a dry-pumped vacuum system.

The SEM primary electron beam damages the semiconductor device. Electron beam penetration into the device results in ionization processes which change the surface oxide properties, and thus degrade the electrical parameters. Digital bipolar devices are very resistant to damage due to electron beam irradiation. Linear bipolar devices are susceptible to parameter changes during SEM examination; however, it is unlikely that it would cause them to cease functioning. MOS devices are readily damaged by exposure to an electron beam. Even a very short exposure can make them inoperative.13,14

For devices for which optimum electrical performance is required after examination, the only way to eliminate electron beam damage is to 


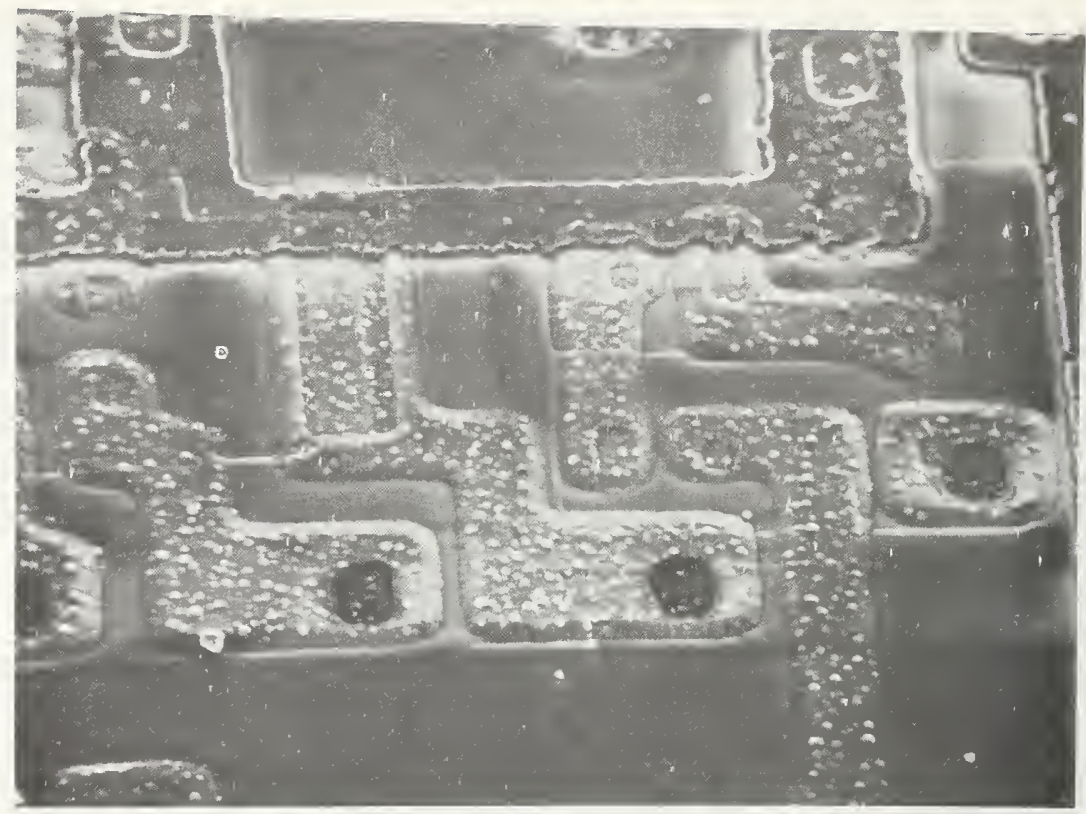

a. Secondary electron image of circuit with charged glass passivation.

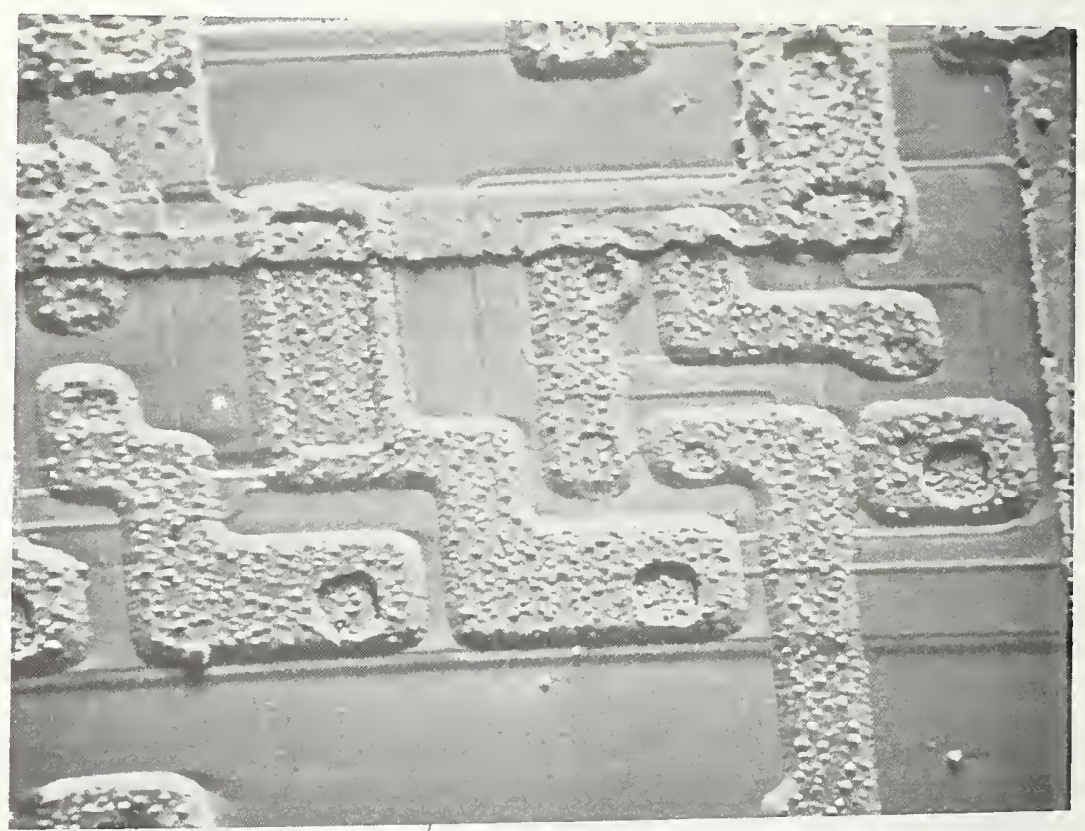

b. Backscattered electron image of the area shown in (a). The high energy reflected electrons are not substantially perturbed by any charge in the glass.

Figure 17. The use of backscattered electrons rather than secondaries to form the image to eliminate charging effects. 


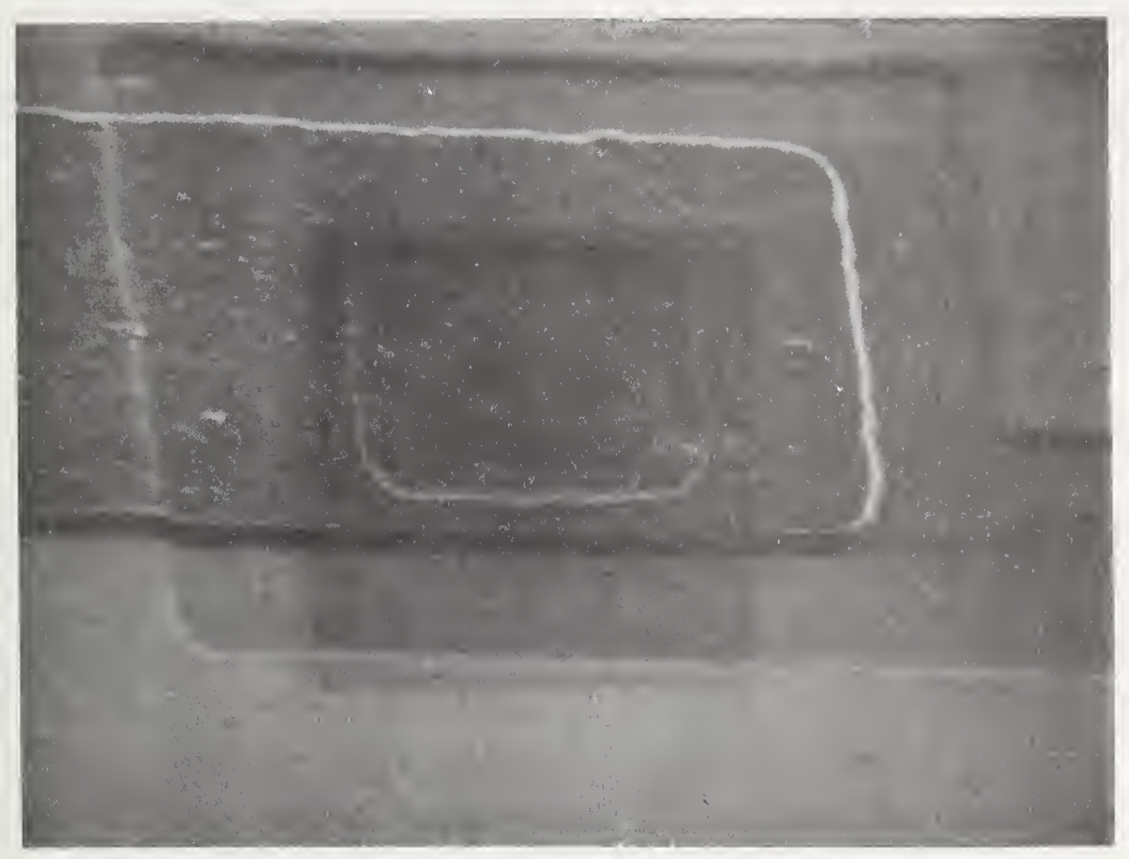

Figure 18. Contamination due to the polymerization of pump oil. 
not examine the device with an SEM. However, if an SEM examination must be performed, an accelerating voltage as low as possible considering the resolution which is required should be used. Also, the lowest practical beam current should be used and the specimen should be irradiated only as long as absolutely necessary. Appropriate alignment techniques are required so that time is not lost searching for the area of interest. If the examination does not include voltage contrast or EBIC modes, a bias should not be applied to the device junctions. It should be noted in subsequent use of the device that the electron beam could have made some irreversible changes in the device.

\section{Conclusion}

SEM operation procedures must not become stereotyped for all semiconductor device applications if optimum images are to be obtained. This report demonstrates the need for flexibility in selecting and using SEM parameters and analytic procedures to yield the maximum information from semiconductor devices. Table 1 summarizes the results of varying significant SEM operating parameters.

The primary consideration in topographical analysis of semiconduc-.. tor devices in the SEM is the reduction of primary electron beam penetration. The methods described for accomplishing this are low accelerating voltage and high specimen tilt. These techniques result in improved SNR and contrast, less charging, and, in general, good resolution. Although increasing the electron beam current is effective in improving SNR, low accelerating voltage is superior. Both techniques reduce PPR, but high beam current does not provide the striking contrast which low voltage does. Also, high beam currents may result in specimen charging, increased hydrocarbon cross-polymerization, and radiation damage. High accelerating voltage is to be used both where maximum PPR must be obtained and to yield subsurface information such as beneath contamination or glassivation layers. These techniques were discussed chiefly in terms of secondary electron emission. However, suggestions were given for using the backscattered electron signal to prevent image distortion due to charging and to gain detail in topography, for using voltage contrast for detecting specimen voltages, and for using EBIC to delineate pn junctions.

The principles established for selecting a line and frame rate should be applied no matter what set of signals is used. A $40 \mathrm{~s}$ frame rate and a $0.04 \mathrm{~s}$ line rate (1000 scan lines) are frequently applicable. In any case, specimen coating is to be considered as a last resort to improve SNR or reduce charging. 


\begin{tabular}{|c|c|c|c|c|c|c|}
\hline 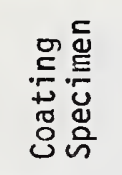 & 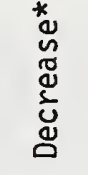 & 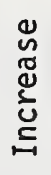 & 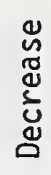 & 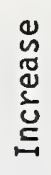 & 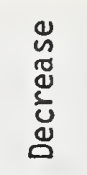 & \\
\hline 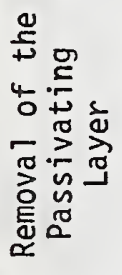 & 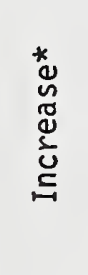 & 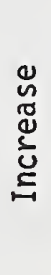 & 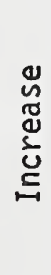 & 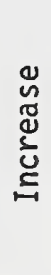 & $\begin{array}{l}\Delta \\
0 \\
0 \\
d \\
\dot{d} \\
\dot{d} \\
0\end{array}$ & \\
\hline 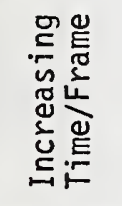 & & 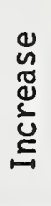 & & & & \\
\hline 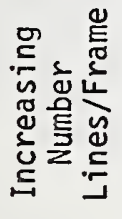 & & & 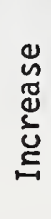 & & & \\
\hline 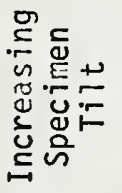 & 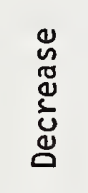 & 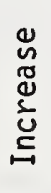 & & 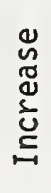 & 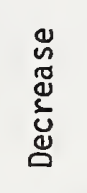 & \\
\hline 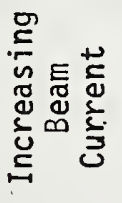 & & 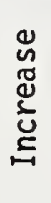 & 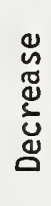 & & 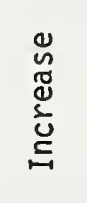 & 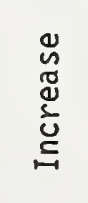 \\
\hline \multirow[t]{2}{*}{ 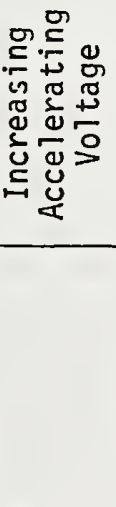 } & 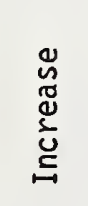 & 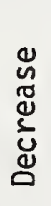 & 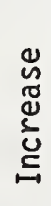 & & 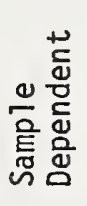 & 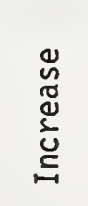 \\
\hline & 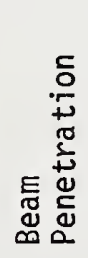 & $\frac{\alpha}{\Sigma}$ & $\frac{\alpha}{0}$ & 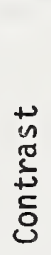 & 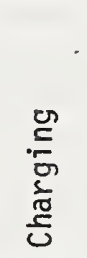 & 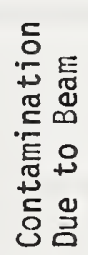 \\
\hline
\end{tabular}




\section{Voltage Contrast}

A voltage contrast image is obtained in the normal secondary electron mode where a potential difference is applied on the specimen surface. This is due to the fact that a secondary electron image is formed by the collection of low energy electrons ( $\leq 50 \mathrm{eV})$. Surface potentials and electric field gradients near the specimen surface easily affect the trajectories of these low energy electrons and modify their detection. Fewer electrons are collected from areas of positive potential and more electrons are collected from areas of negative potential. In the secondary electron image, positive areas appear dark and negative areas appear bright. This voltage contrast effect can be easily observed for potential differences greater than $0.5 \mathrm{~V}$.

Shown in figure 19 is a voltage contrast image of a section of a quad two-input NAND gate with $+5 \mathrm{~V}$ applied to both inputs (marked $\mathrm{A}$ and B) to force the output (marked Y) low. The voltage contrast technique is useful for detecting potential differences such as at discontinuities in metallization, gradients across resistor stripes, or at $p-n$ junctions. It is a valuable tool for semiconductor analysis.

To examine a device in the voltage contrast mode, it is necessary to be careful about charging since charging adds a stray electric field that also influences the paths of the secondary electrons. It is difficult to obtain good voltage contrast from devices mounted in recessed ceramic packages. Glassivation should be removed, and stray nonconducting particles should be blown off the surface. An accelerating voltage between 2 and $10 \mathrm{kV}$ is recommended and the specimen should be tilted toward the secondary electron detector. Further details on the detection of voltage contrast will be found in references by Holt, et $a$ l., 15 and We11s. 16

Voltage contrast has been used dynamically to check the operation of semiconductor devices. This is usually done using stroboscopic techniques and $\mathrm{TV}$ scan rates.17-19

\section{Electron-Beam-Induced Current}

Electron-beam-induced current (EBIC) in semiconductor devices produced by the electron beam of an SEM can be used to image subsurface device features and to measure certain material parameters. The energy deposited by the SEM electron beam can be considered primarily as a mechanism for electron-hole pair production in the device materials. For a simple pn junction, the pairs created in the junction depletion region are immediately separated by the built-in electric field and can be detected in an external circuit. Electron-hole pairs created in either the $n$ - or $p$-type regions which diffuse to the junction will also be 


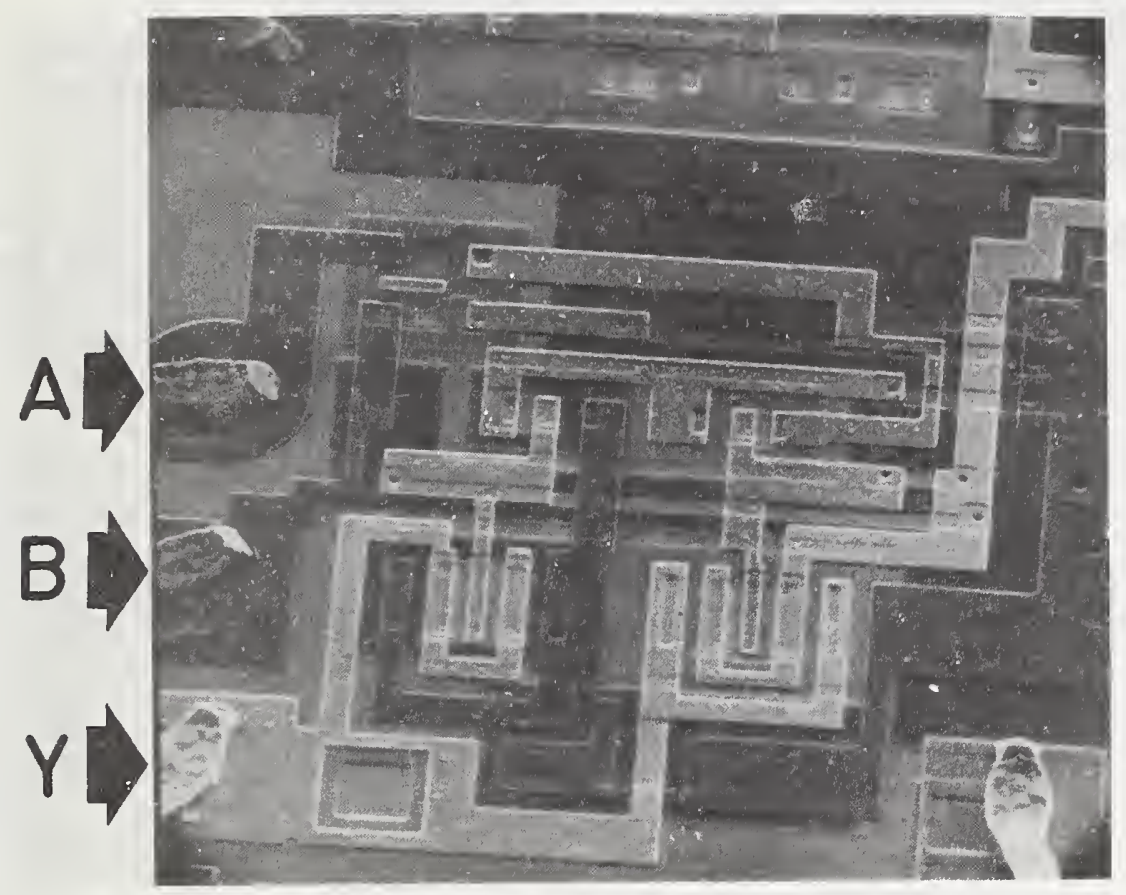

Figure 19. A secondary electron image of a biased microcircuit showing voltage contrast. 
separated and collected. EBIC can be used for SEM imaging by modulating the intensity of a synchronously scanned cathode-ray tube.

EBIC has been used to delineate junctions, locate inversion layers, measure diffusion lengths and carrier lifetimes, detect crystal imperfections, and measure surface recombination.20,21

Photomicrographs of an interdigitated npn transistor are shown in figure 20. Figure $20 \mathrm{a}$ is a routine emissive micrograph of the transistor. Figure $20 \mathrm{~b}$ is an EBIC image when the emitter is the input and the base and collector axe grounded. The accelerating voltage was $30 \mathrm{kV}$ with a beam current of $350 \mathrm{pA}$ for both photographs.

For an integrated circuit, EBIC imaging can result in a very complex display.22 However, EBIC analysis has been successfully applied to integrated circuits in a comparative mode. This has been used primarily as a technique for failure analysis. In circuits of a repetitive nature such as multiple gate devices, multiple bit shift register, flip-flops, or any circuit where a circuit function is duplicated, it is often possible to compare "good" and "bad" regions on the same chip. Where a duplication of function on a single chip is not available, the EBIC display from a defective circuit can be compared with a good circuit. Obviously, the SEM operating conditions must be held constant from specimen to specimen for meaningful comparisons.

As an example of the comparative technique, a defective low-power four-bit shift register was compared with a functional device. The defective device failed to shift the input data. The images were obtained by taking the induced current signal from the substrate with the power input lead grounded and all other leads floating. The accelerating potential was $20 \mathrm{keV}$ and the beam current was approximately $1 \mathrm{nA}$. Figure $21 a$ is the EBIC image of a portion of the defective device. For comparison, the same region of a functioning device is shown in figure $21 b$. The region of difference is indicated by the arrows. In the image of the good device, a junction associated with the parallel enable input is visible, but it is not seen in the defective device. Further examination of this area using other fallure analysis techniques confirmed that this junction was the source of malfunction. In this instance, EBIC analysis did not identify the exact cause of failure, but it rapidly identified a small area for further investigation.

When performing an EBIC examination, due to the low signal levels involved, shielded coaxial cables must be used for all interconnections and a low-noise, high-gain video amplifier is required. The amplifier gain is adjusted to obtain the desired contrast. The beam accelerating voltage is adjusted to control the beam penetration to allow signal collection from the desired depth. A higher than normal beam current might be necessary to provide the sufficient induced current. The specimen is usually not tilted and charging is usually not a problem. 


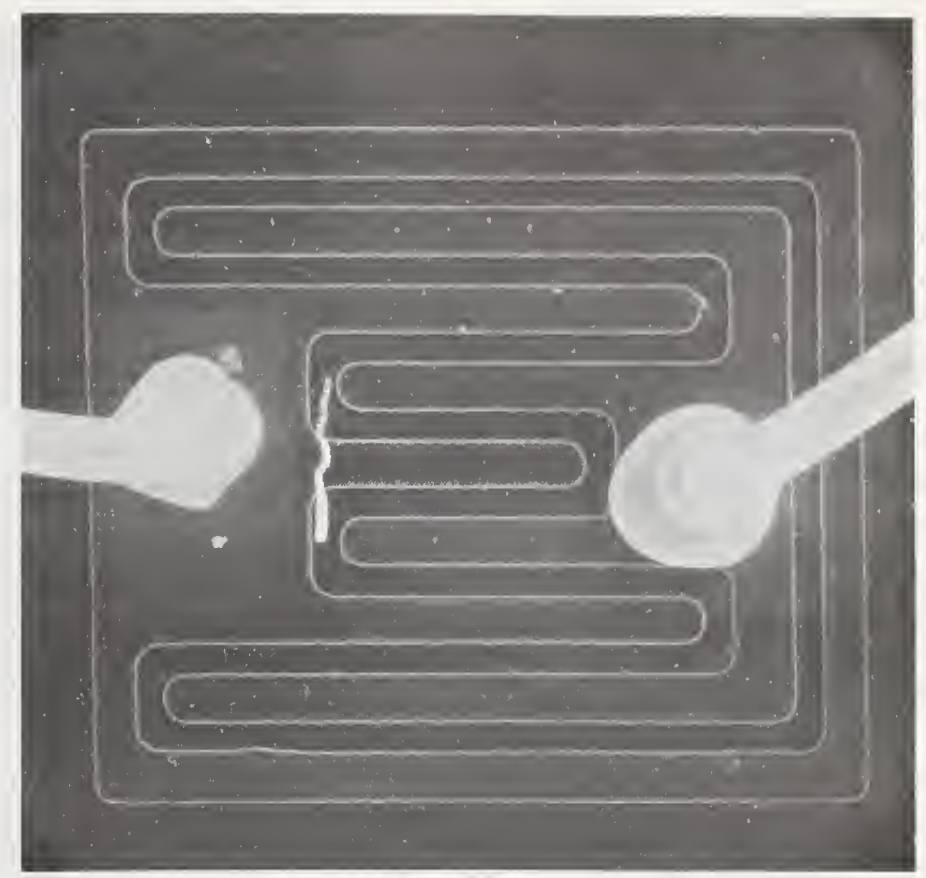

a. Secondary electron image.

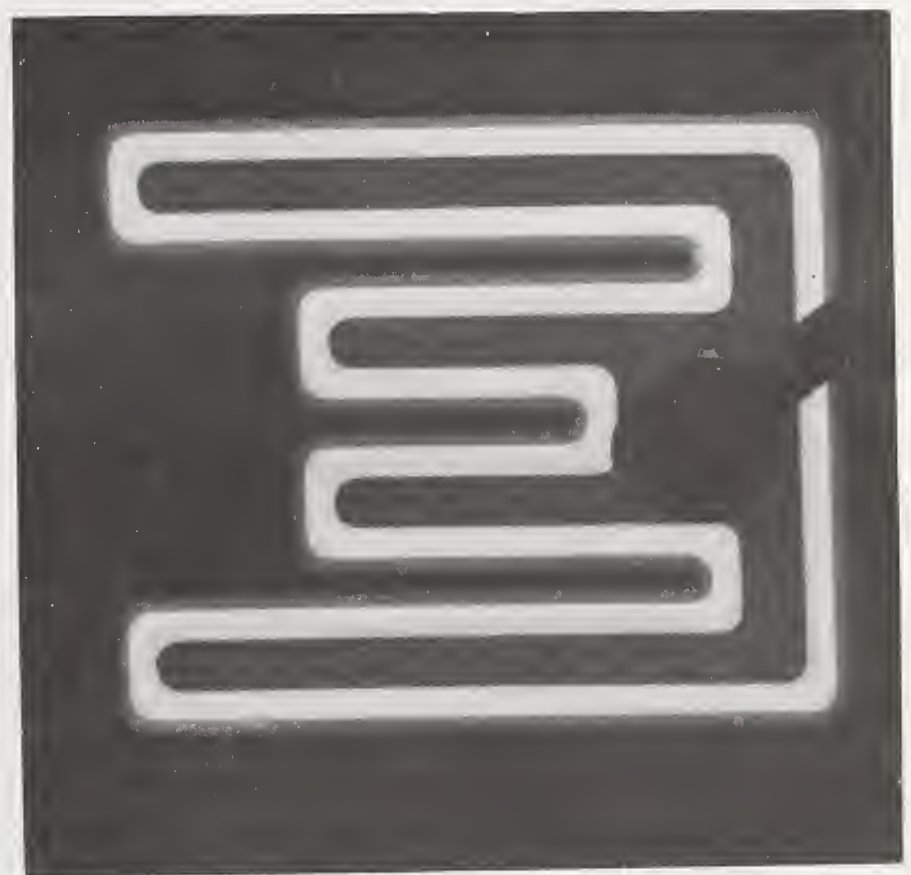

b. EBIC image of the emitter with the base and collector grounded.

Figure 20. Micrographs of an interdigitated mpn transistor made with a beam current of $350 \mathrm{pA}$ and a beam voltage of $30 \mathrm{kV}$. 


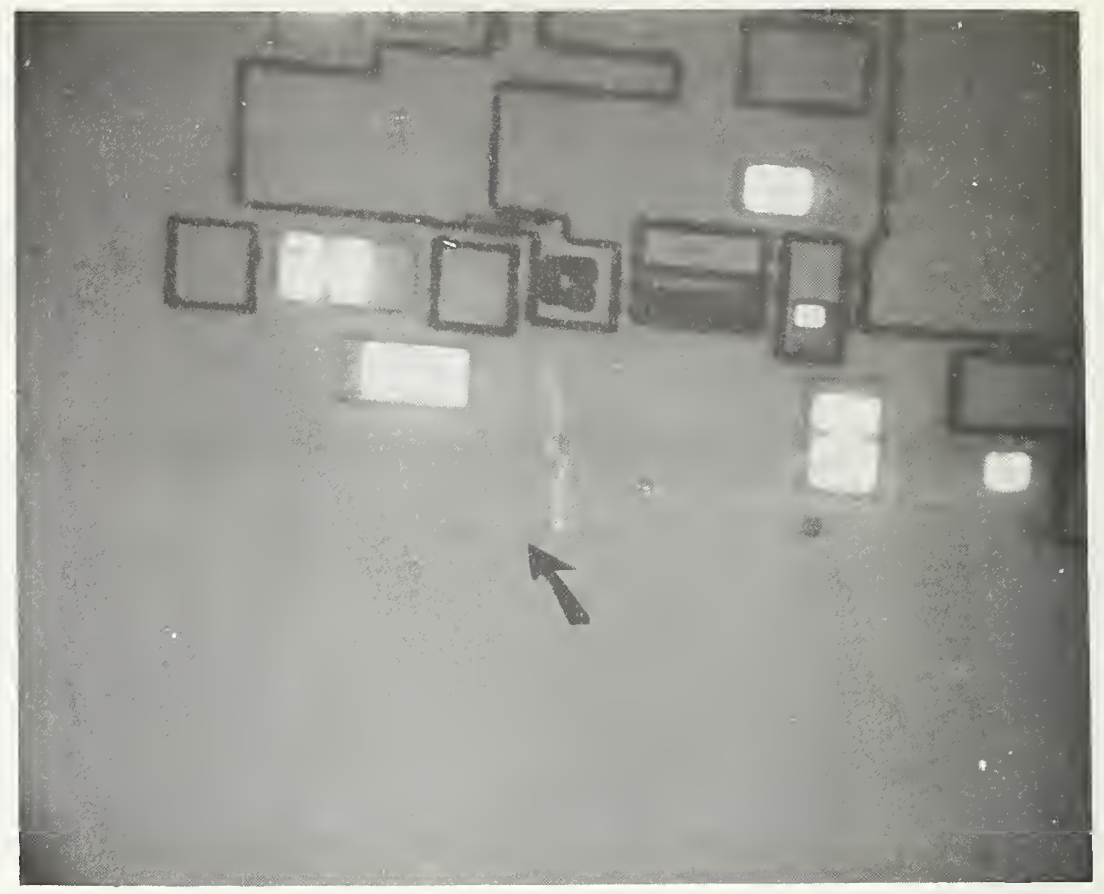

a. Defective shift register.

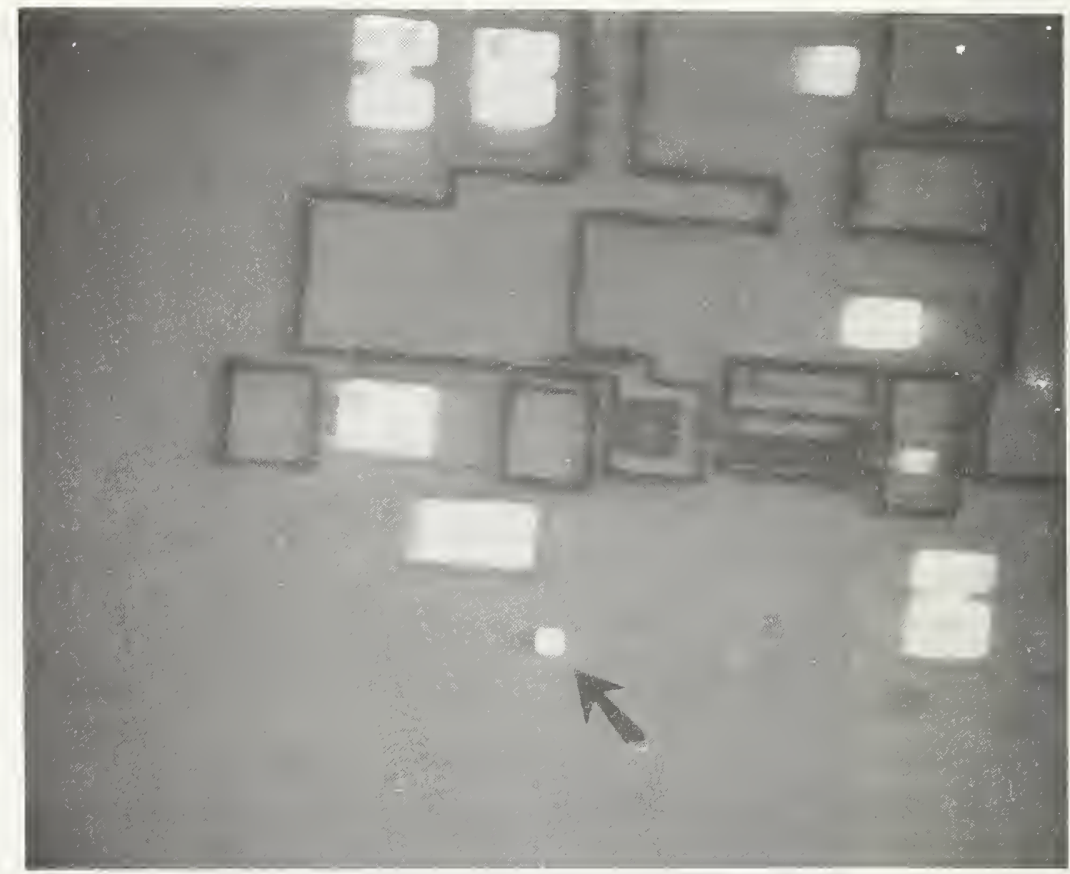

b. Functioning shift register.

Figure 21. EBIC images of portions of two similar shift registers with the arrows indicating the region of difference. 
Semiconductor Specimen Preparation

One of the primary advantages of scanning electron microscopy over optical and transmission electron microscopy is the minimum amount of specimen preparation necessary. However, some preparation is required and if the study is a failure analysis, the microscopist must take care that the preparations do not obscure the cause of failure being studied. An examination with an optical microscope should be made of a semiconductor device immediately after delidding the package. The analyst should observe any contamination that may be present and which appears to be the result of device fallure or poor fabrication. If any solder balls, fragments of broken passivation, or smeared metallization are noted, the sample surface should not be disturbed or valuable information could be 1ost. Photo documentation of the optical examination is desirable.

If the optical examination did not reveal any obvious device problems, the glass passivation layer should be removed from the semiconductor surface. Typically, the glass is removed by a wet acid or gas plasma etch. This is necessary because the glass does not replicate the underlying metallization stripes or oxide steps. Inadequate removal of the glass will leave a residue of glass on the metallization which would make topographical interpretation difficult. The residue also charges, which will normally manifest itself in an inability to focus as illustrated in figure 16c. The specimen should be firmly fixed to the specimen holder using an electrically conductive adhesive or its equivalent and the holder should be firmly mounted in the stage and make electrical contact to it.

Coating the specimen with a thin (5- to 20-nm thick) layer of carbon or metal may be used to enhance secondary emission and reduce charging. However, this deposited coating has potential drawbacks: its application is time consuming, there is die surface detail which is covered by the thin film coating, and the device is rendered inoperable. Despite these drawbacks, specimen coating is the method of suppressing charging and increasing the electrical emissivity of a specimen most often utilized. When applied with the specimen surface parallel to the rays of evaporating coating material, subtle changes in surface topography can be accentuated by shadowing.

In order to reduce the amount of data which is obscured by specimen coating, certain guidelines should be observed. The selection of the evaporant material is the first consideration. Criteria for selection of a material include: electron emissivity, replication ability, oxidation rate, and melting point. Gold has excellent electron emissivity, but, at high magnifications, has an agglomerate appearance. Silver has the best replicating ability, but, in a few days, it tarnishes and the specimen cannot be viewed. Gold-palladium alloy is a compromise between high electron emissivity and replicating ability, but the heat from its 
high melting point may alter the die surface. Aluminum is a good alternative, having good replicating ability, a low melting point, and adequate electron emissivity. On a very irregular specimen surface, carbon is often used on a first layer to establish surface conductivity because its atoms deflect from surrounding surfaces and reapproach the semiconductor surface from many different angles. A second, very thin film of a noble metal is then applied to improve electron emissivity. For x-ray microanalysis, carbon can be used exclusively to establish conduction, while avoiding extraneous $x$-ray information.

The film should be the thinnest possible coating that will suppress charging. The best procedure is to deposit a very thin film of a noble metal ( $\leq 10 \mathrm{~nm}$ thick) and then view the specimen in the SEM to see if the charging has been suppressed. This procedure can be repeated as often as necessary to satisfactorily suppress charging. Although very time consuming, this procedure will limit the amount of die surface data lost.

An evaporated thin film will not be uniform on a semiconductor die surface because of the irregular metallization and oxide steps. A gimbal mechanism may be used to spin the specimen through a complex movement exposing each die surface step for an equal amount of time to multiple evaporate sources, but it is still doubtful that the thin film will be truly uniform. There are two reasons for this. First, there are variations in the specimen source distance while spinning and the thickness of an evaporated thin film depends on the inverse square law. Also, there are changes during evaporation in the nominal angle of deposition.

To prevent the evaporant source heat from altering die surface topography during evaporation, three precautions should be taken. (1) The specimen should be kept at least 3 to $4 \mathrm{~cm}$ from the evaporant source(s). (2) A pre-evaporation shield should be kept between the evaporant source and specimen until the coating material has begun to evaporate. (3) A coating material with a low melting point, such as aluminum, should be used.

An alternative to vacuum evaporation as a specimen coating technique is sputter coating. In the evaporation technique, the coating material is heated to a sufficiently high temperature so that it evaporates, depositing a thin film on the die surface. In the sputter coating technique, atoms from the coating material are ejected when bombarded by relatively high energy particles. Some of the ejected atoms will land on the die surface to be coated. The particles must be of sufficiently high energy in order to overcome the binding energy of the atoms at the surface of the target. The fast heavy particles used to erode the target are usually derived from an ionized inert gas, and are produced by three main processes: ion-beam sputtering, radio-frequency sputtering, and direct current sputtering.

The main advantage of sputter coating is that a continuous thin film is deposited even on parts of the die surface which are complex, and those surfaces which are not directly facing the rays of sputtered 
atoms. This occurs due to the fact that, under the high pressures used, the coating material atoms experience many collisions and approach the die surface from all directions. This effect is achieved without using a gimbal movement. Therefore, the sputter coating technique has good surface replication ability, and there is a reduced chance of surface damage by heating. Noble metals should be used because of their emissivity. Aluminum is not adaptable to this technique because its surface oxide prevents sputtering.

The techniques advised for specimen coating should be rigorously followed. Thin film evaporations which are performed improperly will ruin the possibility for SEM examination. Figure 22 pictures a microcircuit window which has been buried under large globs of aluminum from a poor evaporation process. This specimen is a total loss for examination purposes because of the excessive artifacts introduced. 


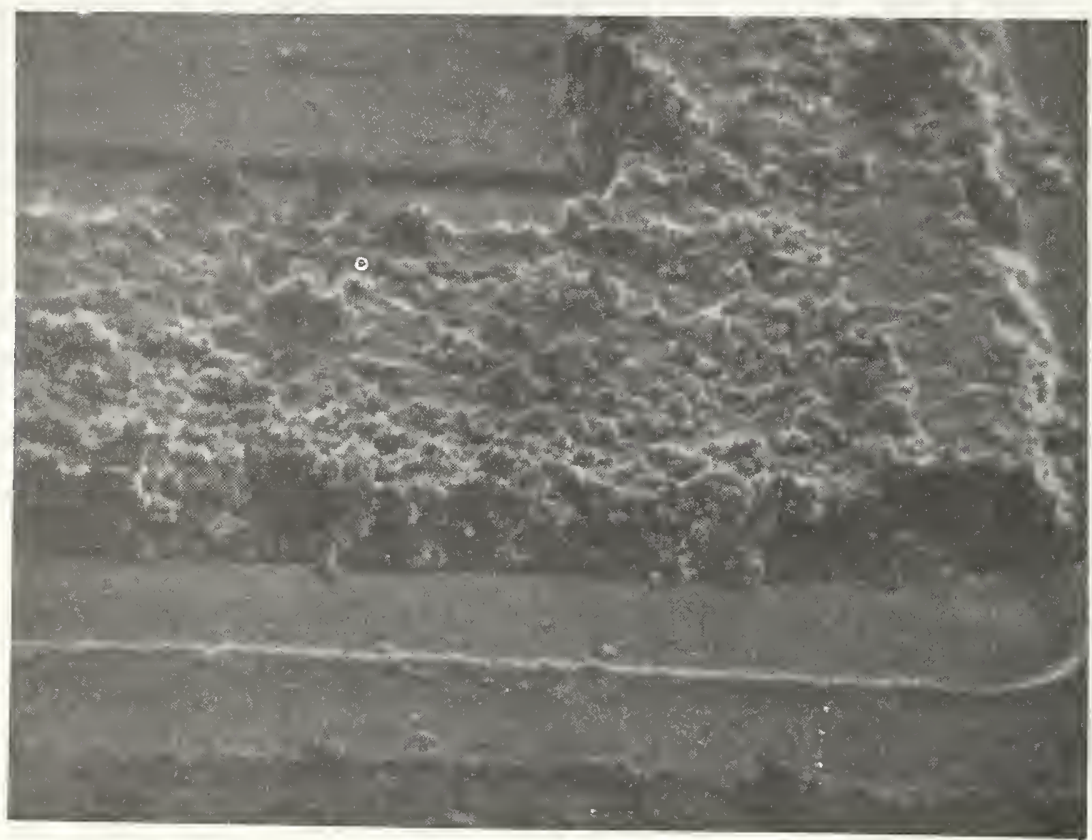

Figure 22. A microcircuit window covered by globs of metal introduced by poor evaporation techniques. 
1. Goldstein, J. I., and Yakowitz, H., eds., Practical Scanning Electron Microscope and Electron Probe Microanalysis (Plenum Press, New York, 1975).

2. Hearle, J.W. S., Sparrow, J. T., and Cross, P. M., The Use of the Scanning EZectron Microscope (Pergamon Press, Oxford, 1972).

3. Holt, D. B., Muir, M. D., Grant, P. R., and Boswawa, I. M., eds., Quantitative Scanning Electron Microscopy (Academic Press, London, 1974).

4. Johari, 0., ed., Scanning EZectron Microscopy/1976/I (Part IV) (IIT Research Institute, Chicago, 1976).

5. Leedy, K. O., A Bibliography on Electron Beam Induced Current Analysis of Semiconductor Devices, Solid State Technology 19, No. 2, 45-48 (1977).

6. Pease, R. F.W., Fundamentals of Scanning Electron Microscopy, Scanning EZectron Microscopy/1971 (Part I), pp. 9-16 (IIT Research Institute, Chicago, 1971).

7. Thornton, P. R., Scanning Electron Microscopy - Applications to Materials and Device Science (Barnes and Noble, Inc., New York, 1968).

8. Wells, 0. C., Scanning Electron Microscopy (McGraw Hill, New York, 1974).

9. Wittry, D. B., Electron Beam Interactions in Solids, Scanning Electron Microscopy/1970, pp. 409-416 (IIT Research Institute, Chicago, 1970).

10. Everhart, T. E., and Thornley, R. F. M., Wide-band detector for micro-microampere low-energy electron currents, J. Sci. Instrum. 37, 246-248 (1960).

11. Broers, A. N., High-Resolution Scanning Electron Microscopy of Surfaces, Microprobe Analysis, C. A. Anderson, ed., pp. 83-121 (Wiley, New York, 1973).

12. Oatley, C.W., The Scanning EZectron Microscope, pp. 148-167 (Cambridge University Press, 1972).

13. Galloway, K. F., Keery, W. J., and Leedy, K. O., Integrated Circuit Damage Resulting from SEM Examination, Proc. 25th Annual EZectronics Components Conference, Washington, D.C., May 12-14, 1975, pp. 263-266. 
14. Keery, W. J., Leedy, K. O., and Galloway, K. F., Electron Beam Effects on Microelectronic Devices, Scanning Electron Microscopy/ 1976/I (Part IV), pp. 507-514 (IIT Research Institute, Chicago, 1976).

15. Holt, D. B., Muir, M. D., Grant, P. R., and Boswawa, I. M., eds., Quantitative Scanning Electron Microscopy, pp. 117-123 (Academic Press, London, 1974).

16. Wells, O. C., Scanning Electron Microscopy, pp. 180-202 (McGraw Hill, New York, 1974).

17. Plows, G. S., and Nixon, W. C., Stroboscopic Scanning Electron Microscopy, J. Sci. Instrum. (J. Phys. E.) Series 2, Vol. 1, 1968, pp. 595-600.

18. Plows, G. S., and Nixon, W. C., Operational Testing of L.S.I. Arrays by Stroboscopic Scanning Electron Microscopy, Microelectronics and Reliability (GB) 10, 317-323 (1971).

19. Gopinath, A., and Hill, M. S., A Technique for the Study of Gunn Devices at $9.1 \mathrm{GHz}$ Using a Scanning Electron Microscope, IEEE Trans. Electron Devices ED-20, 610-612 (1973).

20. Holt, D. B., Muir, M. D., Grant, P. R., and Boswawa, I. M., eds., Quantitative Scanning Electron Microscopy, pp. 213-286 (Academic Press, London, 1974).

21. Thornton, P. R., Scanning Electron Microscopy - Applications to Materials and Device Science, pp. 217-243 (Barnes and Noble, Inc., New York, 1968).

22. Galloway, K. F., Leedy, K. O., and Keery, W. J., Electron-BeamInduced Currents in Simple Device Structures, IEEE Trans. Parts, Hybrids, and Packaging PHP-12, 231-236 (1976). 
NBS.114A (REV 7.73)

\begin{tabular}{|c|c|c|c|}
\hline $\begin{array}{l}\text { U.S. DEPT. OF COMM. } \\
\text { BIB:IOGRAPHIC DATA } \\
\text { SHEET }\end{array}$ & $\begin{array}{l}\text { 1. PUBLICATION OR REPORT NO. } \\
\text { NBS Spec. PubT. } 400-35\end{array}$ & $\begin{array}{l}\text { 2. Gov't Accession } \\
\text { No. }\end{array}$ & 3. Recipient's Accession No. \\
\hline \multicolumn{3}{|l|}{ 4. TITLE AND SUBTITLE } & 5. Publication Date \\
\hline \multirow{2}{*}{\multicolumn{3}{|c|}{$\begin{array}{l}\text { Semiconductor Measurement Technology: Notes on SEM } \\
\text { Examination of Microelectronic Devices }\end{array}$}} & April 1977 \\
\hline & & & 6. Performing Organization Code \\
\hline \multicolumn{3}{|c|}{$\begin{array}{l}\text { 7. AUTHOR(S) } \\
\text { John R. Devaney, K. 0. Leedy, and W. J. Keery }\end{array}$} & 8. Performing Organ. Report No. \\
\hline \multirow{2}{*}{\multicolumn{3}{|c|}{$\begin{array}{l}\text { 9. PERFORMING ORGANIZATION NAME AND ADDRESS } \\
\qquad \begin{array}{l}\text { Hi-Rel Laboratories } \\
911 \text { S. Mountain Avenue, } \\
\text { Monrovia, CA } 91016\end{array}\end{array}$}} & 10. Project/Task/Work Unit No. \\
\hline & & & $\begin{array}{l}\text { 11. Contract/Grant No. } \\
\text { 4-35897 }\end{array}$ \\
\hline \multirow{2}{*}{\multicolumn{3}{|c|}{$\begin{array}{l}\text { 12. Sponsoring Organization Name and Complete Address (Street, City, State, ZIP) } \\
\text { National Bureau of Standards, Washington, DC } 20234 \\
\text { ARPA, } 1400 \text { Wilson Boulevard, Arlington, VA } 22209\end{array}$}} & $\begin{array}{l}\text { 13. Type of Report \& Period } \\
\text { Covered }\end{array}$ \\
\hline & & & $\begin{array}{l}\text { Summary Report } \\
\text { 14. Sponsoring Agency Code }\end{array}$ \\
\hline
\end{tabular}

16. ABSTRACT (A 200-word or less factual summary of most significant information. If document includes a significant hiblineraohv or literature survev, mention it here.)

This report reviews selected scanning electron microscope (SEM) techniques which are appropriate for the examination of microelectronic devices. Illustrated are the results of individual variations in SEM operating parameters such as accelerating voltage, specimen tilt, scan line time, and frame time. Techniques which utilize secondary and backscattered electron emissions are compared and electron-beam-induced current and voltage contrast modes are discussed. Specimen preparation and beam-induced charging artifacts are also discussed. This report demonstrates the need for flexibility in selecting and using SEM parameters and analytic procedures to obtain the maximum information when examining semiconductor devices.

17. KEY WORDS (six to twelve entries; alphabetical order; capitalize only the first letter of the first key word unless a proper name; separated by semicolons) Backscattered emission; EBIC; microelectronic devices; scanning electron microscope; secondary emission; voltage contrast.

8. AVAILABILITY

For Official Distribution. Do Not Release to NTIS

X Order From Sup. of Doc., U.S. Government Printing Office Washington, D.C. 20402, SD Cat. No. C13.10:L00-35

$\square$ Order From National Technical Information Service (NTIS) Springfield, Virginia 22151

\begin{tabular}{|l|c|}
\hline $\begin{array}{l}\text { 19. SECURITY CLASS } \\
\text { (THIS REPURT) }\end{array}$ & 21. NO. OF PAGES \\
UNCL ASSIFIED & 54 \\
\hline $\begin{array}{l}\text { 20. SECURITY CLASS } \\
\text { (THIS PAGE) } \\
\text { UNCLASSIFIED }\end{array}$ & 22. Price $\$ 1.10$ \\
\hline
\end{tabular}

USCOMM-DC $29042-P 74$ 



\section{Announcement of New Publications on Semiconductor Measurement Technology}

Superintendent of Documents, Government Printing Office, Washington, D.C. 20402

\section{Dear Sir:}

Please add my name to the announcement list of new publications to be issued in the series: National Bureau of Standards Special Publication $400-$.

Name

Company

Address

City State Zip Code

(Notification Key $\mathrm{N}-413$ ) 



\section{NBS TECHNICAL PUBLICATIONS}

\section{PERIODICALS}

JOURNAL OF RESEARCH reports National Bureau f Standards research and development in physics, rathematics, and chemistry. It is published in two ections, available separately:

Physics and Chemistry (Section A)

apers of interest primarily to scientists working in hese fields. This section covers a broad range of physial and chemical research, with major emphasis on tandards of physical measurement, fundamental contants, and properties of matter. Issued six times a year. Annual subscription: Domestic, $\$ 17.00$; Foreign, $\$ 21.25$.

Mathematical Sciences (Section B)

Studies and compilations designed mainly for the mathmatician and theoretical physicist. Topics in mathematcal statistics, theory of experiment design, numerical analysis, theoretical physics and chemistry, logical deign and programming of computers and computer sysems. Short numerical tables. Issued quarterly. Annual subscription: Domestic, $\$ 9.00$; Foreign, $\$ 11.25$.

DIMENSIONS/NBS (formerly Technical News Bulle(in)-This monthly magazine is published to inform scientists, engineers, businessmen, industry, teachers, students, and consumers of the latest advances in science and technology, with primary emphasis on the work at NBS. The magazine highlights and reviews such issues as energy research, fire protection, building technology, metric conversion, pollution abatement, health and safety, and consumer product performance. In addition, it reports the results of Bureau programs in measurement standards and techniques, properties of matter and materials, engineering standards and services, instrumentation, and automatic data processing. Annual subscription: Domestic, $\$ 12.50$; Foreign, $\$ 15.65$.

\section{NONPERIODICALS}

Monographs-Major contributions to the technical literature on various subjects related to the Bureau's scientific and technical activities.

Handbooks-Recommended codes of engineering and industrial practice (including safety codes) developed in cooperation with interested industries, professional organizations, and regulatory bodies.

Special Publications-Include proceedings of conferences sponsored by NBS, NBS annual reports, and other special publications appropriate to this grouping such as wall charts, pocket cards, and bibliographies.

Applied Mathematics Series-Mathematical tables, manuals, and studies of special interest to physicists, engineers, chemists, biologists, mathematicians, computer programmers, and others engaged in scientific and technical work.

National Standard Reference Data Series-Provides quantitative data on the physical and chemical properties of materials, compiled from the world's literature and critically evaluated. Developed under a world-wide program coordinated by NBS. Program under authority of National Standard Data Act (Public Law 90-396).
NOTE: At present the priricipal publication outlet for these data is the Journal of Physical and Chemical Reference Data (JPCRD) published quarterly for NBS by the American Chemical Society (ACS) and the American Institute of Physics (AIP). Subscriptions, reprints, and supplements available from ACS, 1155 Sixteenth St. N.W., Wash. D. G. 20056.

Building Science Series-Disseminates technical information developed at the Bureau on building materials, components, systems, and whole structures. The series presents research results, test methods, and performance criteria related to the structural and environmental functions and the durability and safety characteristics of building elements and systems.

Technical Notes-Studies or reports which are complete in themselves but restrictive in their treatment of a subject. Analogous to monographs but not so comprehensive in scope or definitive in treatment of the subject area. Often serve as a vehicle for final reports of work performed at NBS under the sponsorship of other government agencies.

Voluntary Product Standards-Developed under procedures published by the Department of Commerce in Part 10, Title 15, of the Code of Federal Regulations. The purpose of the standards is to establish nationally recognized requirements for products, and to provide all concerned interests with a basis for common understanding of the characteristics of the products. NBS administers this program as a supplement to the activities of the private sector standardizing organizations.

Consumer Information Series-Practical information, based on NBS research and experience, covering areas of interest to the consumer. Easily understandable language and illustrations provide useful background knowledge for shopping in today's technological marketplace.

Order above NBS publications from: Superintendent of Documents, Government Printing Office, Washington, D.C. 20402 .

Order following NBS publications-NBSIR's and FIPS from the National Technical Information Services, Springfield, Va. 22161.

Federal Information Processing Standards Publications (FIPS PUBS)-Publications in this series collectively constitute the Federal Information Processing Standards Register. Register serves as the official source of information in the Federal Government regarding standards issued by NBS pursuant to the Federal Property and Administrative Services Act of 1949 as amended, Public Law 89-306 (79 Stat. 1127), and as implemented by Executive Order 11717 (38 FR 12315, dated May 11, 1973) and Part 6 of Title 15 CFR (Code of Federal Regulations).

NBS Interagency Reports (NBSIR)-A special series of interim or final reports on work performed by NBS for outside sponsors (both government and non-government). In general, initial distribution is handled by the sponsor; public distribution is by the National Technical Information Services (Springfield, Va. 22161) in paper copy or microfiche form.

\section{BIBLIOGRAPHIC SUBSCRIPTION SERVICES}

The following current-awareness and literature-survey bibliographies are issued periodically by the Bureau: Cryogenic Data Center Current Awareness Service. A literature survey issued biweekly. Annual subscription: Domestic, \$20.00; Foreign, \$25.00.

Liquified Natural Gas. A literature survey issued quarterly. Annual subscription: $\$ 20.00$.
Superconducting Devices and Materials. A literature survey issued quarterly. Annual subscription: $\$ 20.00$. Send subscription orders and remittances for the preceding bibliographic services to National Bureau of Standards, Cryogenic Data Center (275.02) Boulder, Colorado 80302. 
